UNIVERSIDADE DE SÃO PAULO

FACULDADE DE ECONOMIA, ADMINISTRAÇÃO E CONTABILIDADE DEPARTAMENTO DE ADMINISTRAÇÃO PROGRAMA DE PÓS-GRADUAÇÃo EM ADMINISTRAÇÃo

PERCEPÇÃO DA MATURIDADE DE GERENCIAMENTO DE PROJETOS DE TECNOLOGIA DA INFORMAÇÃO - UM ESTUDO COMPARATIVO ENTRE SETORES NO BRASIL -

Renan Mastrange Guedes

Orientador: Marilson Alves Gonçalves

SÃO PAULO 
Prof. Dr. João Grandino Rodas Reitor da Universidade de São Paulo

Profa. Dr. Reinaldo Guerreiro

Diretor da Faculdade de Economia, Administração e Contabilidade

Prof. Dr. Adalberto Américo Fischmann

Chefe do Departamento de Administração

Prof. Dr. Lindolfo Galvão de Albuquerque Coordenador do Programa de Pós-Graduação em Administração 
RENAN MASTRANGE GUEDES

\title{
PERCEPÇÃO DA MATURIDADE DE GERENCIAMENTO DE PROJETOS DE TECNOLOGIA DA INFORMAÇÃO - UM ESTUDO COMPARATIVO ENTRE SETORES NO BRASIL -
}

\author{
Dissertação apresentada ao Departamento de \\ Administração da Faculdade de Economia, \\ Administração e Contabilidade da \\ Universidade de São Paulo como requisito \\ para a obtenção do título de Mestre em \\ Administração.
}

Orientador: Marilson Alves Gonçalves 
Dissertação defendida e aprovada no Departamento de Administração da Faculdade de Economia, Administração e Contabilidade da Universidade de São Paulo - Programa de Pós-Graduação em Administração, pela seguinte banca examinadora:

Guedes, Renan Mastrange

Percepção da maturidade de gerenciamento de projetos de tecnologia da informação : um estudo comparativo entre setores no Brasil / Renan Mastrange Guedes. -- São Paulo, 2012.

$132 \mathrm{p}$.

Dissertação (Mestrado) - Universidade de São Paulo, 2012. Orientador: Marilson Alves Gonçalves.

1. Administração de projetos 2. Tecnologia da informação 3. Sistemas de Informação I. Universidade de São Paulo. Faculdade de Economia, Administração e Contabilidade. II. Título.

CDD -658.404 
Aos meus pais, esposa e filho,

pelo apoio, carinho e incentivo. 
Agradeço ao professor e orientador Dr. Marilson Alves Gonçalves, pelo apoio e encorajamento contínuos na pesquisa, aos demais mestres da casa pelos conhecimentos transmitidos, aos professores Dr. Fernando José Barbin Laurindo, Dr. Antonio César Amaru Maximiano, Dr. Roberto Sbragia e Dra. Bernadete Marinho pelas importantes contribuições durante a elaboração desse estudo, e à FEA USP, pelo apoio institucional e pelas facilidades oferecidas.

Agradeço também aos colegas mestrandos da casa Fernando Fonseca, Bruno Cals, Bruno Borges e Gabriela Jardim e aos colegas envolvidos no mercado com o desafio do gerenciamento do projeto Karine Carvalho, Marcus Mendes, Gilberto Cheng e Eduardo Ebel pelas contribuições durante o período de elaboração desta obra.

Finalmente, agradeço a meus alunos que constantemente desafiam meus conhecimentos, estudos e experiência, as empresas e seus profissionais que disponibilizaram seu tempo e paciência nos auxiliando nesse estudo. 
"Todos modelos são, por definição, errados, mas alguns são úteis."

George E. P. Box 


\section{RESUMO}

O contexto global de crescente instabilidade econômica, o desenvolvimento das telecomunicações e a integração dos mercados internacionais aumentou a necessidade das organizações lidarem com um número cada vez maior de variáveis. Sendo os projetos os propulsores da mudança organizacional, concebe-los e planeja-los para atingir os objetivos de maneira eficaz nesse ambiente volátil torna-se ainda mais desafiador. Um dos recursos que tem sido utilizado para esse fim é a melhoria contínua dos processos, técnicas e ferramentas de gestão por meio da avaliação de maturidade organizacional no gerenciamento de projetos. Esta pesquisa busca identificar possíveis semelhanças ou diferenças na maturidade de gestão de projetos de sistemas de informação nas organizações de distintos setores de atividade, em outras palavras, esse trabalho busca analisar se há diferenças entre maturidades quando mantemos constante o tipo de projeto. Nesta pesquisa, analisam-se as diferenças de maturidade em gestão de projetos de sistemas de informação em 56 organizações consolidadas em seus setores de atividades como serviços, comercial, setor público e terceiro setor. Na etapa de revisão bibliográfica foi realizado um levantamento dos trabalhos empíricos nessa temática com o objetivo de entender as principais contribuições de cada trabalho e realizar uma análise crítica de métodos e resultados. Na etapa de pesquisa de campo, foram aplicados questionários eletrônicos para mapeamento das percepções dos profissionais que atuam em projetos de sistemas de informações em diversas organizações. Os resultados não mostram evidências estatísticas da maturidade de gestão de projetos das organizações estar relacionada com o setor de atividade. No entanto, os resultados apontam evidências estatísticas de que: 1) grandes organizações possuem maior maturidade em gestão de projetos em todas as áreas de conhecimento, 2) a maturidade de gestão de integração, comunicações e riscos estão relacionadas com faturamento e quantidade de funcionários enquanto integração, escopo, tempo e riscos estão sim relacionadas ao setor da organização e, 3) as organizações estudas apresentam de maneira geral níveis mais baixos de maturidade de gestão de riscos, comunicações e recursos humanos e níveis mais altos maturidade de tempo e custos. Finalmente, durante a análise de dados foi realizada uma análise de regressão que indicou uma possível correlação positiva entre os níveis de importância com o nível de maturidade em gestão de projetos dessas organizações assim, poderíamos inferir que as características necessárias para suportar e fomentar a gestão de projetos podem estar mais presentes em grandes organizações com maior maturidade em gestão de projetos. 


\begin{abstract}
The global context of increasing economic instability, the telecommunications development and the international markets integration inflated the requirements for organizations to deal with a augmented number of variables. As projects are the drivers for changing businesses, is much more challenge to conceive, develop and plan them in order to achieve best results and to be more efficient in an instable world. One of the supporting initiatives for this matter is the continuous improvement throughout evaluation of project management organizational maturity. This research gathers possible similarities and differences in a cross-industry analysis of maturity levels for managing information systems projects, in other words, what are the differences in term of project management maturity when keeping constant the type of project. This study evaluates differences in 56 organizations consolidated by industries as services, manufacture, retail, public-sector and non-for-profit. During the literature review phase, this study gathered project maturity cross-sector empirical papers emphasizing their main ideas and the current issues behind its methods and outcomes. At the field research phase, web-survey was used to map the project maturity perception of information systems management professionals in several organizations in Brazil. The main data analysis outcome is that there's no evidence that the overall project maturity is related to the organization's industry. On the other hand, the data provides non-parametrical statistic evidence to say that: 1) big organizations have higher level of overall (all knowledge areas) project management maturity, 2) integration, communication and risk management maturity is related to the organizations revenue and number of employees while integration, scope, time and risk management maturity is related to the organization's industry and, 3) in general, organizations experiences lower levels of project management maturity for risk, communication and human resources and higher levels of project management maturity for time and costs. Finally, using a multivariate data analysis technique, the regression analysis, it showed a positive correlation between higher levels of organizational enablers and project maturity that takes to the conclusion that the elements required to support and enable portfolio management are more present at organizations with higher project management maturity.
\end{abstract}




\section{SUMÁRIO}

1 INTRODUÇÃ

1.1. Objetivo Central da Pesquisa .......................................................................... 16

1.2. Perguntas de Pesquisa e Hipóteses ................................................................... 16

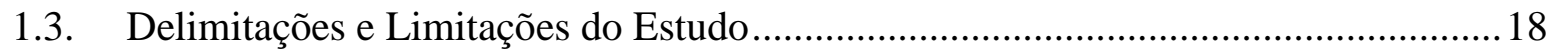

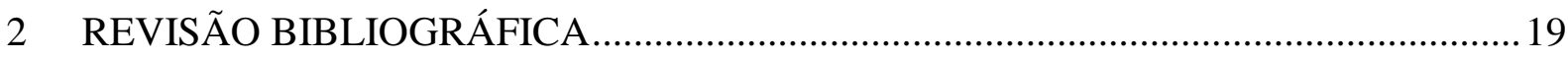

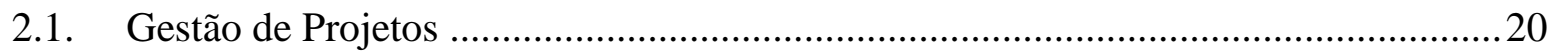

2.1.1. Evolução dos Constructos Fundamentais........................................................ 20

2.1.2. Fatores para Avaliação do Sucesso dos Projetos ..............................................24

2.1.2.1. Desempenho do Projeto ou a Corrente Pragmática .......................................... 24

2.1.2.2. Desempenho do Negócio ou a Corrente Econômica ........................................ 26

2.1.3. Escritório de Gestão de Projetos (PMO) ............................................................... 28

2.1.4. Estratégia e Gestão de Portfolio de Projetos ....................................................... 30

2.2. Gestão de Tecnologia da Informação ................................................................ 38

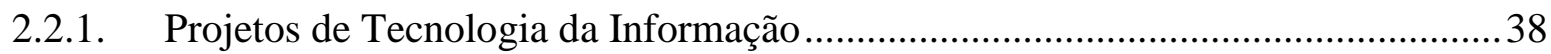

2.2.2. Alinhamento Estratégico da Tecnologia da Informação ..................................... 42

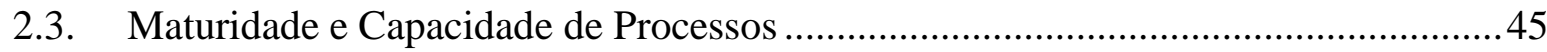

2.3.1. Valor Estratégico dos Modelos da Maturidade .................................................... 48

2.3.2. Modelos de Maturidade de Gestão de Projetos ................................................... 49

2.3.3. Estudos Empíricos de Maturidade de Gestão de Projetos ......................................50

2.3.3.1. KPMMM - Kerzner Project Management Maturity Model ..............................53

2.3.3.2. Modelo de Maximiano e Rabechini................................................................ 54

2.3.3.3. MMGP - Modelo de Maturidade em Gerenciamento de Projetos .......................55

2.3.3.4. Organizational Project Maturity Management Model (OPM3) ........................56

2.3.4. Análise Crítica dos Modelos de Maturidade _.........................................................59

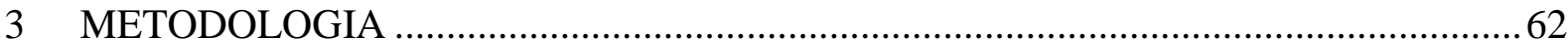

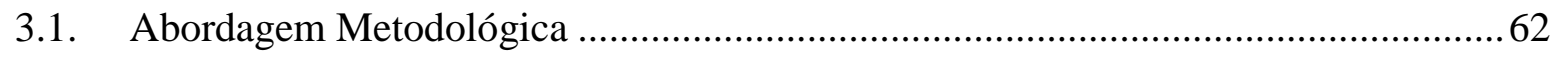




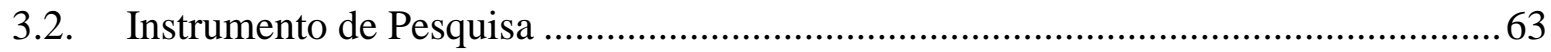

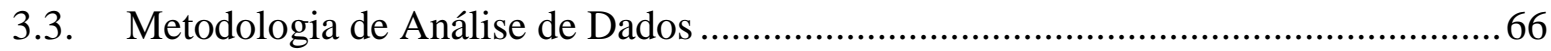

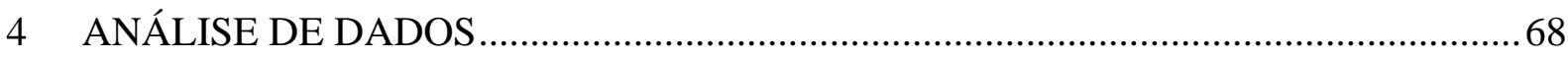

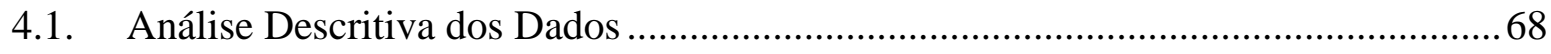

4.2. Análise Estatística dos Dados de Importância dos Facilitadores Organizacionais para

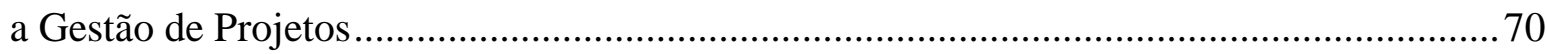

4.3. Análise Estatística dos Dados de Maturidade em Gestão de Projetos .........................76

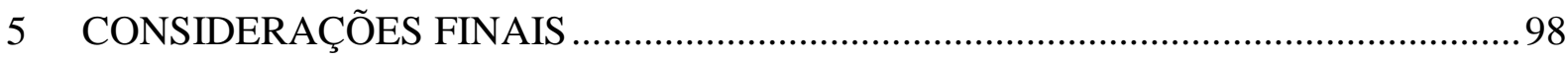

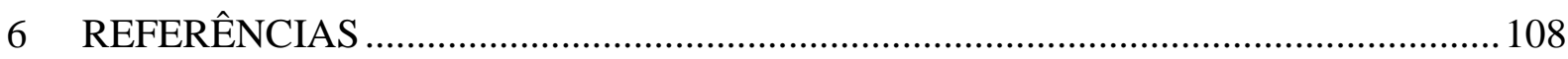




\section{LISTA DE ABREVIATURAS E SIGLAS}

ABGP - Associação Brasileira em Gerenciamento de Projetos

ANSI - American National Standards Institute

CAPM - Certified Associate in Project Management

CMM - Capability Maturity Model

CMMI - Capability Maturity Model Integration

DMAIC - Define, Measure, Act, Improve \& Control

FEA-USP - Faculdade de Economia, Administração e Contabilidade da Universidade de São Paulo

FIA - Fundação Instituto de Administração

IPMA - International Project Management Association

ISO - International Organization for Standardization

KPMMM - Kerzner Project Management Maturity Model

MBA - Master Business Administration

MMGP - Modelo de Maturidade em Gerenciamento de Projetos

OGC - Office of Government Commerce

OPM3 - Organizational Project Maturity Management Model

$\mathrm{P} \& \mathrm{D}$ - Pesquisa \& Desenvolvimento

PDCA - Plan, Do, Check \& Act

PECE - Programa de Educação Continuada

PfM Guide - Portfolio Management Guide

PMBOK Guide - Project Management Body of Knowledge Guide

PMI - Project Management Institute

PMP - Project Management Professional

Poli-USP - Escola Politécnica da Universidade de São Paulo

PPM - Project Portfolio Management

PRINCE2 - Projects in Controlled Environments 2

QFD - Quality Function Deployment

RBC - Referencial Brasileiro de Competências em Gerenciamento de Projetos

SEI - Software Engineering Institute da Carnegie Mellon University

TI - Tecnologia da Informação

USP - Universidade de São Paulo 


\section{LISTA DE QUADROS}

Quadro 1. Perguntas de Pesquisa e Hipóteses ....................................................................... 17

Quadro 2. Evolução da Definição de Projeto ...................................................................... 21

Quadro 3. As nove escolas de gestão de projetos e suas perspectivas ................................... 22

Quadro 4. Fatores Críticos de Sucesso dos Projetos .............................................................. 24

Quadro 5. Processos de Gerenciamento do Portfólio de Projetos ............................................. 33

Quadro 6. Processo de Gerenciamento do Portfólio e Barreiras ............................................... 37

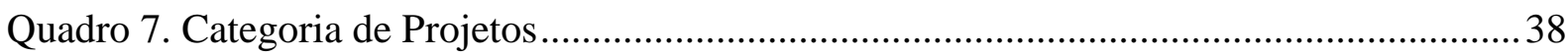

Quadro 8. Estudos de Avaliação de Maturidade de Gestão de Projetos...................................52

Quadro 9. Relacionamentos entre as Dimensões de Maturidade e os Níveis de Maturidade ..55

Quadro 10. Dimensões, Grupos de Processos e Níveis do OPM3 ...........................................59

Quadro 11. Escala de Avaliação de Maturidade de Projetos Adaptada de Prado (2008) e

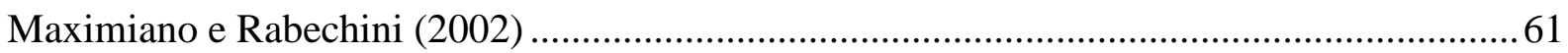

Quadro 12. Sumários dos Resultados das Hipóteses ................................................................ 100 


\section{LISTA DE TABELAS}

Tabela 1. Teste de Kolmogov-Smirnov de Percepção de Maturidade em Gestão de Projetos e Percepção de Importância dos Facilitadores Organizacionais da Gestão de Projetos...............67

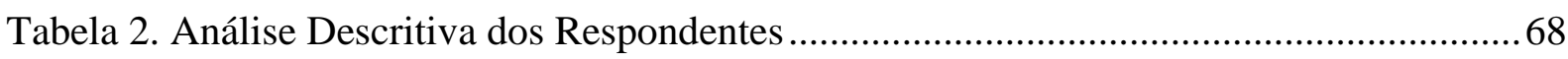

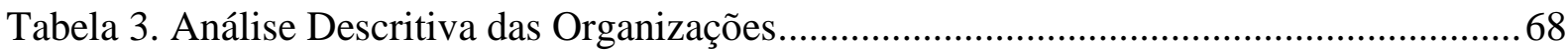

Tabela 4. Análise Descritiva da Percepção de Importância dos Facilitadores Organizacionais à

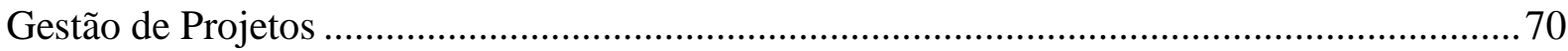

Tabela 5. Importância dos Facilitadores Organizacionais por Faturamento ............................ 70

Tabela 6. Importância dos Facilitadores Organizacionais por Setor ...................................... 72

Tabela 7. Importância dos Facilitadores Organizacionais por Origem da Organização .......... 72

Tabela 8. Importância dos Facilitadores Organizacionais por Nível Hierárquico ....................73

Tabela 9. Importância dos Facilitadores Organizacionais por Experiência ..............................74

Tabela 10. Importância dos Facilitadores Organizacionais por Nível de Maturidade em Gestão

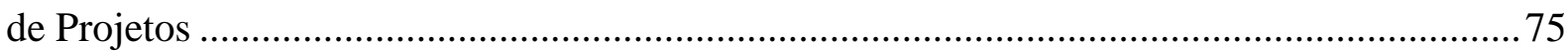

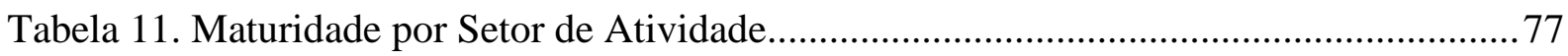

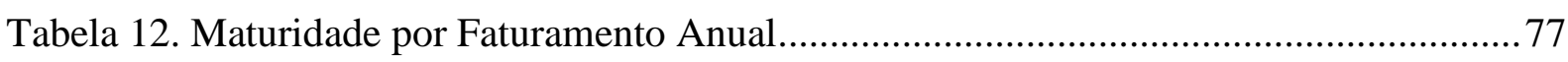

Tabela 13. Maturidade por Quantidade de Funcionários ...................................................... 78

Tabela 14. Maturidade por Agrupamento de Faturamento.................................................... 78

Tabela 15. Maturidade por Agrupamento de Quantidade de Funcionários..............................79

Tabela 16. Maturidade por Setor e Faturamento ...................................................................... 79

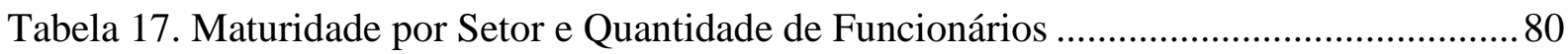

Tabela 18. Maturidade por Setor e Agrupamento de Faturamento Agrupado ........................ 81

Tabela 19. Maturidade por Setor e Agrupamento de Quantidade de Funcionários ..................82

Tabela 20. Maturidade por Função Hierárquica .................................................................... 82

Tabela 21. Maturidade por Função Hierárquica Agrupada .................................................... 83

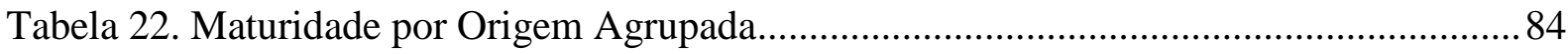

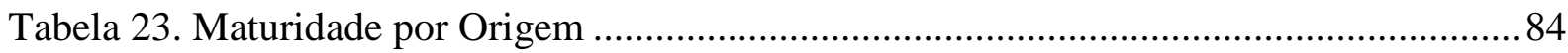

Tabela 24. Maturidade por Tempo de Atuação no Mercado .................................................... 85

Tabela 25. Maturidade por Escopo Geográfico.................................................................. 86

Tabela 26. Maturidade das Áreas de Conhecimento por Setor de Atividade ........................... 86

Tabela 27. Maturidade das Áreas de Conhecimento por Faturamento..................................... 88

Tabela 28. Maturidade das Áreas de Conhecimento por Quantidade de Funcionários.............89

Tabela 29. Maturidade das Áreas de Conhecimento por Tempo de Atuação ...........................91 
Tabela 30. Maturidade das Áreas de Conhecimento por Escopo de Atuação ..........................93

Tabela 32. Resumo da Regressão Linear (Variável Independente Maturidade) ..................... 95

Tabela 33. ANOVA da Regressão Linear (Variável Independente Maturidade).....................95

Tabela 34. Coeficientes da Regressão Linear (Variável Independente Maturidade) ...............95

Tabela 31. Mediana da Maturidade de Gestão e Projeto por Setor de Atividade e Área do

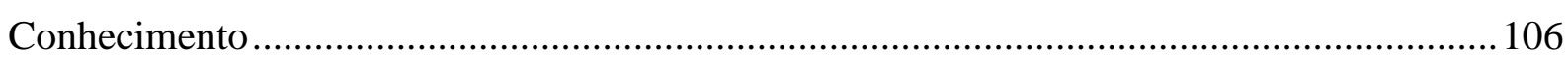




\section{LISTA DE GRÁFICOS}

Gráfico 1. Análise Descritiva das Medianas das Percepções de Importância dos Facilitadores

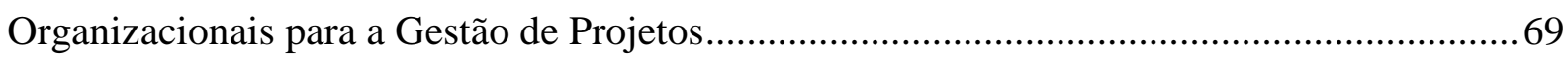

Gráfico 2. Regressão Linear (Variável Independente Maturidade) ........................................96

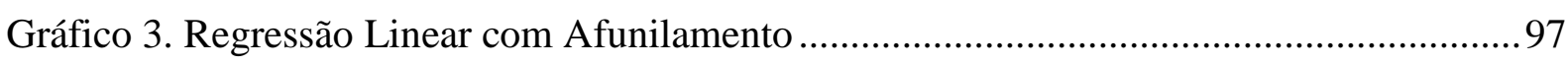

Gráfico 4. Percepção de Maturidade dos Grupos de Processos de Iniciação e Planejamento de

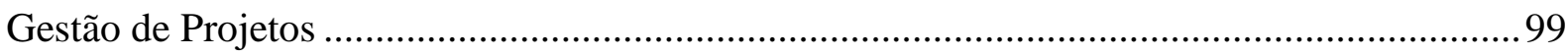

Gráfico 5. Mediana de Maturidade das Áreas de Conhecimento por Setor de Atividade...... 106 


\section{LISTA DAS DEMAIS ILUSTRAÇÕES}

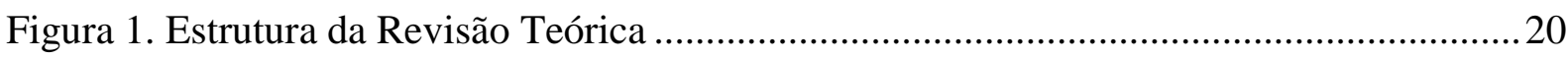

Figura 2. Componentes que Contribuem para o Sucesso do Projeto .................................... 26

Figura 3. Possíveis Dimensões do Sucesso de um Projeto.....................................................2

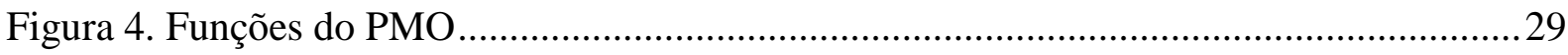

Figura 5. Proposta de processo de planejamento estratégico e alinhamento do portfólio.........32

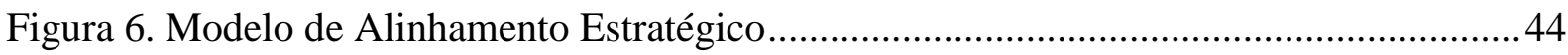

Figura 7. Domínios da Maturidade de Gestão de Projetos ..................................................... 47

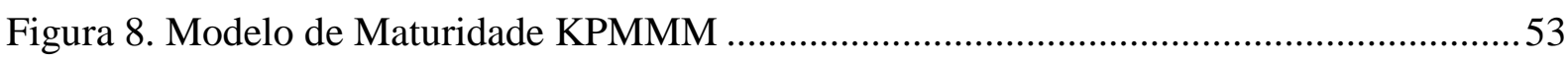

Figura 9. Modelo de Maximiano e Rabechini ...................................................................5

Figura 10. Relação entre Melhores Práticas, Capacidades, Resultados e Indicadores do OPM3.

Figura 11. Processo de Implantação e Melhoria Contínua ...........................................................58

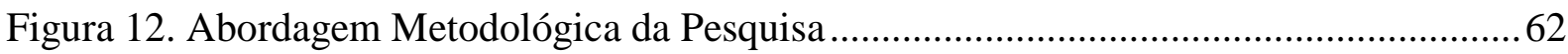

Figura 13. Processo de Seleção dos Questionários Válidos .....................................................66 


\section{INTRODUÇÃO}

As organizações vêm cada vez mais fazendo uso dos projetos para atingir seus objetivos estratégicos enquanto o ambiente socioeconômico se torna cada vez mais complexo, incerto e competitivo. Estima-se que atualmente mais de $20 \%$ das atividades econômicas sejam realizadas por meio de projetos e que, em países emergentes, esse número deve exceder 30\% (BREDILLET, 2010).

Aubry e Hobbs (2011) em sua investigação sobre os reflexos da gestão de projetos e do escritório de gestão de projetos no desempenho organizacional dividem a literatura e pesquisa em duas correntes distintas: econômica e pragmática.

A primeira corrente que busca estabelecer a relação da gestão de projetos e do escritório de gestão de projetos com o desempenho econômico das organizações de uma forma ou de outra tocam o conceito de retorno sobre o investimento (ROI - Return On Investiment) seja de maneira direta ou indireta (AUBRY \& HOBBS, 2011).

Tanto Dai e Wells (2004) quanto Ibbs, Reginatto e Kwak (2004) confirmaram a correlação entre a gestão de projetos e o escritório de projetos com o desempenho econômico. No entanto, segundo Thomas e Mullaly (2008), estes estudos não são estatisticamente significantes e não podem ser tomados como definitivos.

Já a segunda corrente, chamada de pragmática, busca estabelecer a relação da gestão de projetos e do escritório de gestão de projetos com o desempenho em relação a fatores de sucesso, inovação, processos e pessoas (AUBRY \& HOBBS, 2011; MORAES \& KRUGLIANSKAS, 2010; RABECHINI JR et al. 2010; THAMHAIN, 2004; TURNER \& KEEGAN, 2004; WINCH, 2004).

Dessa forma, infere-se que a corrente pragmática enfoca basicamente o conceito da criação de vantagem por meio do desenvolvimento ativos estratégicos da visão baseada em recurso (JUGDEV \& THOMAS, 2002).

Seja por uma corrente ou outra, a literatura evidencia que a gestão de projetos é um mecanismo importante na implementação da estratégia e que, quanto mais eficiente, melhor 
poderá contribuir para a construção e sustentação de vantagens competitivas (ARTTO \& DIETRICH, 2004; DIETRICH \& LEHTONEN, 2005; JAMIESON \& MORRIS, 2004; KATHURIA, JOSHI \& PORTH, 2007; SHENHAR \& DVIR, 2010; SHENHAR, 1999; SRIVANNABOON \& MILOSEVIC, 2004; SRIVANNABOON, 2006)

Callahan e Brooks (2004), Cooper et al. (2001), IPMA (2006), Kendal e Rollins (2003), Levine (2005), Martisuo e Lehtonen (2007), Miller (2002), OGC (2008) e PMI (2008b) buscaram propor possíveis modelos, acadêmicos ou consultivos, para avaliação da maturidade em gestão de projetos oferecendo assim um roteiro para a evolução e desenvolvimento da prática dentro das organizações.

Diversos pesquisadores procuraram aplicar tais modelos e assim desenvolveram estudos empíricos investigando possíveis diferenças de maturidade de gestão de projetos entre diversos setores de atividade e outras variáveis (BAI et al., 2010; BYDE, 2008; COOKEDAVIES \& ARZYMANOW, 2003; CRAWFORD, 2005; MULLALY, 2006; GUANGSHE et al., 2008; IBBS, REGINATTO \& KWAK, 2004; LEVENE, BENTLEY \& JARVIS, 1995; GRANT \& PENNYPACKER, 2006; SILVEIRA, 2008; ZWIKAEL \& GLOBERSON; 2006).

Segundo Archibald (2004), a maturidade de gestão de projetos está associada a categoria do projeto e, consequentemente, a comparação entre setores distintos pode não ser adequada. Isto decorre do fato de que dentro de uma mesma organização, Projetos de Mudança Organizacional ou Negócios possuem maturidade diferente de Projetos de Desenvolvimento de Produtos ou Serviços, Projetos de Pesquisa e Desenvolvimento e de Projetos de Sistemas de Informação (Softwares).

Sendo assim, pouco apropriado avaliar as diferenças de maturidade de gestão de projetos entre diversos setores considerando na análise todos os tipos de projetos que as organizações executam, este estudo enfocará em projetos de sistemas de informação ou, como mais recentemente vem sendo chamados, projetos de tecnologia da informação.

A importância da gestão de projetos de TI para meio acadêmico pode ser evidenciada tomando-se por base, por exemplo, o Project Management Journal e seu predecessor o Project Management Quartely, revistas acadêmicas do PMI (Project Management Institute) que dos seus aproximadamente 700 artigos publicados entre 1970 e 2005, 40 abordavam da 
gestão de projetos de sistemas de informação sendo que entre os anos de 2000 a 2004 mais de 15\% dos artigos publicados versaram sobre esta temática (RIVARD \& DUPRÉ, 2009).

\subsection{Objetivo Central da Pesquisa}

Considerando o contexto apresentado, o objetivo deste estudo é analisar e comparar os diferentes níveis de maturidade de gestão de projetos de tecnologia da informação nos setores de serviços, comercial, manufatureira, setor público e terceiro setor no Brasil.

Cumprindo o objetivo central da pesquisa pergunta-se: projetos de tecnologia da informação têm maturidade distinta entre os diversos setores no Brasil?

Buscando responder tal questionamento, foram analisadas organizações dos diversos setores de atividade no Brasil, como:

- organizações do setor de serviços representadas por empresas como bancos, financeiras, serviços profissionais e mídia;

- organizações do setor manufatureiro representadas por empresas de bens de consumo, eletroeletrônicos, mineração e metais, papel e celulose, químicas, petroquímica, farmacêutica e têxtil;

- organização do setor público e terceiro setor representadas por universidades, agências de pesquisa, serviços de utilidade pública e agências reguladoras;

- organizações do setor comercial e varejista representadas por empresas como redes varejistas e revendedores.

Estas organizações foram estudadas por meio de questionários aplicados a funcionários ou prestadores de serviços que atuam diretamente em projetos de tecnologia da informação.

\subsection{Perguntas de Pesquisa e Hipóteses}


Considerando o objetivo central de pesquisa, derivaram-se perguntas de pesquisa e se formularam algumas possíveis hipóteses a serem investigadas empiricamente como explicitamos no Quadro 1.

\section{Quadro 1. Perguntas de Pesquisa e Hipóteses}

\begin{tabular}{|c|c|c|c|}
\hline \# & Pergunta de Pesquisa & \# & Hipóteses \\
\hline \multirow[t]{4}{*}{$\mathrm{P} 1$} & \multirow{4}{*}{$\begin{array}{l}\text { A maturidade de gestão de projetos de } \\
\text { tecnologia da informação entre os distintos } \\
\text { setores é diferente? } \\
\text { Como isso muda quando comparamos os } \\
\text { setores dividindo as organizações de } \\
\text { tamanhos semelhantes? }\end{array}$} & $\mathrm{H} 1$ & $\begin{array}{l}\text { Organizações do mesmo setor tendem a ter } \\
\text { maturidades semelhantes }\end{array}$ \\
\hline & & $\mathrm{H} 2$ & $\begin{array}{l}\text { Organizações de serviços ou comerciais têm } \\
\text { maior de maturidade que manufatureiras }\end{array}$ \\
\hline & & $\mathrm{H} 3$ & $\begin{array}{l}\text { Organizações maiores têm maior maturidade } \\
\text { que organizações menores }\end{array}$ \\
\hline & & $\mathrm{H} 4$ & $\begin{array}{l}\text { Organizações do mesmo setor e de tamanhos } \\
\text { distintos possuem maturidades semelhantes }\end{array}$ \\
\hline \multirow[t]{3}{*}{$\mathrm{P} 2$} & \multirow{3}{*}{$\begin{array}{l}\text { A maturidade de gestão de projetos de } \\
\text { tecnologia da informação entre os distintos } \\
\text { setores é diferente quando analisamos por } \\
\text { área do conhecimento (integração, escopo, } \\
\text { tempo, custo, risco, comunicação, qualidade, } \\
\text { recursos humanos, aquisições)? } \\
\text { Como isso muda quando comparamos os } \\
\text { setores dividindo as organizações de } \\
\text { tamanhos semelhantes? }\end{array}$} & $\mathrm{H} 1$ & $\begin{array}{l}\text { Organizações de setores diferentes têm } \\
\text { maturidades semelhantes }\end{array}$ \\
\hline & & $\mathrm{H} 2$ & $\begin{array}{l}\text { Organizações de serviços ou comerciais têm } \\
\text { maior de maturidade que manufatureiras }\end{array}$ \\
\hline & & H3 & $\begin{array}{l}\text { Organizações do mesmo tamanho possuem } \\
\text { maturidades semelhantes }\end{array}$ \\
\hline P3 & $\begin{array}{l}\text { A maturidade de gestão de projetos } \\
\text { percebida pelos respondentes é diferente } \\
\text { quando comparamos as respostas de } \\
\text { profissionais com características distintas? }\end{array}$ & $\mathrm{H} 1$ & $\begin{array}{l}\text { Os facilitadores organizacionais são } \\
\text { percebidos da mesma forma por profissionais } \\
\text { de características distintas }\end{array}$ \\
\hline \multirow[t]{2}{*}{$\mathrm{P} 4$} & \multirow{2}{*}{$\begin{array}{l}\text { Os facilitadores organizacionais disponíveis } \\
\text { nos distintos setores são diferentes? } \\
\text { Como isso muda quando comparamos os } \\
\text { setores dividindo as organizações por faixa } \\
\text { de faturamento, por número de funcionários, } \\
\text { por tempo de atuação ou por amplitude do } \\
\text { seu escopo geográfico? }\end{array}$} & $\mathrm{H} 1$ & $\begin{array}{l}\text { Organizações de origem latino-americana } \\
\text { dão menos importância para os facilitadores } \\
\text { organizacionais para a gestão de projetos do } \\
\text { que as empresas de outros países. }\end{array}$ \\
\hline & & $\mathrm{H} 2$ & $\begin{array}{l}\text { Organizações menores dão menor } \\
\text { importância aos facilitadores organizacionais } \\
\text { para a gestão de projetos do que as empresas } \\
\text { maiores. }\end{array}$ \\
\hline
\end{tabular}




\subsection{Delimitações e Limitações do Estudo}

Os projetos de tecnologia da informação foram alvo do estudo, pois ao restringir o segmento de análise é possível eliminar variações decorrentes da comparação de diferentes tipos de projetos em diferentes setores. Assim buscou-se isolar o fenômeno de possíveis diferenças de maturidade que possam estar ligadas à categoria do projeto (ARCHIBALD, 2004).

Com o objetivo de delimitar o estudo, a análise abrangeu os grupos de processos de iniciação e planejamento de gestão de projetos, com o objetivo de contribuir com a comunidade científica para o entendimento e análise do fenômeno, bem como ajudar organizações e pessoas que enfrentam o desafio de gerenciar projetos em suas organizações.

A análise foi delimitada aos dois primeiros grupos de processos da gestão de projetos: a iniciação e o planejamento, pois durante o estudo identificou-se na revisão bibliográfica e no pré-teste que esses dois grupos representam de forma significativa os demais. Este delimitação foi particularmente útil também para viabilizar a aplicação de questionários a um maior número de organizações e respondentes.

A maturidade de gestão de projetos nas organizações foi estudada por meio de questionários aplicados a funcionários ou prestadores de serviços que atuam diretamente em projetos de tecnologia da informação.

Assim, é preciso considerar que esse estudo faz uma avaliação indireta da percepção dos respondentes em relação à maturidade de gestão de projetos nas organizações em que se encontram.

Evidentemente, este método possui suas limitações por avaliar de maneira indireta o fenômeno por meio da percepção dos respondentes, o que é uma limitação intrínseca do estudo. Por outro lado, tal abordagem propiciou a possibilidade de ampliar a amostra e o número de organizações envolvidas na pesquisa, tendo assim, beneficiado a possibilidade de comparar resultados de diversos setores com maior significância estatística. 


\section{REVISÃO BIBLIOGRÁFICA}

Dando sustentação teórica ao objeto de pesquisa, esta revisão bibliográfica buscou abranger as pesquisas relacionadas à gestão de projetos, tecnologia da informação e maturidade de processos.

Inicialmente, investigou-se a evolução dos constructos fundamentais dos projetos para dar embasamento teórico ao estudo.

Subsequentemente, pesquisou-se de forma não exaustiva temas como a estratégia, alinhamento estratégico e gestão de portfolio de projetos, as funções do escritório de gestão de projetos e fatores para avaliação do sucesso dos projetos.

Finalmente, dando subsídio e contexto para análise dos projetos estudados, buscou-se a literatura referente ao papel estratégico da tecnologia da informação, ao alinhamento estratégico e a gestão da tecnologia da informação, assim como, aos projetos de tecnologia da informação.

De posse deste alicerce, abordou-se os conceitos de maturidade e capacidade de processo, as propostas de modelos de maturidade de tecnologia da informação e de gestão de projetos, finalizando pela compilação não exaustiva das pesquisas empíricas de avalição multi-setorial de maturidade de projetos, em geral, e de projetos de tecnologia da informação.

Esta sustentação teórica e científica foi base para a construção do instrumento de pesquisa, trabalho de campo e análise de dados da qual se valeu para analisar a maturidade da gestão de projetos de tecnologia de informação no Brasil como ilustrado na Figura 1. 


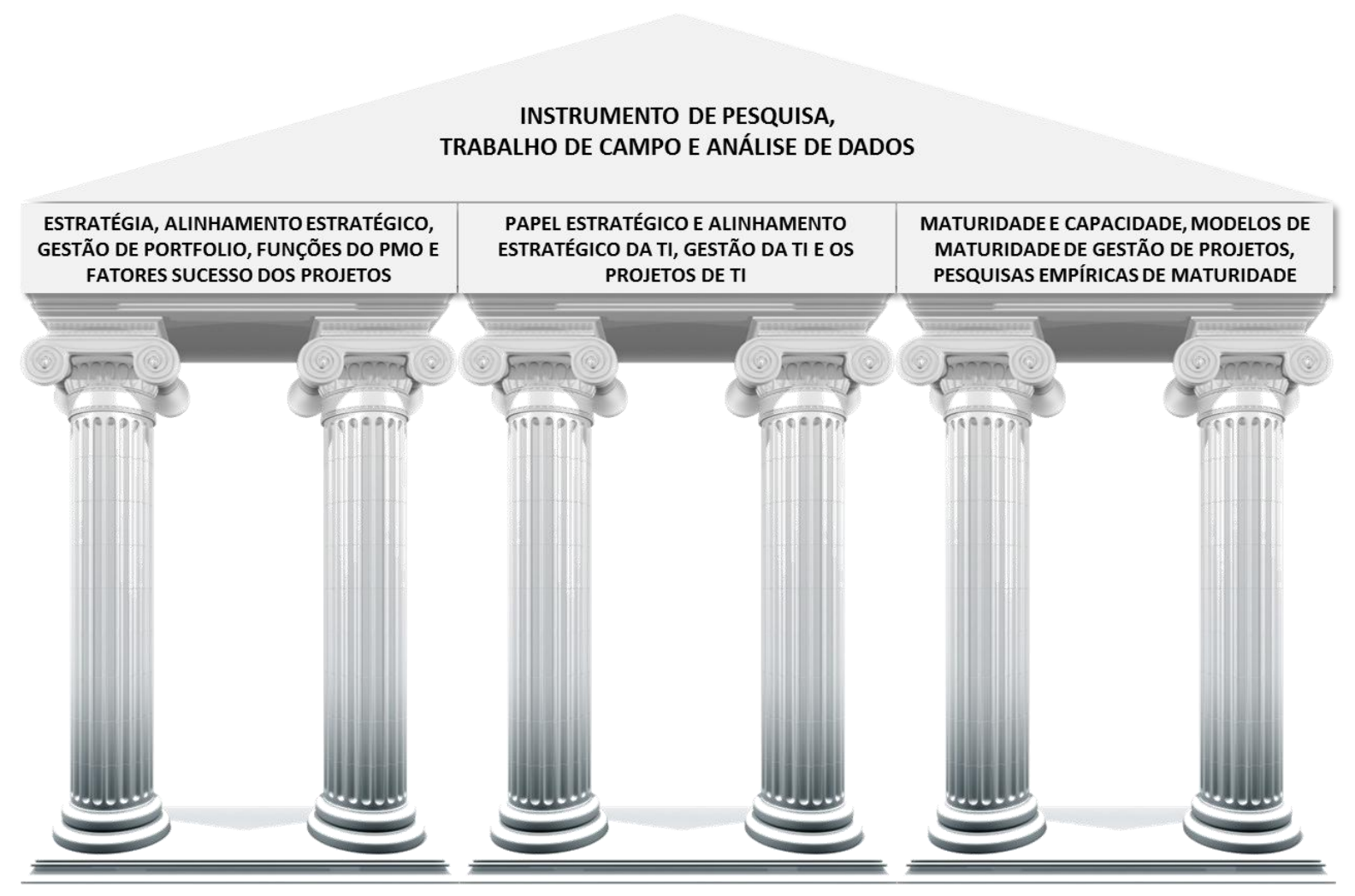

Figura 1. Estrutura da Revisão Teórica

\subsection{Gestão de Projetos}

\subsubsection{Evolução dos Constructos Fundamentais}

A definiçãa de projeto como empreendimento com objetivo definido e sujeito a restrições de prazo e custo pode ser considerada um construto operacional e normativo orientado para a eficiência. Esta definição, no entanto, tem evoluído incorporando assim novas perspectivas e aspectos. Neste contexto, ao se falar na geração de valor por meio de projetos, uma abordagem estratégica desta disciplina se torna necessária (JUGDEV et al., 2001).

Isto é particularmente verdadeiro no caso das empresas orientadas para projetos (project oriented businesses), que baseiam seus negócios na venda de produtos e serviços sob encomenda (ARCHIBALD, 2004; RAD \& RAGHAVAN, 2000; PINTO, 2002). 
Mas não deixa de ser relevante nas demais organizações que fazem uso dos projetos como alavancas propulsores de novas ideias e de construção de competências essenciais (SHENHAR \& DVIR, 2010).

Assim, uma visão sistêmica dos projetos compreenderia três níveis ou dimensões: estratégia, tática e operacional (

Quadro 2).

Quadro 2. Evolução da Definição de Projeto

\begin{tabular}{|c|c|}
\hline Amplitude & Definição \\
\hline Operacional & $\begin{array}{l}\text { "Um projeto é um esforço temporário, empreendido para criar um produto, serviço ou resultado } \\
\text { único" (PROJECT MANAGEMENT INSTITUTE, 2008a, p. 5). }\end{array}$ \\
\hline \multirow{3}{*}{ Tática } & $\begin{array}{l}\text { "[...] um projeto pode ser definido por uma série de atividades e tarefas que têm o resultado } \\
\text { específico que é entregue dentro de certas especificações, possui data início e término, possui em } \\
\text { muitos casos limitações de fundos e custos, consome recursos materiais e humanos e são } \\
\text { multifuncionais" (KERZNER, 2009, p. 2). }\end{array}$ \\
\hline & $\begin{array}{l}\text { "Um projeto é uma organização temporária, criada pela organização principal, para realizar um } \\
\text { empreendimento em seu benefício" (ANDERSEN, 2008, p. 10). }\end{array}$ \\
\hline & $\begin{array}{l}\text { "[...] um empreendimento onde recursos humanos, materiais e financeiros são organizados de } \\
\text { uma maneira nova para realizar um escopo único de trabalho, dado por uma certa especificação, } \\
\text { que possui restrições de custos e tempo e que deve alcançar uma certa mudança em indicadores } \\
\text { quantitativos e qualitativos." (TURNER, 1993) }\end{array}$ \\
\hline \multirow{4}{*}{ Estratégica } & $\begin{array}{l}\text { "Projetos são os motores que impulsionam inovações de ideias à comercialização. [...] os } \\
\text { propulsores que fazem com que as organizações sejam melhores, mais fortes e mais eficientes } \\
\text { [...] definimos um projeto como sendo uma organização temporária e o processo estabelecido } \\
\text { para alcançar uma meta específica sob as restrições de tempo, orçamento e outros recursos" } \\
\text { (SHENHAR \& DVIR, 2010, p. 17). }\end{array}$ \\
\hline & $\begin{array}{l}\text { Projetos abordam "a mudança, procurando adaptar a organização à evolução de seu ambiente, } \\
\text { pelo reforço de sua coesão interna" (BOUTINET, 2006, p. 48). }\end{array}$ \\
\hline & $\begin{array}{l}\text { "Uma forma de a organização movimentar sua estratégia é pela criação de determinados } \\
\text { projetos" (ANDERSEN, 2008, p.66). }\end{array}$ \\
\hline & $\begin{array}{l}\text { "Um projeto é conjunto de ações limitadas no tempo e espaço, inseridas e relacionadas com o } \\
\text { ambiéte político-sócio-econômico que objetivam atingir de maneira progressiva um objetivo } \\
\text { que é definido e redefinido pela dialética entre o pensamento (plano) e a realidade (execução)." } \\
\text { (DECLERCK, DEBOURSE \& DECLERCK, 1997; DECLERCK, DEBOURSE \& NAVARRE, } \\
\text { 1983) }\end{array}$ \\
\hline
\end{tabular}

FONTE: ANSELMO \& MAXIMIANO, 2010 - ampliado pelo autor.

Bredillet (2010) defende que atualmente a gestão de projetos pode ser considerada uma disciplina acadêmica madura com algum nível de diversidade e complexidade que tem contribuído de maneira direta e indireta para outros campos de conhecimento da administração. O autor ainda aponta a existência de menos linhas teóricas de gestão de projetos podem ser identificadas na literatura (Quadro 3). 
Quadro 3. As nove escolas de gestão de projetos e suas perspectivas

\begin{tabular}{|c|c|c|c|c|c|c|c|c|}
\hline Escola & Metáfora & $\begin{array}{c}\text { Ideia } \\
\text { Principal }\end{array}$ & $\begin{array}{l}\text { Principais } \\
\text { Variáveis }\end{array}$ & Proeminência & Influência & $\begin{array}{c}\text { Perspectiva } \\
\text { Ontológica } \\
\end{array}$ & $\begin{array}{c}\text { Perspectiva } \\
\text { Epistemológica }\end{array}$ & $\begin{array}{c}\text { Perspectivas } \\
\text { Teóricas } \\
\end{array}$ \\
\hline Otimização & $\begin{array}{l}\text { o projeto } \\
\text { como uma } \\
\text { máquina }\end{array}$ & $\begin{array}{l}\text { otimizar o } \\
\text { resultado do } \\
\text { projeto por } \\
\text { meio de } \\
\text { processos } \\
\text { matemáticos }\end{array}$ & tempo & Finais de 1940 & $\begin{array}{l}\text { Pesquisa } \\
\text { operacional }\end{array}$ & $\begin{array}{l}\text { Ser } \\
\text { Parmênides: } \\
\text { ênfase em uma } \\
\text { realidade } \\
\text { permanente e } \\
\text { constante }\end{array}$ & $\begin{array}{l}\text { Objetivismo } \\
\text { a realidade existe } \\
\text { independente do nosso } \\
\text { conhecimento dela }- \text { há } \\
\text { uma realidade objetiva } \\
\text { "lá fora" }\end{array}$ & $\begin{array}{l}\text { Positivismo } \\
\text { observação científica, } \\
\text { investigação empírica, } \\
\text { lidando com os fatos }\end{array}$ \\
\hline \multirow{4}{*}{ Modelagem } & \multirow{4}{*}{$\begin{array}{l}\text { o projeto } \\
\text { como um } \\
\text { espelho }\end{array}$} & \multirow{4}{*}{$\begin{array}{l}\text { utilização da } \\
\text { teoria de hard } \\
\text { e soft-systems } \\
\text { e estáveis para } \\
\text { modelar o } \\
\text { projeto }\end{array}$} & \multirow{4}{*}{$\begin{array}{l}\text { tempo, custo, } \\
\text { desempenho, } \\
\text { qualidade, } \\
\text { risco, etc }\end{array}$} & \multirow{4}{*}{$\begin{array}{l}\text { hard -systems em } \\
\text { meados de } 1950 \\
\text { soft-systems em } \\
\text { meados de } 1990\end{array}$} & $\begin{array}{l}\text { Teoria de } \\
\text { sistemas }\end{array}$ & \multirow[b]{2}{*}{ Ser } & Objetivismo & Positivismo \\
\hline & & & & & \multirow{3}{*}{ Soft-systems } & & $\begin{array}{l}\text { Construtivismo } \\
\text { a "verdade" e o sentido } \\
\text { são criados pela } \\
\text { interação do sujeito com } \\
\text { o mundo }\end{array}$ & $\begin{array}{l}\text { Interpretativismo } \\
\text { interação simbólica, } \\
\text { fenomenologia, } \\
\text { etnografia, naturalístico, } \\
\text { investigação, } \\
\text { hermenêutica }\end{array}$ \\
\hline & & & & & & \multirow{2}{*}{$\begin{array}{l}\text { Se tornar } \\
\text { Heráclito: mundo } \\
\text { em transformação } \\
\text { e desenvolvimento }\end{array}$} & \multirow{2}{*}{$\begin{array}{l}\text { Subjetivismo } \\
\text { significado do objeto é } \\
\text { imposto pelo sujeito, o } \\
\text { sujeito constrói o } \\
\text { significado por meio e } \\
\text { com o inconsciente } \\
\text { coletivo, da fé, crença... }\end{array}$} & $\begin{array}{l}\text { Investigação crítica } \\
\text { descarta "falsa } \\
\text { ignorância" para } \\
\text { desenvolver novas } \\
\text { maneira de entendimento } \\
\text { como um guia para ação } \\
\text { efetiva }\end{array}$ \\
\hline & & & & & & & & $\begin{array}{l}\text { Pós-modernismo } \\
\text { ênfase na multiplicidade, } \\
\text { ambiguidade, } \\
\text { ambivalência, } \\
\text { fragmentação... }\end{array}$ \\
\hline \multirow[b]{2}{*}{ Governança } & \multirow[b]{2}{*}{$\begin{array}{l}\text { o projeto } \\
\text { como uma } \\
\text { entidade } \\
\text { legal }\end{array}$} & \multirow[b]{2}{*}{$\begin{array}{l}\text { governe o } \\
\text { projeto e as } \\
\text { relações entre } \\
\text { os } \\
\text { participantes }\end{array}$} & \multirow[b]{2}{*}{$\begin{array}{l}\text { o projeto, seus } \\
\text { participantes e } \\
\text { mecanismos } \\
\text { de governança }\end{array}$} & \multirow{2}{*}{$\begin{array}{l}\text { Contratos no } \\
\text { início de } 1970 \\
\text { Organização } \\
\text { temporária em } \\
\text { meados de } 1990 \\
\text { Governança no } \\
\text { final de } 1990\end{array}$} & \multirow[b]{2}{*}{$\begin{array}{l}\text { Contratos e lei, } \\
\text { governança, } \\
\text { custos de } \\
\text { transação, teoria } \\
\text { de agência }\end{array}$} & \multirow[b]{2}{*}{ Ser } & Objetivismo & Positivismo \\
\hline & & & & & & & Construtivismo & Interpretativismo \\
\hline
\end{tabular}




\begin{tabular}{|c|c|c|c|c|c|c|c|c|}
\hline Escola & Metáfora & $\begin{array}{c}\text { Ideia } \\
\text { Principal } \\
\end{array}$ & $\begin{array}{l}\text { Principais } \\
\text { Variáveis } \\
\end{array}$ & Proeminência & Influência & $\begin{array}{c}\text { Perspectiva } \\
\text { Ontológica }\end{array}$ & $\begin{array}{c}\text { Perspectiva } \\
\text { Epistemológica } \\
\end{array}$ & $\begin{array}{c}\text { Perspectivas } \\
\text { Teóricas } \\
\end{array}$ \\
\hline \multirow{3}{*}{ Comportamento } & \multirow{3}{*}{$\begin{array}{l}\text { o projeto } \\
\text { como um } \\
\text { sistema } \\
\text { social }\end{array}$} & \multirow{3}{*}{$\begin{array}{l}\text { gerenciar os } \\
\text { relacionament } \\
\text { os entres as } \\
\text { pessoas no } \\
\text { projeto }\end{array}$} & \multirow{3}{*}{$\begin{array}{l}\text { pessoas e } \\
\text { equipes } \\
\text { trabalhando } \\
\text { em projetos }\end{array}$} & \multirow{3}{*}{$\begin{array}{l}\text { Comportamento } \\
\text { org. em meados } \\
1970 \\
\text { Gestão de RH no } \\
\text { início de } 2000\end{array}$} & \multirow{3}{*}{$\begin{array}{l}\text { Comportamento } \\
\text { organizacional } \\
\text { Gestão de } \\
\text { Recursos }\end{array}$} & \multirow{2}{*}{ Ser } & Objetivismo & Positivismo \\
\hline & & & & & & & Construtivismo & Interpretativismo \\
\hline & & & & & & Se tornar & Subjetivismo & $\begin{array}{l}\text { Investigação crítica, } \\
\text { pós-modernismo }\end{array}$ \\
\hline Sucesso & $\begin{array}{l}\text { o projeto } \\
\text { como um } \\
\text { objetivo de } \\
\text { negócio }\end{array}$ & $\begin{array}{l}\text { definir o } \\
\text { sucesso e } \\
\text { identificar } \\
\text { causas de } \\
\text { falha } \\
\end{array}$ & $\begin{array}{l}\text { critérios de } \\
\text { sucesso e } \\
\text { fatores de } \\
\text { sucesso }\end{array}$ & Meados de 1980 & $\begin{array}{l}\text { Interna ao } \\
\text { gerenciamento de } \\
\text { projeto }\end{array}$ & Ser & Objetivismo & Positivismo \\
\hline Decisão & $\begin{array}{l}\text { o projeto } \\
\text { como um } \\
\text { computador }\end{array}$ & $\begin{array}{l}\text { processamento } \\
\text { de } \\
\text { informações } \\
\text { durante o ciclo } \\
\text { de vida do } \\
\text { projeto }\end{array}$ & $\begin{array}{l}\text { informações } \\
\text { com as quais } \\
\text { as decisões } \\
\text { são tomadas }\end{array}$ & Final de 1980 & $\begin{array}{l}\text { Teorias de } \\
\text { decisão, custos de } \\
\text { transação }\end{array}$ & Ser & Objetivismo & Positivismo \\
\hline Processo & $\begin{array}{l}\text { o projeto } \\
\text { como um } \\
\text { algoritmo }\end{array}$ & $\begin{array}{l}\text { encontrar um } \\
\text { caminho } \\
\text { apropriado } \\
\text { para gerar o } \\
\text { resultado } \\
\text { esperado }\end{array}$ & $\begin{array}{l}\text { o projeto, seus } \\
\text { processos e } \\
\text { subprocessos }\end{array}$ & Final de 1980 & $\begin{array}{l}\text { Tecnologia da } \\
\text { informação, } \\
\text { estratégia }\end{array}$ & Ser & Objetivismo & Positivismo \\
\hline \multirow{3}{*}{ Contingência } & \multirow{3}{*}{$\begin{array}{l}\text { o projeto } \\
\text { com um } \\
\text { camaleão }\end{array}$} & \multirow{3}{*}{$\begin{array}{l}\text { categorizar o } \\
\text { tipo do projeto } \\
\text { e selecionar os } \\
\text { sistemas } \\
\text { apropriados } \\
\end{array}$} & \multirow{3}{*}{$\begin{array}{l}\text { fatores que } \\
\text { diferenciam } \\
\text { projetos }\end{array}$} & \multirow{3}{*}{ Início de 1990} & \multirow{3}{*}{$\begin{array}{l}\text { Teoria da } \\
\text { contingência, } \\
\text { teoria de liderança }\end{array}$} & \multirow{2}{*}{ Ser } & Objetivismo & Positivismo \\
\hline & & & & & & & Construtivismo & Interpretativismo \\
\hline & & & & & & Se tornar & Subjetivismo & $\begin{array}{l}\text { Investigação crítica, } \\
\text { pós-modernismo }\end{array}$ \\
\hline \multirow{3}{*}{ Marketing } & \multirow{3}{*}{$\begin{array}{l}\text { o projeto } \\
\text { como um } \\
\text { outdoor de } \\
\text { propaganda }\end{array}$} & \multirow{3}{*}{$\begin{array}{l}\text { comunicar } \\
\text { com todos os } \\
\text { stakeholders } \\
\text { para obter seu } \\
\text { apoio }\end{array}$} & \multirow{3}{*}{$\begin{array}{l}\text { stakeholders e } \\
\text { seu } \\
\text { compromisso } \\
\text { com o projeto } \\
\text { e com a gestão } \\
\text { do projeto }\end{array}$} & \multirow{3}{*}{$\begin{array}{l}\text { Stakeholders: em } \\
\text { meados de } 1990 \\
\text { Outdoor: início de } \\
2000\end{array}$} & \multirow{3}{*}{$\begin{array}{l}\text { Gerenciamento } \\
\text { dos stakeholders, } \\
\text { governança, } \\
\text { estratégia }\end{array}$} & \multirow{2}{*}{ Ser } & Objetivismo & Positivismo \\
\hline & & & & & & & Construtivismo & Interpretativismo \\
\hline & & & & & & Se tornar & Subjetivismo & $\begin{array}{l}\text { Investigação crítica, } \\
\text { pós-modernismo }\end{array}$ \\
\hline
\end{tabular}

FONTE: BREDILLET, 2010 - traduzido livremente pelo autor. 


\subsubsection{Fatores para Avaliação do Sucesso dos Projetos}

Yazici (2009) entende que a percepção do reflexo dos projetos para o desempenho organizacional é composto por dois constructos distintos: desempenho do negócio e desempenho dos projetos.

Já Aubry e Hobbs (2011), em sua investigação sobre os impactos dos projetos no desempenho organizacional, organizam as pesquisas e literatura em duas correntes distintas. A primeira corrente, denominada econômica, avalia a relação dos projetos com o desempenho financeiro da organização enquanto a segunda, batizada pelos autores de pragmática, avalia o projeto e seus fatores de sucesso.

\subsubsection{Desempenho do Projeto ou a Corrente Pragmática}

Fortune e White (2006) desenvolveram um modelo representado no

Quadro 4 para consolidar os fatores críticos de sucesso de projetos que os autores encontraram por meio uma revisão sistemática da literatura vigente.

Esta revisão considerou 63 publicações que investigaram de maneira empírica os fatores críticos de sucesso de projetos sendo que alguns destes estudos analisaram casos múltiplos e outros fizeram uso de questionários.

Quadro 4. Fatores Críticos de Sucesso dos Projetos

\begin{tabular}{|l|l|}
\hline Componentes & Fatores críticos de sucesso identificados na literatura \\
\hline $\begin{array}{l}\text { Metas e } \\
\text { Objetivos }\end{array}$ & $\begin{array}{l}\text { Objetivos realistas e claros } \\
\text { Business Case forte que embase o projeto }\end{array}$ \\
\hline $\begin{array}{l}\text { Monitoramento } \\
\text { do Desempenho }\end{array}$ & $\begin{array}{l}\text { Monitoramento e controle efetivo } \\
\text { Planejamento prévio do fechamento, revisão ou aceitação de possível insucesso }\end{array}$ \\
\hline
\end{tabular}




\begin{tabular}{|c|c|}
\hline Componentes & Fatores críticos de sucesso identificados na literatura \\
\hline $\begin{array}{l}\text { Tomadores de } \\
\text { Decisão }\end{array}$ & $\begin{array}{l}\text { Suporte da alta administração } \\
\text { Gerente de projeto competente } \\
\text { Plano completo e detalhado que esteja atualizado } \\
\text { Cronograma e prazos realistas } \\
\text { Boa liderança } \\
\text { Escolha correta e experiências anteriores em ferramentas e metodologia de gestão de } \\
\text { projetos }\end{array}$ \\
\hline Transformações & Equipe de projeto competente, qualificada e em quantidade suficiente \\
\hline Comunicação & Boa comunicação e feedback \\
\hline Ambiente & $\begin{array}{l}\text { Estabilidade política } \\
\text { Influências ambientais } \\
\text { Experiências passadas de onde se pôde aprender e referenciar } \\
\text { Estrutura e cultura organizacional, bem como, capacidade de adaptação }\end{array}$ \\
\hline Fronteira & Tamanho do projeto, nível de complexidade, pessoas envolvidas e duração \\
\hline Recursos & $\begin{array}{l}\text { Orçamento adequado } \\
\text { Recursos suficientes e corretamente alocados } \\
\text { Treinamento } \\
\text { Familiaridade com a tecnologia e tecnologia conhecida } \\
\text { Bom desempenho de fornecedores, subcontratados e/ou consultores }\end{array}$ \\
\hline Continuidade & $\begin{array}{l}\text { Identificação, encaminhamento e gerenciamento de riscos } \\
\text { Envolvimento dos clientes e/ou usuários } \\
\text { Apreciação e consideração de diferentes pontos de vistas } \\
\text { Patrocinador ou Champion do projeto } \\
\text { Gerenciamento eficiente da mudança }\end{array}$ \\
\hline
\end{tabular}

FONTE: FORTUNE \& WHITE, 2006 - traduzido livremente pelo autor.

Outras investigações empíricas buscaram estabelecer a relação da gestão de projetos e do escritório de gestão de projetos com o desempenho em relação a fatores de sucesso, inovação, processos e pessoas (AUBRY \& HOBBS, 2011; MORAES \& KRUGLIANSKAS, 2010; RABECHINI JR et al. 2010; THAMHAIN, 2004; TURNER \& KEEGAN, 2004; WINCH, 2004).

Desta forma, poder-se-ia induzir que realizar projetos de maneira mais madura pode beneficiar os fatores críticos de sucesso e, claro, reduzir esforços e custos necessários para executá-los. 
A combinação de fatores críticos de sucesso identificados por Fortune e White (2006) e sua contribuição para o sucesso do projeto poderia ser matematicamente representada como na Figura 2.

$$
\begin{aligned}
& f(\text { Sucesso do Projeto }) \\
& =\alpha\left(\sum \text { Maturidade de Gestão de Projetos }\right) \\
& +\beta\left(\sum \text { Fatores Críticos Sucesso }\right)+\varepsilon
\end{aligned}
$$

Figura 2. Componentes que Contribuem para o Sucesso do Projeto

Os coeficientes $\alpha$ e $\beta$ seriam a respectivas contribuições da maturidade dos processos de gestão de projetos e dos fatores críticos de sucesso para o sucesso do projeto. Enquanto $\varepsilon$ representa outros fatores não determinados que também interferem no sucesso do projeto.

\subsubsection{Desempenho do Negócio ou a Corrente Econômica}

Shenhar e Dvir (2010) vislumbram a importância estratégica dos projetos e enfatizam a potencial criação e sustentação de vantagens competitivas por meio dos projetos além de outras contribuições importantes dos projetos para as organizações (Figura 3).

Assim, Moraes e Laurindo (2010) propõe a aplicação das dimensões do sucesso de projetos de Shenhar e Dvir (2010) em projetos de tecnologia de informação. Sendo uma relevante contribuição do trabalho a proposição de avaliar o sucesso do projeto de TI em dois momentos distintos: ex ante e ex post.

Tanto Dai e Wells (2004) quanto Ibbs, Reginatto e Kwak (2004) procuraram confirmar a correlação entre a gestão de projetos com o desempenho econômico. No entanto, segundo Thomas e Mullaly (2008), estes estudos não são estatisticamente significantes e não podem ser tomados como definitivos.

Thomas e Mullaly (2008) exploram a dificuldade de demonstrar influência direta da gestão de projetos sobre o ROI. 


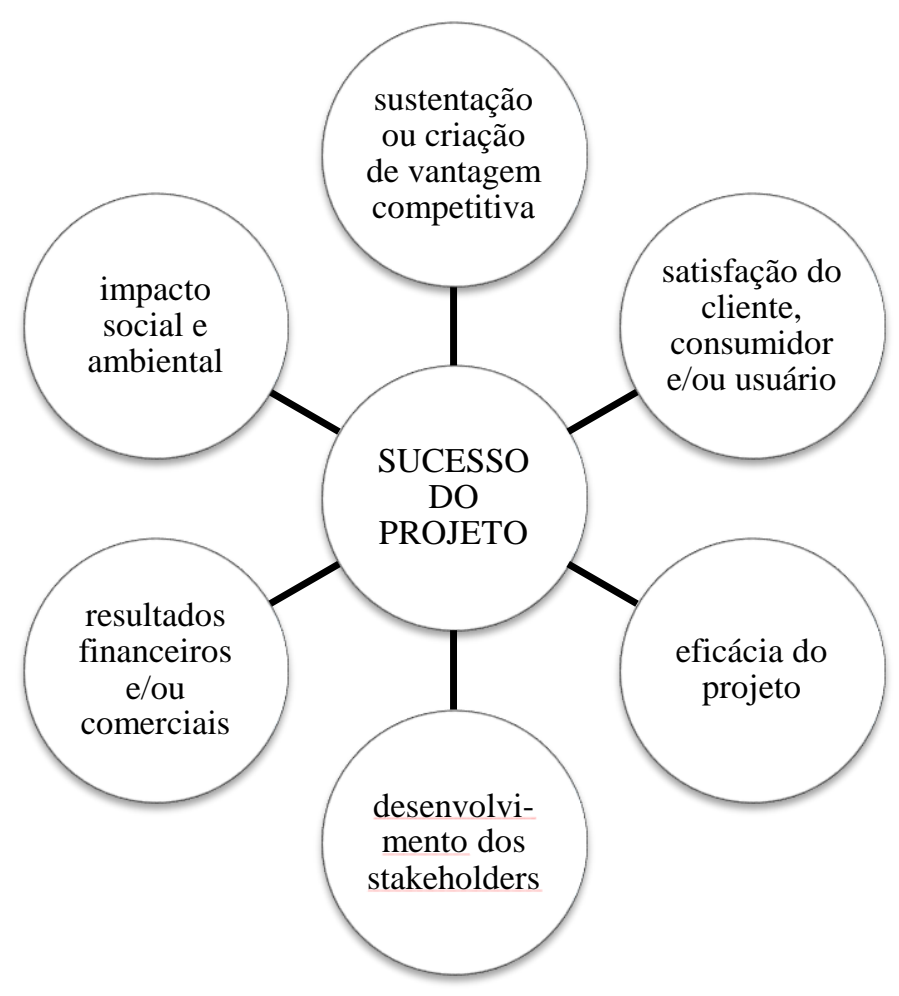

Figura 3. Possíveis Dimensões do Sucesso de um Projeto FONTE: SHENHAR \& DVIR, 2010 - adaptado pelo autor.

Já Norrie e Walker (2004) e Stewart (2001) propõe a aplicação do Balanced Scorecard como alternativa para avaliar os resultados dos projetos de maneira mais holística apontando para a contribuição destes para as quatro perspectivas do modelo: financeira, cliente, processos internos e, aprendizagem e crescimento.

De qualquer forma, parece haver uma possível contribuição da maturidade de gestão de projetos para o sucesso do projeto como verificado em Ibbs e Kwak (2000a e b).

Moraes e Kruglianskas (2010) procuraram explorar, em projetos de TI, as possíveis relações entre fatores críticos sucesso, maturidade dos processos de gestão de projetos e o sucesso do projeto. Este estudo apontar uma possível correlação das variáveis estudadas.

Desta maneira, poder-se-ia induzir que realizar projetos de maneira mais madura pode beneficiar o desempenho do resultado do projeto seja ele um produto, serviço ou mesmo uma melhoria em um processo ou competência essencial. 


\subsubsection{Escritório de Gestão de Projetos (PMO)}

O escritório de gestão de projeto, traduzido literalmente de Project Management Office (PMO), é a entidade organizacional perene encarregada pela gestão centralizada e coordenada dos projetos sob seu domínio, desde apoio até a responsabilidade pelo gerenciamento efetivo dos projetos (PROJECT MANAGEMENT INSTITUTE, 2008a).

Hobbs (2007), por meio de um estudo exploratório, identificou 28 funções distintas em diversos PMOs que procuramos agrupar verossimilhança nos seguintes temas:

- Alinhamento estratégico

- participar do planejamento estratégico

○ prover aconselhamento à alta gerência

- desenvolver e manter um quadro estratégico de projetos (project scoreboard)

- Gestão de benefícios (value delivery management)

- gerenciar os benefícios de programas

- Gestão centralizada da carteira de programas e projetos (portfolio)

○ identificar, selecionar e priorizar novos projetos

- gerenciar um ou mais portfólios

○ promover o gerenciamento de projetos dentro da organização

- informar o status dos projetos para a alta gerência

- monitorar e controlar o desempenho de projetos

- coordenar e integrar projetos de um portfólio

- Escritório de apoio ao gerenciamento de programas e projetos

- conduzir auditorias de projetos

- executar tarefas especializadas para os gerentes de projetos

- gerenciar um ou mais programas

- monitorar e controlar o desempenho do próprio PMO

- Relacionamento

- gerenciar interfaces de clientes

- mapear o relacionamento e o ambiente de projetos

- Gestão de recursos

○ recrutar, selecionar, avaliar e determinar salários dos gerentes de projetos

- alocar recursos entre os projetos 
- Capacitação

○ desenvolver as competências dos profissionais, inclusive treinamento

○ prover mentoring para os gerentes de projetos

- Padronização de processos, documentos, ferramentas e sistemas de informações

○ desenvolver e implementar a metodologia padrão

○ implementar e operar sistemas de informação dos projetos

○ prover um conjunto de ferramentas sem o esforço de padronização

○ gerenciar arquivos/acervos de documentação de projetos

○ conduzir revisões pós-gerenciamento do projeto (lições aprendidas)

○ implementar e gerenciar banco de dados de lições aprendidas e riscos

Assim, representou-se na Figura 4 o agrupamento das funções do escritório de gestão de projetos identificadas por Hobbs (2007).

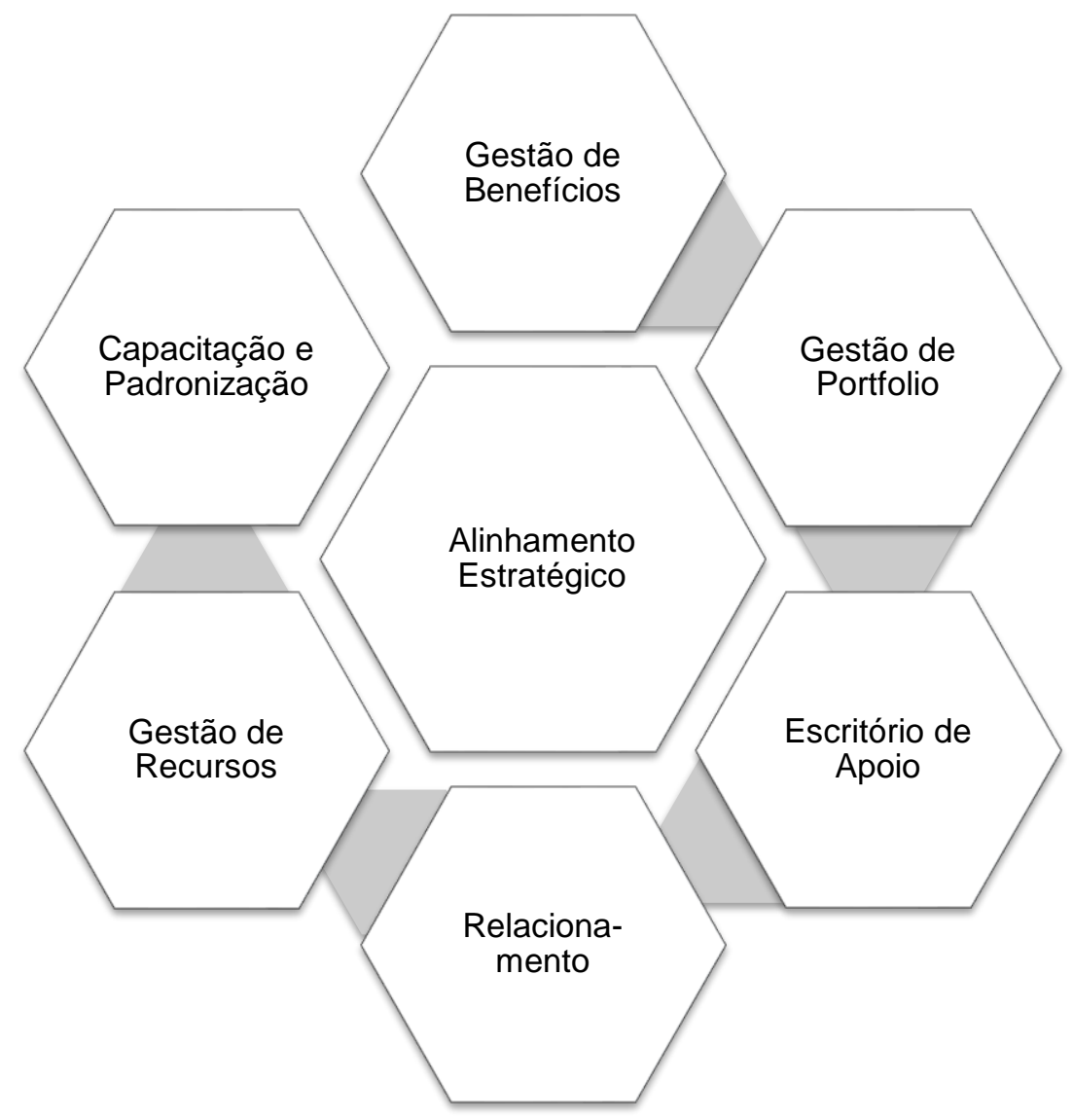

Figura 4. Funções do PMO

Apoiando-se em Frame (1999) e Rabechini Jr. (2003), os autores Rodrigues, Rabechini Jr. \& Csillag (2006) discorrem sobre a capacidade do PMO em promover a prática de gestão de 
projeto e, por consequência, aumentar a maturidade da gestão de projeto organizacional, da equipe de projeto e dos indivíduos.

Rodrigues, Rabechini Jr. \& Csillag (2006) ainda apontam que parece o escritório de projeto parece ajudar as organizações a atingir maior maturidade em gestão de projetos principalmente na dimensão organizacional.

Já Carvalho e Rabechini Jr. (2007) exploram a dimensão do individuo e sua relação com a construção de competências como meio para amadurecimento da gestão de projeto nas organizações.

\subsubsection{Estratégia e Gestão de Portfolio de Projetos}

Resumidamente, a gestão do portfólio de projetos consiste em tomar decisões sobre quais projetos executar e que recursos usar para executá-los (ARCHIBALD, 2004).

A implementação da estratégia, por meio da gestão competente do portfólio, é um dos fatores críticos para construção e manutenção de vantagens competitivas para as organizações tão quanto para a criação de ativos estratégicos (ARTTO \& DIETRICH, 2004; AUBRY \& HOBBS, 2011; DIETRICH \& LEHTONEN, 2005; JAMIESON \& MORRIS, 2004; JUGDEV \& THOMAS, 2002; KATHURIA et al., 2007; SHENHAR, 1999; SRIVANNABOON \& MILOSEVIC, 2004; SRIVANNABOON, 2006).

Cooper et al. (2001a e b), Miller (2002), Kendall e Rollins (2003), Callahan e Brooks (2004), Martinsuo e Lehtonen (2007), PMI (2008), IPMA (2006) e OGC (2008) buscam identificar processos e práticas de maneira normativa, propondo modelos e padrões para realização do alinhamento estratégico e gerenciamento do portfolio de projetos.

Já Bossidy et al. (2002), Govindarajan e Trimble (2010), Mullaly e Thomas (2009) e Pfeffer e Sutton (2000) discutem o alinhamento estratégico dos projetos como processo de gestão. 
Segundo Mintzberg et al. (2000), a concepção da administração estratégica como um sistema fechado, normativo e cíclico pode ser encontrada nas escolas prescritivas como a do design, do planejamento e do posicionamento, como por exemplo é proposto no Balanced Scorecard de Kaplan e Norton (1992, 1996 e 2008).

Assim, Kaplan e Norton (2008) indicam a importância da implementação da estratégia por meio de uma gestão madura da carteira de projetos corporativos sendo que o elo entre o planejamento estratégico e a sua execução é crítico para o sucesso no longo prazo e para a construção de vantagens competitivas sustentáveis.

No entanto, para Mintzberg (1994) e Collins (2001), seria impróprio entender a estratégia como um processo formal, cíclico e fechado.

Desta forma, Mintzberg et al. (2000) apontam a existência das escolas descritivas, tais como a empreendedora, a cognitiva, a de aprendizado, a do poder, a cultural e a ambiental, ou mesmo, a escola da configuração, que sugerem uma estratégia que é emergente mais da cultura e aprendizagem, do que do processo de planejamento.

No nível estratégico, as organizações tomam decisões sobre quais projetos executar e que recursos usar para executá-los (ARCHIBALD, 2004). Para que a escolha assegure o alinhamento dos projetos com a estratégia organizacional, é necessário usar o conceito e as ferramentas da gestão de portfólios.

Diversos modelos de alinhamento estratégico da organização (PRIETO et al., 2009) procuraram explorar a implementação da estratégia por meio da gestão do portfolio de projetos apontando para a importância deste como fatores críticos para o sucesso no longo prazo.

Assim, poder-se-ia dizer que estratégia de uma organização compreende tanto os objetivos, políticas e iniciativas deliberadas, que são formais e explícitas, quanto as emergentes, que são implementadas independentemente de qualquer planejamento (MINTZBERG, 1994).

O mesmo ocorre com os projetos, há os oficiais e os extraoficiais, todos compondo o portfólio dos projetos que a organização deve gerenciar (BLICHFELDT \& ESKEROD, 2008). Esta 
convivência entre os projetos oficiais e extraoficiais reforça a necessidade do alinhamento dos projetos com estratégia e também aponta para a hipótese de que a estratégia emergente pode estar mais relacionada com os projetos extraoficiais e que não necessariamente passam um processo formal de seleção, priorização, categorização e autorização.

O alinhamento dos projetos à estratégia da organização é amplamente discutido em Shenhar (1999), Kathuria et al. (2007), Artto e Dietrich (2004), Jamieson e Morris (2004), Srivannaboon e Milosevic (2004), Dietrich e Lehtonen (2005) e Srivannaboon (2006).

OGC (2008) elaborou um modelo que procura ilustrar de maneira gráfica a interação entre o planejamento estratégico e a gestão do portfólio (Figura 5Erro! Fonte de referência não encontrada.).

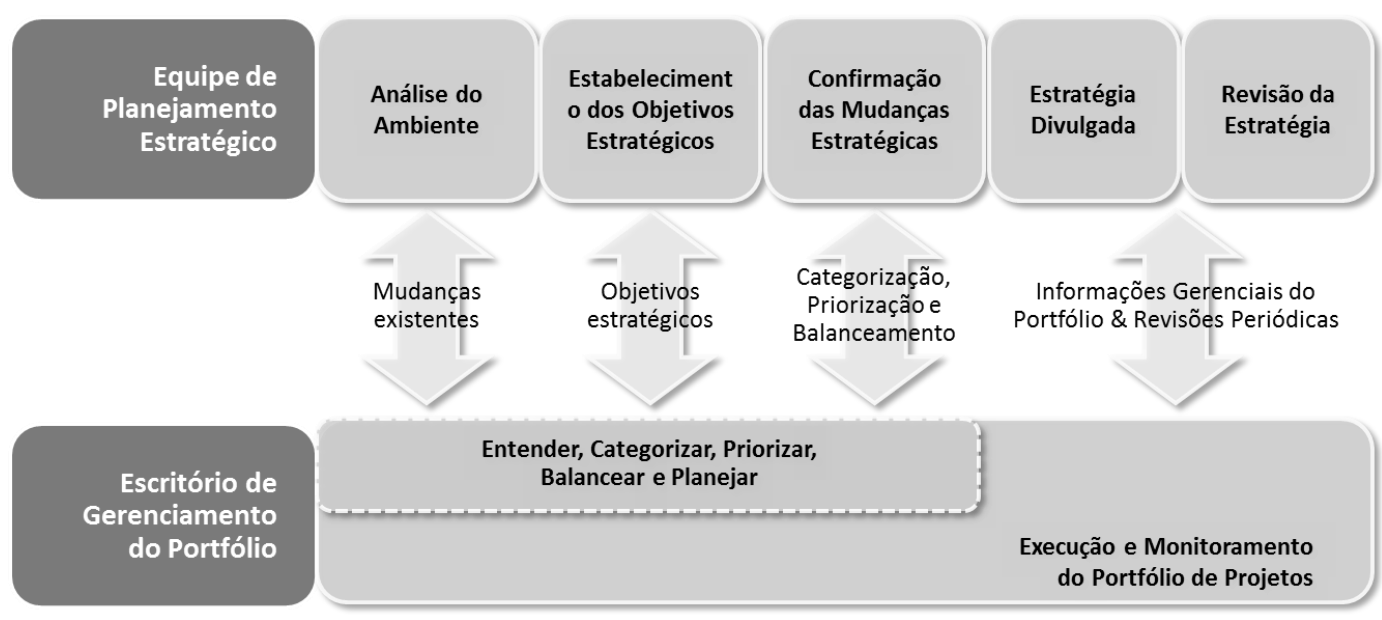

Figura 5. Proposta de processo de planejamento estratégico e alinhamento do portfólio FONTE: OGC, 2008 - traduzido livremente pelo autor.

Diversos autores têm proposto modelos para atender a essa necessidade como Cooper et al. (2001a e b), Miller (2002), Kendall e Rollins (2003), Callahan e Brooks (2004), Martinsuo e Lehtonen (2007).

Os modelos propostos por PMI (2008), IPMA (2006) e OGC (2008) objetivaram prescrever um conjunto de processos, ferramentas e técnicas para identificação, categorização, avaliação, seleção, priorização, balanceamento, autorização, reporte e revisão, bem como, controle da mudança do portfólio de projetos corporativos. Assim, buscou-se consolidar as contribuições dos principais modelos de gestão de portfolio no Quadro 5. 
Quadro 5. Processos de Gerenciamento do Portfólio de Projetos

\begin{tabular}{|c|c|c|c|c|c|c|c|c|c|c|c|}
\hline & rupos c & de Processo e Processos & $\begin{array}{l}\text { Cooper } e t \\
\text { al. }(2001)\end{array}$ & $\begin{array}{l}\text { Miller } \\
(\mathbf{2 0 0 2})\end{array}$ & $\begin{array}{c}\text { Kendal e } \\
\text { Rollins }\end{array}$ & $\begin{array}{c}\text { Callahan e } \\
\text { Brooks }\end{array}$ & $\begin{array}{l}\text { Levine } \\
(2005)\end{array}$ & $\begin{array}{c}\text { Martisuo e } \\
\text { Lehtonen }\end{array}$ & $\underset{(2008 \mathrm{c})}{\text { PMI }}$ & $\begin{array}{l}\text { IPMA } \\
\text { (2006) }\end{array}$ & OGC \\
\hline & & Missão e Visão & & & & & & & $\mathrm{X}$ & & \\
\hline $\begin{array}{r}\text { Ac } \\
\text { Estra }\end{array}$ & m. égica & Planejamento Estratégico & & & & & & & $\mathrm{X}$ & & $\mathrm{X}$ \\
\hline & & $\begin{array}{l}\text { Objetivos } \\
\text { Estratégicos e Indicadores }\end{array}$ & & & & & & & $\mathrm{X}$ & $\mathrm{X}$ & $\mathrm{X}$ \\
\hline & & $\begin{array}{l}\text { Identificação de } \\
\text { componentes }\end{array}$ & & $\mathrm{X}$ & & & & & $\mathrm{X}$ & $\mathrm{X}$ & $\mathrm{X}$ \\
\hline & 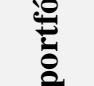 & $\begin{array}{l}\text { Categorização de } \\
\text { componentes }\end{array}$ & & $\mathrm{X}$ & & & & & $\mathrm{X}$ & & $\mathrm{X}$ \\
\hline .8 & 坣 & Avaliação de componentes & $\mathrm{X}$ & $\mathrm{X}$ & $\mathrm{X}$ & $\mathrm{X}$ & $\mathrm{X}$ & $\mathrm{X}$ & $\mathrm{X}$ & $\mathrm{X}$ & \\
\hline$\frac{\pi}{n=0}$ & 率 & Seleção de componentes & $\mathrm{X}$ & $\mathrm{X}$ & $\mathrm{X}$ & $\mathrm{X}$ & $\mathrm{X}$ & $\mathrm{X}$ & $\mathrm{X}$ & $\mathrm{X}$ & \\
\hline 苞 & $A$ & $\begin{array}{l}\text { Priorização de } \\
\text { componentes }\end{array}$ & $\mathrm{X}$ & $\mathrm{X}$ & $\mathrm{X}$ & & $\mathrm{X}$ & $\mathrm{X}$ & $\mathrm{X}$ & $\mathrm{X}$ & $\mathrm{X}$ \\
\hline$\overline{\mathrm{g}}$ & $\stackrel{8}{0}$ & $\begin{array}{l}\text { Identificação dos riscos do } \\
\text { portfólio }\end{array}$ & & & & & & & $\mathrm{X}$ & & \\
\hline & 氖 & $\begin{array}{l}\text { Análise dos riscos do } \\
\text { portfólio }\end{array}$ & & & & & & & $\mathrm{X}$ & & \\
\hline & 离 & $\begin{array}{l}\text { Desenvolvimento do plano } \\
\text { de resposta a riscos }\end{array}$ & & & & & & & $\mathrm{X}$ & & \\
\hline
\end{tabular}




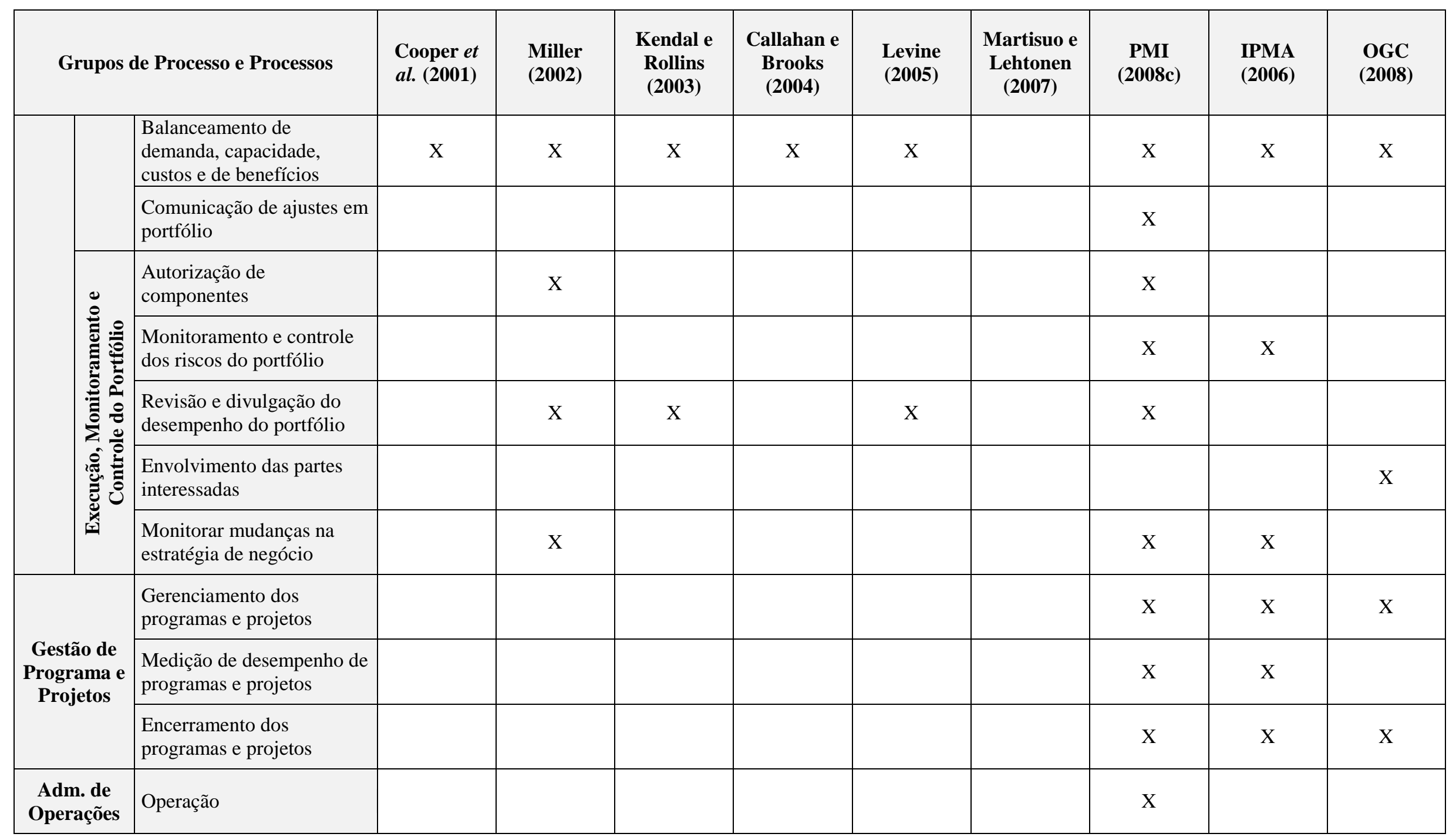

FONTE: SANCHEZ, ROBERT \& PELLERIN, 2008 - adaptado pelo autor 
Embora muitas organizações gerenciem seus portfólios de projetos segundo os preceitos da gestão de portfolio (PPM - Project Portfolio Management), há problemas em relação ao número de projetos atrasados, à concorrência por recursos, ao estresse e à falta de uma visão holística (BLICHFELDT \& ESKEROD; 2008).

Segundo Blichfeldt e Eskerod (2008), a razão-chave pela qual as organizações não realizam bem a gestão de portfolio é que, em geral, essa gestão se concentra somente em uma pequena parte do conjunto de projetos da organização: os projetos que são relevantes o suficiente para terem sido submetidos à avaliação e autorização da alta-administração, ou seja, os projetos oficiais.

No entanto, segundo os autores, há projetos extraoficiais que emergem e, sem serem submetidos à análise e priorização da alta-administração, consomem os recursos que foram aprovados para os projetos constantes no portfólio oficial das empresas.

Muitos projetos de pequena escala são iniciados, executados e finalizados sem anuência ou consciência da alta-administração. Assim, duas soluções parecem razoáveis para esse problema: 1) abranger todos os projetos, sem exceção, na PPM e, 2) alocar mais recursos para um pulmão de recursos flexivelmente-controlados para que os projetos extraoficiais avancem (BLICHFELDT e ESKEROD, 2008).

Desta maneira, ao estudar a gestão do portfólio de projetos seria adequado levar em consideração o conjunto total de projetos das organizações, sejam eles oficiais ou extraoficiais.

Nolan (1979) identificou a necessidade de balancear o orçamento entre projetos controlados e iniciativas mais flexivelmente gerenciadas quando se fale em projetos de TI. O autor ainda aponta para evidências de que projetos mais flexivelmente gerenciados costumam nutrir mais inovações.

Blichfeldt e Eskerod (2008) sugerem ainda que procurar abranger todos os projetos na PPM tem algumas implicações a serem consideradas tais como se: 1) a alta-administração tem capacidade limitada (cognitivamente, bem como em termos de tempo) para aplicar PPM a todos os projetos, 2) pode ser difícil identificar e estimar as atividades nos projetos 
extraoficiais e, ainda mais, realizar um detalhamento da alocação e necessidade de recursos para esses projetos, 3) a carga de trabalho e custo associados a identificar e administrar pequenos projetos pode ser muito alta e ter uma má relação de custo-benefício e, 4) a burocracia pode gerar menor flexibilidade e liberdade para projetos independentes ou mesmo individuais.

Alocar mais recursos para um pulmão de recursos controlado flexivelmente para que os projetos extraoficiais avancem pode trazer consequências como: 1) o trabalho rotineiro pode atrapalhar a execução tanto dos projetos oficiais como dos extraoficiais, 2) quando há prazos curtos em um projeto em específico, parece ser mais salutar focar os recursos neste projeto ao invés de espalhá-los por diversos projetos, 3) essa estratégia pode depender de um alto nível de confiança nos funcionários, 4) a implementação dessa estratégia pode requerer que os gestores definam onde estaria a fronteira entre os projetos oficiais e extraoficiais e, 5) pode ser problemático não submeter os projetos extraoficiais há algum tipo de avaliação e aprovação (BLICHFELDT e ESKEROD, 2008).

Assim, Blichfeldt e Eskerod (2008) e Nolan (1979) corroboram ao apontar a necessidade de balancear os esforços e número de iniciativas oficiais e extraoficiais para haver controle orçamentário dos recursos aplicados nos mesmo.

Hrebiniak (2005) identificou as principais barreiras à implementação e à execução da estratégia. Relacionando essas barreiras à gestão do portfólio de projetos, pode-se identificar diversos processos que potencialmente as minimizam ou mesmo as eliminam (Quadro 6). 


\section{Quadro 6. Processo de Gerenciamento do Portfólio e Barreiras}

\begin{tabular}{|c|c|c|c|}
\hline \multicolumn{3}{|c|}{ Grupos de Processos e Processos adaptado de Sanchez, Robert e Pellerin (2008) } & Barreiras identificadas em Hrebiniak(2005) \\
\hline \multicolumn{2}{|c|}{$\begin{array}{l}\text { Administração } \\
\text { Estratégica }\end{array}$} & $\begin{array}{l}\text { Missão e Visão, Planejamento Estratégico, Objetivos } \\
\text { Estratégicos e Indicadores }\end{array}$ & - Estratégia vaga ou pobre; \\
\hline \multirow{8}{*}{ 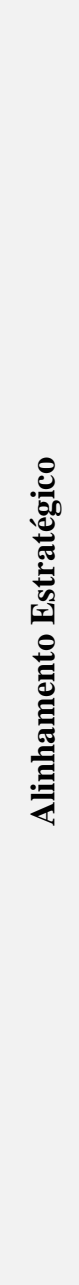 } & \multirow{3}{*}{ 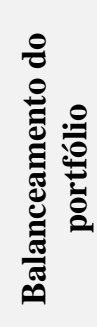 } & $\begin{array}{l}\text { Identificação dos riscos do portfólio, Análise dos riscos do } \\
\text { portfólio e Desenvolvimento do plano de resposta a riscos }\end{array}$ & $\begin{array}{l}\text { - Pouca habilidade em gerir a mudança de maneira efetiva para ultrapassar a } \\
\text { resistência interna à mudança; } \\
\text { - Tentar executar uma estratégia conflitante com a estrutura de poder vigente; }\end{array}$ \\
\hline & & $\begin{array}{l}\text { Balanceamento do portfólio: demanda vs. capacidade, adm. } \\
\text { financeira e de benefícios }\end{array}$ & $\begin{array}{l}\text { - Falta de comunicação das responsabilidades associadas à execução da estratégia } \\
\text { em relação a tomada de decisões ou ações associadas a implementação. }\end{array}$ \\
\hline & & Comunicação de ajustes em portfólio & $\begin{array}{l}\text { - Falta de um entendimento comum do papel da estrutura e desenho organizacional } \\
\text { no processo de implementação. }\end{array}$ \\
\hline & \multirow{5}{*}{ 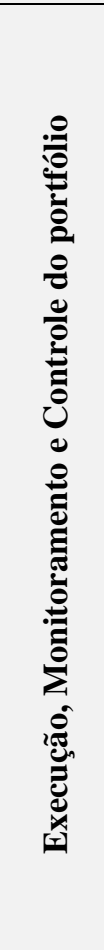 } & Autorização de componentes & $\begin{array}{l}\text { - Falta de um guia ou modelo que pudesse guiar os esforços de implementação e } \\
\text { execução estratégia; } \\
\text { - Falta de um entendimento comum do papel da estrutura e desenho organizacional } \\
\text { no processo de implementação. }\end{array}$ \\
\hline & & Monitoramento e controle dos riscos do portfólio & $\begin{array}{l}\text { - Pouca habilidade em gerir a mudança de maneira efetiva para ultrapassar a } \\
\text { resistência interna à mudança; } \\
\text { - Tentar executar uma estratégia conflitante com a estrutura de poder vigente; }\end{array}$ \\
\hline & & Revisão e divulgação do desempenho do portfólio & $\begin{array}{l}\text { - Compartilhamento pobre ou inadequado de informações entre indivíduos ou } \\
\text { unidades de negócio responsáveis pela execução da estratégia. }\end{array}$ \\
\hline & & Envolvimento das partes interessadas & $\begin{array}{l}\text { - Pouca habilidade em gerir a mudança de maneira efetiva para ultrapassar a } \\
\text { resistência interna à mudança; } \\
\text { - Tentar executar uma estratégia conflitante com a estrutura de poder vigente; } \\
\text { - Falta de comunicação das responsabilidades associadas à execução da estratégia } \\
\text { em relação à tomada de decisões ou ações associadas a implementação; } \\
\text { - Falta de sentimento de propriedade (comprometimento) de empregados chave } \\
\text { com a estratégia ou planos de execução. }\end{array}$ \\
\hline & & Monitorar mudanças na estratégia de negócio & $\begin{array}{l}\text { - Compartilhamento pobre ou inadequado de informações entre indivíduos ou } \\
\text { unidades de negócio responsáveis pela execução da estratégia; } \\
\text { - Falta de comunicação das responsabilidades associadas à execução da estratégia } \\
\text { em relação a tomada de decisões ou ações associadas a implementação. }\end{array}$ \\
\hline
\end{tabular}




\subsection{Gestão de Tecnologia da Informação}

\subsubsection{Projetos de Tecnologia da Informação}

Segundo Archibald (2004), os projetos podem ser categorizados para o aperfeiçoamento do gerenciamento de cada categoria este autor criou uma comunidade internacional (Quadro 7).

$\mathrm{O}$ autor ainda sugere que as características particulares de cada categoria sejam estudadas de maneira independente. Assim, cada categoria de projeto poderia ser investigada de maneira mais apropriada considerando suas nuances e especificidades.

Quadro 7. Categoria de Projetos

\begin{tabular}{|c|c|}
\hline Categorias e subcategorias & Exemplos \\
\hline $\begin{array}{l}\text { 1. Projetos de Defesa, Segurança e Aeroespacial } \\
\text { 1.1 Sistemas de defesa } \\
\text { 1.2 Espacial } \\
\text { 1.3 Operações Militares }\end{array}$ & $\begin{array}{l}\text { - Novos armamentos; melhoria em sistemas maiores. } \\
\text { - Desenvolvimento/lançamento de satélite; módulo } \\
\text { espacial. } \\
\text { - Força-tarefa ofensiva } \\
\text { - Melhoria ou ampliação da Segurança Pública }\end{array}$ \\
\hline $\begin{array}{l}\text { 2. Projetos de Mudanças Organizacionais e em } \\
\text { Negócios } \\
\text { 2.1 Aquisição/Fusão } \\
\text { 2.2 Melhoria de processos de gestão } \\
\text { 2.3 Empreendimento de novos negócios } \\
\text { 2.4 Reestruturação organizacional } \\
\text { 2.5 Eventos Judiciais } \\
\text { 2.6 Mudanças organizacionais derivadas de Qualidade } \\
\text { Total }\end{array}$ & $\begin{array}{l}\text { - Aquisição e integração de companhias concorrentes. } \\
\text { - Grandes melhorias em gerenciamento de projetos. } \\
\text { - Formação e lançamento de uma nova companhia. } \\
\text { - Consolidação de divisões e "downsizing" de } \\
\text { companhias. } \\
\text { - Grande caso de litígio. } \\
\text { - Melhoria de indicadores financeiros e operacionais }\end{array}$ \\
\hline $\begin{array}{l}\text { 3. Projetos de Sistemas de Comunicação (dados, voz } \\
\text { e imagem) } \\
\text { 3.1 Sistemas de comunicação em rede } \\
\text { 3.2 Sistemas de comunicação "Switching" }\end{array}$ & $\begin{array}{l}\text { - Rede de comunicação via micro-ondas } \\
\text { - Sistema de comunicação sem fio de terceira geração }\end{array}$ \\
\hline $\begin{array}{l}\text { 4. Projetos de Eventos } \\
\text { 4.1 Eventos internacionais } \\
\text { 4.2 Eventos Nacionais }\end{array}$ & $\begin{array}{l}\text { - Olimpíadas de } 2004 \\
\text { - Copa do Mundo de } 2006 \\
\text { - Campeonato Norte-Americano de Boliche - } 2005 \\
\text { - Convenções Eleitorais de } 2004\end{array}$ \\
\hline $\begin{array}{l}\text { 5a. Projetos de Design de Engenharia, Arquitetura, } \\
\text { etc. }\end{array}$ & $\begin{array}{l}\text { - Projetos efetuados por empresas de engenharia, } \\
\text { arquitetura, decoração e afins. }\end{array}$ \\
\hline
\end{tabular}




\begin{tabular}{|c|c|}
\hline $\begin{array}{l}\text { 5b. Projetos de Empreendimentos, Investimentos, } \\
\text { Construções e Obras } \\
\text { 5.1 Desmontagem } \\
\text { 5.2 Demolição } \\
\text { 5.3 Manutenção e modificação } \\
\text { 5.4 Projeto/contratação/construção (Civil, Energia, } \\
\text { Meio Ambiente, Edificações, Industrial Comercial, } \\
\text { Residencial, Naval) }\end{array}$ & $\begin{array}{l}\text { - Desativação de uma usina nuclear. } \\
\text { - Demolição de um edifício. } \\
\text { - Execução do processo de manutenção em uma fábrica. } \\
\text { - Construção de uma planta para novos } \\
\text { produtos/mercados. } \\
\text { - Barragens; viadutos. } \\
\text { - Nova termelétrica a gás; oleoduto. } \\
\text { - Limpeza de dejetos químicos. } \\
\text { - Grande prédio de escritórios. } \\
\text { - Nova fábrica. } \\
\text { - Novo Shopping; prédio comercial. } \\
\text { - Expansão de uma residência. } \\
\text { - Petroleiro, cargueiro ou navio de passageiros. }\end{array}$ \\
\hline 6. Projetos de Sistemas de Informação (Softwares) & $\begin{array}{l}\text { - Novo sistema de gerenciamento de projetos } \\
\text { (Desenvolvimento de equipamentos de informática - } \\
\text { hardware - são considerados como sendo projetos de } \\
\text { desenvolvimento de produtos). }\end{array}$ \\
\hline $\begin{array}{l}\text { 7. Projetos de Desenvolvimento Regional ou } \\
\text { Internacional } \\
\text { 7.1 Desenvolvimento agropecuário/rural } \\
\text { 7.2 Educação } \\
\text { 7.3 Saúde } \\
\text { 7.4 Nutrição } \\
\text { 7.5 Populacional } \\
\text { 7.6 Empreendimentos em pequena escala } \\
\text { 7.7 Infraestrutura: energia (petróleo, gás, carvão, } \\
\text { geração e distribuição de energia, industrial, } \\
\text { telecomunicações, transportes, urbanização, } \\
\text { fornecimento e tratamento de água, irrigação) }\end{array}$ & $\begin{array}{l}\text { - Projetos sociais e de desenvolvimento intensivo } \\
\text { - Em países em desenvolvimento custeados pelo Banco } \\
\text { Mundial, bancos de desenvolvimento regional, US-AID, } \\
\text { ONU, outras organizações de países, agências } \\
\text { governamentais e: } \\
\text { - Projetos intensivos em capital/construção civil } \\
\text { - De alguma forma diferente do item } 5 \text {. } \\
\text { - Projetos de empreendimentos, considerando-se como } \\
\text { características do projeto: a criação de uma estrutura } \\
\text { organizacional para operar e manter o empreendimento e } \\
\text { ações de agentes financiadores definindo o ciclo de vida } \\
\text { do projeto e requisitos de prestação de contas. }\end{array}$ \\
\hline $\begin{array}{l}\text { 8. Projetos de Entretenimento e Mídia } \\
\text { 8.1 Filme } \\
\text { 8.2 Programa de TV } \\
\text { 8.3 Peça teatral ou uma apresentação musical }\end{array}$ & $\begin{array}{l}\text { - Novo filme (película ou digital). } \\
\text { - Novo episódio de um programa. } \\
\text { - Estreia de uma ópera. }\end{array}$ \\
\hline $\begin{array}{l}\text { 9. Projetos de Desenvolvimento de Produtos ou } \\
\text { Serviços } \\
\text { 9.1 Equipamentos de informática } \\
\text { 9.2 Produtos/processos industriais } \\
\text { 9.3 Produtos/processos para o consumo } \\
\text { 9.4 Produtos/processos farmacêuticos } \\
\text { 9.5 Serviços (financeiros, outros) }\end{array}$ & $\begin{array}{l}\text { - Novo computador de mesa. } \\
\text { - Nova máquina de movimentação de terra. } \\
\text { - Novo carro, novo produto alimentício. } \\
\text { - Novo medicamento de redução do colesterol. } \\
\text { - Novo seguro de vida/plano de previdência privada. } \\
\text { - Projetos de Marketing e Desenvolvimento de Produtos } \\
\text { e Serviços de Telecomunicações }\end{array}$ \\
\hline $\begin{array}{l}\text { 10. Projetos de Pesquisa e Desenvolvimento } \\
\text { 10.1 Meio ambiente } \\
\text { 10.2 Industrial } \\
\text { 10.3 Desenvolvimento econômico } \\
\text { 10.4 Medicina } \\
\text { 10.5 Científico }\end{array}$ & $\begin{array}{l}\text { - Medição das mudanças na camada de ozônio. } \\
\text { - Como reduzir emissão de poluentes. } \\
\text { - Teste de um novo tratamento para o câncer de mama. }\end{array}$ \\
\hline
\end{tabular}

FONTE: ARCHIBALD, 2004.

Rivard e Dupré (2009) apontam importantes tendências na pesquisa em gestão de projetos de tecnologia da informação sendo a primeira delas enriquecer as melhores práticas, em especial 
o PMBOK®, com processos, ferramentas e técnicas de gestão de stakeholders como usuários de sistemas.

Outra tendência importante apontada por Rivard e Dupré (2009) e por Luftman e Kempaiah (2007) está associada a crescente tendência de terceirização (outsourcing) no ambiente de projetos, sendo assim, seria louvável ampliar a discussão no meio acadêmico e profissional em relação a este fenômeno e seu impacto na gestão de projetos como podemos encontrar.

Jeffery e Leliveld (2004) estimaram que 68\% dos projetos corporativos de TI não alcançam os objetivos de negócio originais e excedem o prazo e orçamento previstos. Enquanto Standish (2009) estimou que 44\% dos projetos de TI entre 2008 e 2009 nos Estados Unidos estão atrasados ou foram entregues com atraso, excederam orçamento ou seu resultado não atendeu às especificações. Estimou, ainda, que $24 \%$ dos projetos foram cancelados antes de terminarem ou seus produtos finais não foram realmente utilizados.

McFarlan (1981) indica estatísticas alarmantes em relação ao sucesso dos projetos de TI e apontam como uma das possíveis origens do insucesso como a incapacidade de avaliar adequadamente o risco individual dos projetos ou mesmo de consolidar essa análise no nível do portfolio de projeto.

Já Flyvbjerg e Budzier (2011) investigaram 1.471 projetos de TI comparando seus orçamentos e retornos estimados com os custos incorridos e resultados alcançados. Este estudo encontrou um estouro orçamentário médio de $27 \%$ mas ao plotar a distribuição da variação de custos os pesquisadores encontram uma cauda longa que aponta, de maneira alarmante, que um grande número de projeto apresenta um desvio bastante significativo.

Estes autores ainda identificaram que 1 a cada 6 projetos da amostra estouram o orçamento em $200 \%$ na média e excedem os prazos em aproximadamente $70 \%$. Estes projetos foram denominados de cisnes negros por estarem na cauda longa da distribuição.

Embora os estudos de Flyvbjerg e Budzier (2011) e McFarlan (1981) terem aproximadamente 30 anos de distância um do outro ambos sugerem a mesma falha recorrente em projetos de TI: a dificuldade de avaliar adequadamente os riscos de cada projeto e de balanceá-los no nível do portfolio. 
Dessa forma, parece existir certo espaço para o desenvolvimento de estudos que busquem auxiliar de alguma forma as organizações a melhorarem a taxa de sucesso e o retorno sobre portfólio de projetos de TI.

Primordialmente Nolan e Gibson (1974) apontaram a existência de quatro estágios de crescimento processamento de dados corporativo.

Um pouco mais tarde, Nolan (1979) identificou seis possíveis estágios no crescimento processamento de dados corporativo que podem ser revisitados hoje como estágios de maturidade em tecnologia da informação.

O autor ainda sugere que a transição entre estágios não envolve somente a restruturação organizacional da área de tecnologia como também a aplicação de novas práticas de gestão. Assim, poder-se-ia complementar a análise de maturidade de gestão de projetos de TI considerando o próprio estágio de maturidade em gestão de tecnologia da informação.

McFarlan (1981) também identificou como uma possível falha na gestão de projetos de TI a incapacidade de reconhecer que projetos diferentes exigem abordagens distintas.

Este autor propõe que se apliquem as ferramentas de gestão de projetos de maneira geral por métodos quatro distintos: integração externa, integração interna, planejamento formal, controle formal.

Ele ainda complementa identificando oito tipos de projetos de TI considerando o nível de estrutura, tecnologia e tamanho, o que já aponta para algumas das dimensões posteriormente identificadas em Shenhar e Dvir (2010).

Shenhar e Dvir (2010) enfatizam a necessidade de buscar aplicar processos e técnicas de gestão distintas em projetos que tenham diferentes composições de complexidade, ritmo, inovação e tecnologia. Assim, as quatro dimensões do diamante, assim como os autores as intitulam, provocam uma necessidade de adaptação às práticas de gestão de projetos. 
Assim, poder-se-ia dizer que, como cada projeto é único, o conjunto de processos e práticas para seu sucesso pode ser variável, seja por causa das dimensões de Shenhar e Dvir (2010), seja por causa dos quatros métodos gerais apontados por McFarlan (1981) em projetos de TI.

\subsubsection{Alinhamento Estratégico da Tecnologia da Informação}

Luftman e Ben-Zvi (2011) afirmam que o alinhamento estratégico da tecnologia da informação está entre as maiores preocupações dos executivos de TI segundo um levantamento longitudinal realizado de 2003 até 2011. Neste levantamento o alinhamento estratégico foi apontado como a primeira preocupação em 2003 a 2006, em 2008 e em 2011, no entanto, foi apontando como a segunda maior preocupação somente em 2007 e 2009 e, como a terceira maior preocupação em 2010.

O alinhamento estratégico tem sido conceituado como a forma pela qual a estratégia corporativa, organização, estrutura e processos de negócio se relacionam, integram e interagem com a estratégia, organização, estrutura e processos de TI com o objetivo de mutuamente se auxiliarem e apoiarem no atingimento de objetivos comuns (SAUER \& YETTON, 1997; REICH \& BENBASAT, 1996; HENDERSON \& VENKATRAMAN, 1993; MCKEEN \& SMITH, 2003; LUFTMAN \& BRIER, 1999; CAMPBELL, KAY \& AVISON, 2005).

Assim, o alinhamento estratégico da tecnologia da informação deverá permear as decisões de investimento parar gerar ativos específicos. Estes comprometimentos estratégicos muitas vezes são de difícil reversão e geram impacto de longo prazo, restringindo opções e criando uma inflexibilidade em seus processos e ações.

As escolhas intensivas em comprometimento estratégico demandam uma análise minuciosa buscando as possíveis fontes de vantagem competitiva, da sustentabilidade da vantagem e da flexibilidade que a empresa terá depois que realizar o investimento estratégico (BESANKO, DRANOVE, SHANLEY et al., 2006). 
Neste contexto, o papel da tecnologia da informação tem sido vastamente discutido na literatura acadêmica e no mercado. McFarlan (1984) inicialmente propôs a Grade Estratégica, do inglês Strategic Grid, onde se poderia auxiliar executivos e gestores a avaliarem os quatro possíveis papeis da TI em suas organizações como 1) suporte, 2) fábrica, 3) estratégico e, 4) turnaround. Assim, os autores procuram dar subsidio para as discussões sobre investimentos em tecnologia sobre um prisma mais holístico do que simplesmente analisar o retorno sobre o investimento.

Ao constatarem uma tendência de evolução do papel da tecnologia de informação de puramente suporte administrativo para estratégico, Henderson e Venkatraman (1993) buscaram conceber um modelo teórico denominado Modelo de Alinhamento Estratégico.que estabelece quatro domínios fundamentais da escolha estratégica: 1) estratégia de negócio, 2) estratégia de tecnologia da informação, 3) infraestrutura organizacional e processos e, 4) infraestrutura de tecnologia de informação e processos.

Os autores justificam a aplicação deste modelo na administração estratégica, mais especificamente, no alinhamento estratégico de TI. Este alinhamento seria dado ao se usar o modelo para avaliar as decisões de TI sob a perspectiva de aderência estratégica e a integração funcional, bem como, as relações de automação entre negócio e TI como se buscou ilustrar na Figura 6. 


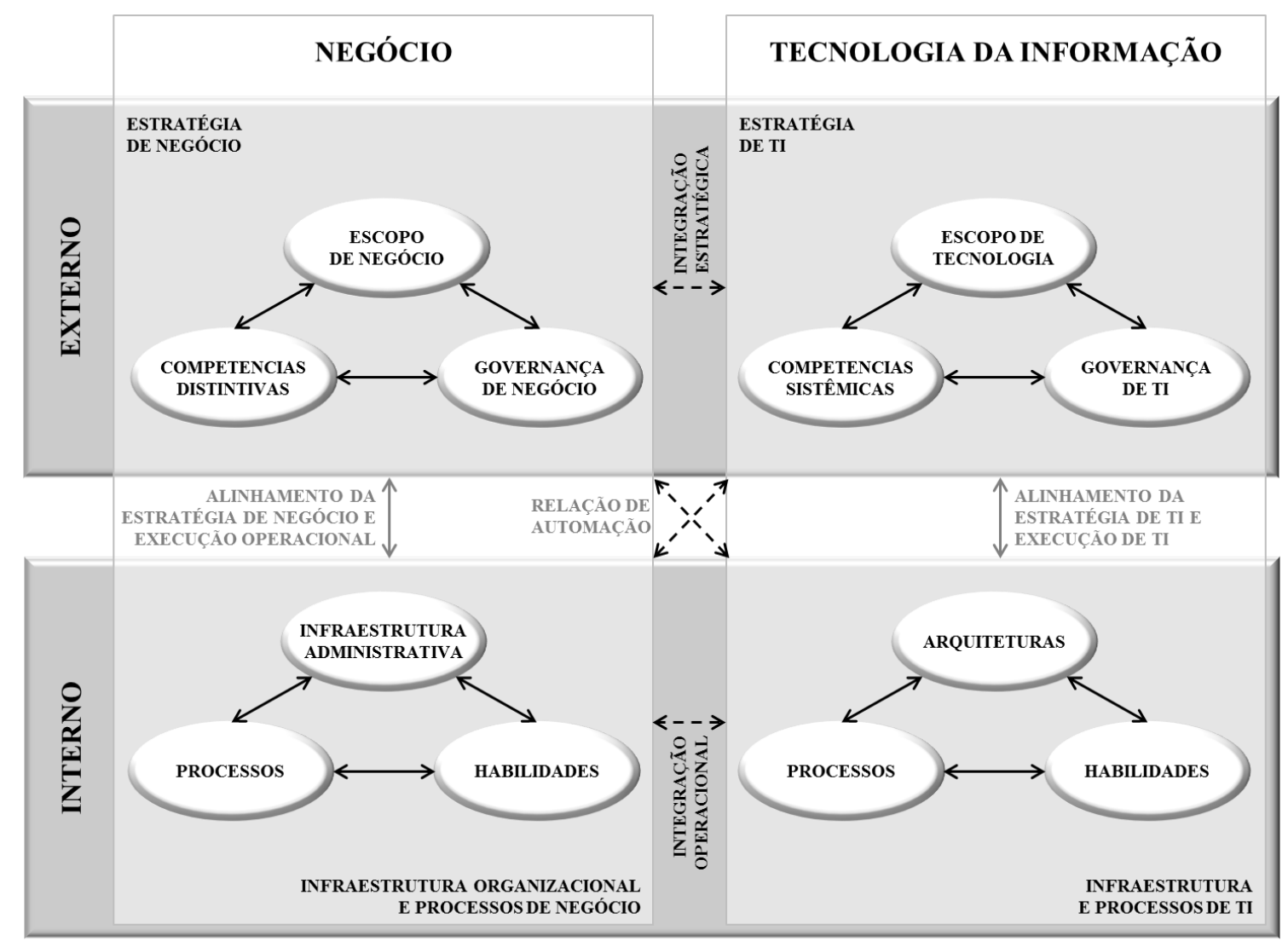

Figura 6. Modelo de Alinhamento Estratégico

FONTE: HENDERSON \& VENKATRAMAN, 1993 - traduzido e adaptado pelo autor,

Henderson e Venkatraman (1993) e Luftman et al. (1993) identificaram como sendo quatro as principais perspectivas de alinhamento estratégico: 1) execuçãoda estratégia, 2) transformação tecnológica, 3) potencial competitivo e, 4) nível de serviço.

Chan e Reich (2007) buscaram consolidar as principais linhas teóricas e discussões das últimas três décadas sobre o alinhamento entre estratégico de TI apontando que os principais contra-argumentos em relação a pesquisa e literatura de alinhamento estratégico são 1) a pesquisa sobre alinhamento é mecanicista e falha em capturar todas as nuances da vida real, 2) o alinhamento não é possível se a estratégia é desconhecida, vaga, acidental ou emergente, 3) o alinhamento não é desejável como finalidade visto que o negócio deve mudar constantemente, 4) a tecnologia da informação deveria constantemente desafiar o negócio e não simplesmente segui-lo, 5) a lacuna de conhecimento de estratégia e negócios dos executivos e gestores de TI, bem como, dos executivos e gestores de áreas de negócio em relação a TI e, finalmente, 6) a incredulidade ou ignorância da importância do alinhamento na prática (BAETS, 1992; BAETS, 1996; CAMPBELL, KAY \& AVISON, 2005; CHAN \& HUFF, 1993; CIBORRA, 1997; CIBORRA. 1996; HENDERSON \& VENKATRAMAN, 
1993; KAARST-BROWN \& ROBEY, 1999; MINTZBERG, 1994; ORLIKOWSKI, 1996; REICH \& BENBASAT, 2000; SAUER \& YETTON, 1997; VAN DER ZEE \& DE LONG, 1999; VITALE, IVES \& BEATH, 1986).

No entanto, alguns estudos empíricos inferem que o alinhamento estratégico leva a obtenção de melhores resultados sobre os investimentos em TI (CHAN et al., 1997; CHAN et al., 2006; DE LEEDE et al., 2002; IRANI, 2002; KEARNS \& LEDERER, 2003; LAURINDO \& MORAES, 2006).

Banker et al. (2011), por exemplo, ao investigar a estrutura organizacional de TI no que tange a subordinação do CIO (Chief-Information-Officer) ao CFO (Chief-Financial-Officer) ou CEO (Chief-Executive-Officer) encontrou evidências substanciais de que a estrutura de subordinação do CIO estaria correlacionada com o posicionamento estratégico da organização

Assim, organizações que buscam diferenciação tendem a apresentar o CIO reportando diretamente ao CEO enquanto organizações que buscam serem líderes em custo/volume tendem a apresentar o CIO reportando ao CFO. Enquanto organizações que não seguem esse padrão apresentaram resultados inferiores das que o seguem. (BANKER et al., 2011)

\subsection{Maturidade e Capacidade de Processos}

Maturidade, do latim maturitate, o mesmo que madureza, idade madura ou perfeição. Grau em que as atitudes, a socialização e a estabilidade afetiva de um indivíduo refletem, como característica normal do homem adulto, um estado de adaptação ou ajustamento ao seu próprio meio (MICHAELIS, 1998).

Michaelis (1998) afirma que capacidade, derivado do latim capacitate, seria o mesmo que o poder, aptidão ou possibilidade de fazer ou produzir qualquer coisa. Enquanto para a psicologia seria a potencialidade individual para o exercício de qualquer função e que encontra limite na constituição psicofisiológica.

Dessa forma, por mero silogismo, poderíamos induzir que quanto maior a maturidade, maior seria a capacidade usando como base o sentido etimológico das palavras. Assim Lee e 
Anderson (2006) propõe uma correlação positiva entre a maturidade em gestão de projetos de TI e a capacidade de gestão de projetos de TI, sendo que deveríamos levar em consideração também alguns fatores adicionais exógenos e endógenos.

Enquanto, para administração da produção, o conceito de maturidade e capacidade remetem ao controle estatístico do processo (SPC - Statistical Process Control) onde a aplicação de suas técnicas levava a dois resultados básicos: 1) redução da variabilidade inerente ao processo e, 2) melhoria na eficiência e eficácia do processo (DEMING, 1986; COOKEDAVIES \& ARZYMANOW, 2003, SALVIANO \& FIGUEIREDO, 2008).

O surgimento dos modelos de maturidade de gestão de projetos, por sua vez, é comumente relacionado aos modelos de maturidade de processo de TI, em especial, o CMM (Capability Maturity Model) modelo este desenvolvido pelo SEI (Software Engineering Institute) da Univesidade Carnagie-Mellon entre 1986 e 1993 (GRANT \& PENNYPACKER, 2006; COOKE-DAVIES \& ARZYMANOW, 2003; RODRIGUES, RABECHINI JR. \& CSILLAG, 2006; JUGDEV \& THOMAS, 2002; IBBS \& KWAK, 2000; KERZNER, 2001)

Alguns autores como Smith et al. (1985), Scott (1971), Chandler (1962) e Haire (1959) buscaram pontuar o conceito de maturidade do processo ou, em inglês, process capability. Nestes trabalhos encontramos uma proposição de que as organização amadurecem por estágios seguindo um certo padrão uniforme. Embora essa uniformidade possa ser questionada, os modelos de avaliação de maturidade ou estágios tornaram-se comuns em padronização de processo por meio da ISO 9000, 9001 e demais da International Organization for Standarization, engenharia de software com o CMM (Capability Maturity Model) e CMMI (Capability Maturity Model Integration) da SEI (Software Engineering Institute) e, também, em gestão de projetos.

Segundo Von Wangenheim et al. (2010) os modelos mais são utilizados nas pesquisas empíricas sobre de maturidade em TI seria o CMM que é utilizando em 58\% das vezes, seguido pelo ISO/IEC 15504 que é base para 36\% delas. Já os demais modelos seriam o CMMI, o ISO 9000, e o ISO/IEC 12207 que aparecem, respectivamente em 21\%, 17\% e 15\% das pesquisas. 
Harter, Krishnan e Slaughter (2000) investigaram os efeitos da maturidade sobre a qualidade, tempo de ciclo e esforço em projetos de desenvolvimento de software. Estes pesquisadores encontraram evidências de que aumentar o nível de maturidade dos processos leva a uma maior qualidade, no entanto, aumenta o esforço. Enquanto aumentar a qualidade leva a redução do tempo de ciclo e esforço.

Neste contexto, inicia-se a discussão da maturidade de gestão de projetos tanto no meio profissional quanto no meio acadêmico e, em 1998, o PMI (Project Management Institute) com o objetivo de estabelecer um padrão para os modelos de maturidade em gestão de projetos desenvolveu o OPM3 (Organizational Project Management Maturity Model) (GRANT \& PENNYPACKER, 2006).

No entanto, a maturidade de gestão de projetos transcendeu a etimologia da palavra visto que nos modelos propostos ela é analisada no âmbito dos indivíduos em relação a suas competências, da equipe e stakeholders no que se refere as suas relações, da organização em relação aos seus processos, sistemas, cultura e estrutura e, finalmente, no âmbito do contexto ou ambiente competitivo como ilustrado na Figura 7 (FRAME; 1999, RABECHINI JR., 2003; RODRIGUES, RABECHINI JR. \& CSILLAG, 2006)

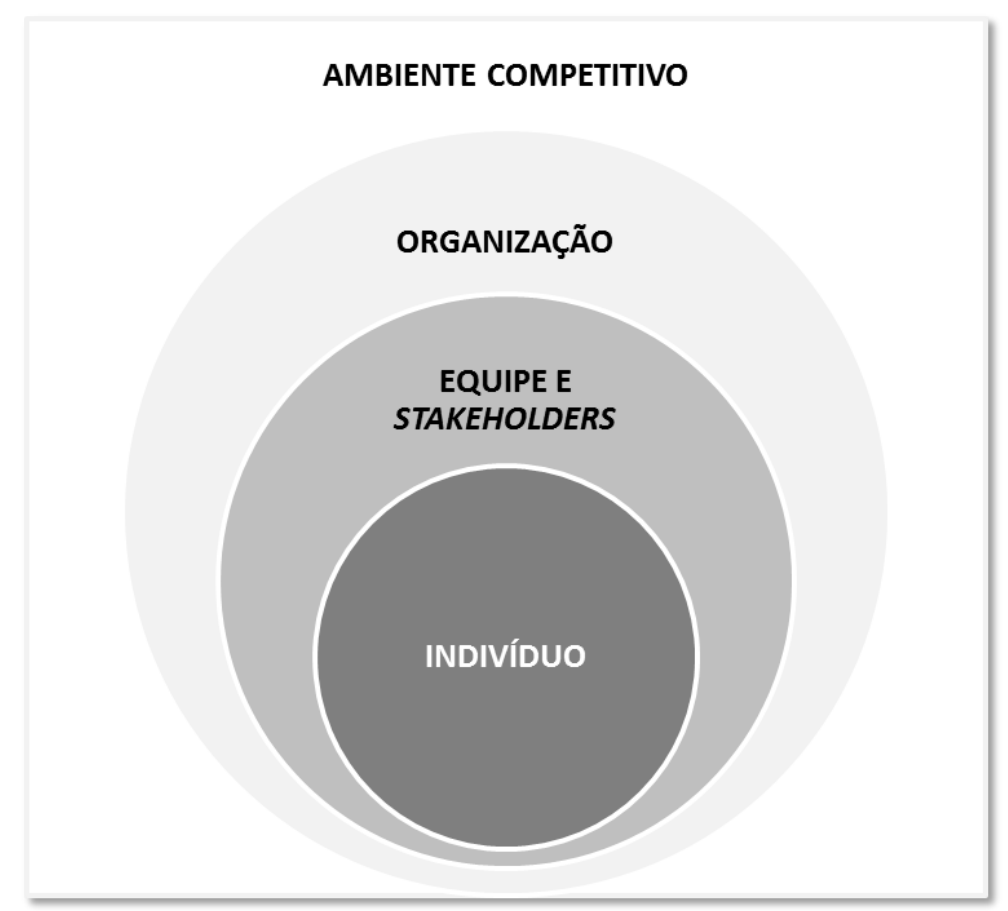

Figura 7. Domínios da Maturidade de Gestão de Projetos 
Embora os modelos de maturidade de gestão de projetos sejam criticados em Cabanis (1998), Disnmore (1998) e Kujala e Artto (2000) por razões diversas, alguns trabalhos empíricos constaram evidências de que maior maturidade em gestão de projetos poderia provocar melhor desempenho organizacional (BERSSANETI et al., 2008; BIRNBERG, 2001; COOKE-DAVIES, 2002; DORLING, 1993; IBBS \& KWAK, 2000; MORAES \& KRUGLIANSKAS, 2010)

\subsubsection{Valor Estratégico dos Modelos da Maturidade}

Embora a aplicação de um modelo de maturidade ou outro não gera por si só vantagem competitiva e, em alguns casos, pode-se até mesmo entender que o uso de padrões levam a convergência competitiva visto que as práticas de negócio passam a ser bastante semelhantes de uma organização para a outra no longo-prazo (BARNEY, 1986; PORTER, 1996).

No entanto, segundo Collins (2001, 2009 e 2011) o que cria vantagem competitiva sustentável ao longo do tempo não é certa prática ou modelo que a organização escolhe utilizar e sim como ela faz uso e por qual motivo ela a aplica e, principalmente, sob quais circunstâncias tal prática não será mais válida.

Moore (2002 e 2005) analisa o desafio de buscar a inovação contínua do negócio em torno core de uma organização, os processos do negócio que diferenciam negócios aos olhos de seus clientes, enquanto todo o restante é somente seu contexto. A finalidade do core de uma empresa é direcionar a inovação do negócio e buscar diferenciação em relação ao competidor para estimular o crescimento.

Segundo o autor, o objetivo preliminar do contexto é ser operado tão eficientemente quanto possível. Assim o core somente permanece como core enquanto ele ainda gera vantagem competitiva. Uma vez copiado, o core transforma-se contexto e já não uma inovação e neste ponto, a organização deve o reformular o contexto buscando melhorar a eficiência e a produtividade.

Entende-se, assim, que somente é commodity o processo de negócio ou aplicativo que não trás vantagem competitiva, que é padronizado para todas as empresas da mesma indústria e que não é origem de diferenciação. Assim sendo, temos que a TI deve posicionar-se como um 
papel chave na busca de inovação e vantagem competitiva, gerenciando a camada commoditizada com foco em disponibilidade somente a não ser que a mesma possa ser alvo de reformulação e que possa voltar a trazer vantagem competitiva (BARNEY, 1986; JUGDEV \& THOMAS, 2002; MOORE, 2005; PRAHALAD \& HAMEL, 1990).

Assim, pode-se afirmar que os modelos de maturidade auxiliam na construção de ativos estratégicos ou competências chaves que podem levar a criação, manutenção e renovação de vantagem competitiva se utilizados de maneira deliberada e como um meio, não como um fim.

\subsubsection{Modelos de Maturidade de Gestão de Projetos}

Essa análise dos modelos teóricos de avaliação de maturidade dos processos de gestão de projetos não tem por objetivo exaurir o tema. Seu enfoque central foi tentar proporcionar uma visão geral dos mais usuais ou conhecidos modelos no mundo acadêmico e corporativo no Brasil e, para tanto, demos uma ênfase maior aos três modelos que mais interessaram ao nosso estudo.

Segundo Silveira (2008), os modelos mais conhecidos de avaliação de maturidade em gerenciamento de projetos são:

- Project Management Maturity Model (PMMM) da PM Solutions;

- KPMMM - Kerzner Project Management Maturity Model;

- ESI International's Project Framework (ESI);

- PM3 - Project Management Maturity Model (Berkeley);

- Project Management Process Maturity (PM)2;

- OGC Project Management Process Maturity;

- Integrated Management Systems Incorporated (IMSI);

- OGC Portfolio Management Maturity Model (P3M3);

- OPM3® - Organizational Project Management Maturity Model (PMI®).

Além desses modelos internacionais de maturidade em gestão de projetos, há duas propostas de modelos nacionais. O modelo Maximiano e Rabechini (2002) e Modelo de Maturidade em Gerenciamento de Projetos (MMGP) de Prado (2008) uma vez que o escopo de nosso 
trabalho é a avaliação de maturidade da gestão de projetos em organizações no Brasil.

Dessa forma, esse estudo não se propõe a fazer uma revisão exaustiva dos modelos e suas diversas abordagens, pelo contrário, buscou-se referenciar os principais modelos considerando sua contribuição profissional e acadêmica dando um panorama geral do progressivo avanço das propostas iniciais aos modelos mais discutidos e aplicados na atualidade.

Assim, enfocou-se em explorar as características dos quatro modelos a seguir e, mais profundamente, do modelo selecionado como base para o desenvolvimento do trabalho de campo, o OPM3.

\subsubsection{Estudos Empíricos de Maturidade de Gestão de Projetos}

Embora durante a pesquisa bibliográfica tenha-se identificado diversos artigos acadêmicos que descrevem, comparam e até mesmo propõem modelos de medição de maturidade, poucos são os trabalhos empíricos disponíveis nas bases de dados como Academic Search Premier (EBSCO), Web of Science (ISI), ABI/INFORM (ProQuest) ou mesmo nas revistas acadêmicas Project Management Journal (PMI) e do International Project Management Journal (IPMA/Elsevier) que se propõem a realizar análise cruzada entre setores. Ainda durante o levantamento de estudos anteriores, não há nessas bases e revistas nenhum trabalho com a proposta de realizar uma análise comparativa entre setores para projetos de sistemas de informações ou mesmo comparando a maturidade na gestão de projetos com o tamanho da empresa ou a origem.

Um dos primeiros estudos comparativos foi desenvolvido por Levene, Bentley e Jarvis (1995), apontando níveis de maturidade similares em 13 empresas que utilizavam gestão de projetos em tecnologia de informação, nos setores de telecomunicação, bancário e prestação de serviços essenciais.

Um grande estudo longitudinal (MULLALY, 2006), com mais de 2500 participantes de 550 empresas do Canadá e Estados Unidos, ao longo de 6 anos (1998 a 2003), apontou que grande parte das empresas encontravam-se com baixos níveis de maturidade, e que, ao longo do tempo, o número de empresas com níveis cada vez mais baixos era crescente. Os maiores 
níveis de maturidade foram encontrados em empresas de telecomunicação, também apontando um forte declínio na maturidade ao longo do tempo, devido, principalmente, às mudanças regulamentares ocorridas no setor, naqueles países.

Um estudo envolvendo 38 empresas (IBBS \& KWAK, 2000), objetivando determinar os impactos financeiros e organizacionais da gestão de projetos acabaram também por apontar uma maior maturidade na gestão de projetos em empresas de engenharia e manufatura de altatecnologia, se comparadas a empresas de telecomunicações e tecnologia de informação.

Uma pesquisa realizada no Reino Unido (BYDE, 2008) envolvendo 238 empresas, apontou um maior nível de performance na gestão de projetos no setor de construção civil, uma maior performance em projetos relacionados à construção civil e maior maturidade na gestão de projetos envolvendo construção civil, se comparados a outras empresas que utilizavam gestão de projetos (tecnologia de informação, projetos estratégicos e projetos de mudança organizacional).

Zwikael e Globerson (2006) chegaram a resultados semelhantes, apontando que o planejamento de projetos, nos setores de construção e de engenharia, possui uma maior qualidade, se comparado ao planejamento de projetos do setor de tecnologia (software e telecomunicação), serviços e manufatura.

Cooke-Davies e Arzymanow (2003) realizaram um estudo qualitativo, apontando que empresas petroquímicas possuíam uma maior maturidade na gestão de projetos, se comparadas ao setor de defesa e farmacêutico. Tal resultado foi apontado como decorrente da atuação como empresa de engenharia, pressionada por redução de custos e resultados financeiros decorrentes da descoberta de poços de petróleo.

Silveira (2008), após realizar um estudo efetuado com 473 pessoas diretamente envolvidas com gestão de projetos, apontou um maior nível de maturidade em empresas de controle estrangeiro, se comparado a empresas de controle nacional, empresas públicas ou entidades do terceiro setor. Foi verificado também que empresas de maior porte tendem a apresentar, uma maior maturidade na gestão de projetos, e que, quanto maior for a intensidade de dependência tecnológica, maior a maturidade na gestão de projetos. 
Um estudo quantitativo, realizado na Austrália, Estados Unidos e Reino Unido, envolvendo pessoas que trabalhavam diretamente com projetos, identificou que não há relação estatística significativa entre a adoção de padrões (metodologias) de gestão de projetos e a respectiva performance (CRAWFORD, 2005).

Um trabalho envolvendo uma pesquisa com 123 gerentes seniores (PANNYPACKER; GRANT, 2003) apontou que não houve diferença estatística significativa, entre medições de maturidade em empresas de setores diferentes, bem como entre empresas de tamanhos diferentes.

O Quadro 8 foi elaborado com o objetivo de consolidar de forma não-exaustiva os trabalhos empíricos que procuraram estudar o problema da maturidade da gestão de projetos. Embora sejam divergentes do nosso estudo em termos de contexto temporal e geográfico, na metodologia e instrumentos de mensuração e, em alguns casos, nas conclusões, eles corroboram no delineamento de algumas clarificações sobre a natureza do fenômeno.

Quadro 8. Estudos de Avaliação de Maturidade de Gestão de Projetos

\begin{tabular}{|c|c|c|c|}
\hline Objetivo de pesquisa & Autores & Metodologia & Conclusões \\
\hline $\begin{array}{l}\text { Identificação de } \\
\text { competências que geram a } \\
\text { maturidade na gestão de } \\
\text { projetos }\end{array}$ & $\begin{array}{l}\text { Levene, } \\
\text { Bentley e } \\
\text { Jarvis (1995) }\end{array}$ & $\begin{array}{l}\text { Estudo em } 13 \\
\text { empresas que utilizam } \\
\text { gestão de projetos de } \\
\text { tecnologia de } \\
\text { informação }\end{array}$ & $\begin{array}{l}\text { Maturidade na gestão de projetos de } \\
\text { tecnologia de informação, entre } \\
\text { empresas de setores diversos (setores } \\
\text { de telecomunicação, bancário e } \\
\text { prestação de serviços essenciais) são } \\
\text { similares }\end{array}$ \\
\hline $\begin{array}{l}\text { Identificar impactos } \\
\text { financeiros e } \\
\text { organizacionais da gestão } \\
\text { de projetos }\end{array}$ & $\begin{array}{l}\text { Ibbs e Kwak } \\
(2000)\end{array}$ & $\begin{array}{l}\text { Questionário de } 148 \\
\text { questões efetuado em } \\
38 \text { empresas de } 4 \\
\text { setores diferentes }\end{array}$ & $\begin{array}{l}\text { Empresas de engenharia }(3,36) \text { e } \\
\text { manufatura de alta-tecnologia }(3,34) \\
\text { possuem maiores níveis de } \\
\text { maturidade, se comparadas a } \\
\text { empresas de telecomunicações }(3,30) \\
\text { e tecnologia de informação }(3,06) \\
\end{array}$ \\
\hline $\begin{array}{l}\text { Identificar a natureza e } \\
\text { extensão das diferenças de } \\
\text { maturidade na gestão de } \\
\text { projetos entre empresas de } \\
\text { seis setores diferentes }\end{array}$ & $\begin{array}{l}\text { Cooke-Davies } \\
\text { e Arzymanow } \\
(2003)\end{array}$ & $\begin{array}{l}\text { Estudo qualitativo em } \\
27 \text { empresas }\end{array}$ & $\begin{array}{l}\text { Empresas do setor petroquímico } \\
\text { possuíam uma maior maturidade na } \\
\text { gestão de projetos, se comparadas ao } \\
\text { setor de defesa, e farmacêutico }\end{array}$ \\
\hline $\begin{array}{l}\text { Medição de maturidade na } \\
\text { gestão de projetos e } \\
\text { identificação de fatores de } \\
\text { influência }\end{array}$ & $\begin{array}{l}\text { Grant e } \\
\text { Pennypacker } \\
\text { Grant (2003) }\end{array}$ & $\begin{array}{l}\text { Survey com } 123 \\
\text { empresas (manufatura, } \\
\text { informação, finanças e } \\
\text { serviços técnicos } \\
\text { profissionais) }\end{array}$ & $\begin{array}{l}\text { Grande maioria das empresas }(67 \%) \\
\text { possuem níveis baixos de maturidade. } \\
\text { Não foram verificadas diferenças } \\
\text { estatisticamente relevantes entre } \\
\text { empresas de setores diversos e } \\
\text { empresas de tamanhos diversos. }\end{array}$ \\
\hline $\begin{array}{l}\text { Avaliação da influência do } \\
\text { uso das metodologias de } \\
\text { gestão de projetos na } \\
\text { performance organizacional }\end{array}$ & $\begin{array}{l}\text { Crawford } \\
(2005)\end{array}$ & $\begin{array}{l}\text { Survey envolvendo } \\
208 \text { respondentes em } 3 \\
\text { países (Estados } \\
\text { Unidos, Reino Unido e } \\
\text { Austrália) }\end{array}$ & $\begin{array}{l}\text { Não há correlação estatística, avaliada } \\
\text { de forma geral, e entre os elementos } \\
\text { da metodologia. }\end{array}$ \\
\hline
\end{tabular}




\begin{tabular}{|llll|}
\hline Objetivo de pesquisa & Autores & Metodologia & Conclusões \\
\hline $\begin{array}{l}\text { Acompanhamento dos } \\
\text { níveis de maturidade de } \\
\text { gestão de projetos em } \\
\text { setores diversos ao longo do } \\
\text { tempo }\end{array}$ & $\begin{array}{l}\text { Mullaly } \\
\text { (2006) }\end{array}$ & $\begin{array}{l}\text { Survey com 2500 } \\
\text { participantes de 550 } \\
\text { empresas do Canadá e } \\
\text { Estados Unidos, ao } \\
\text { longo de 6 anos (1998 } \\
\text { a 2003) }\end{array}$ & $\begin{array}{l}\text { Verificado declínio dos níveis de } \\
\text { maturidade ao longo do tempo, } \\
\text { principalmente no setor de } \\
\text { telecomunicação, motivado pela } \\
\text { desregulamentação }\end{array}$ \\
\hline $\begin{array}{l}\text { Identificar os setores que } \\
\text { possuem maior qualidade de } \\
\text { planejamento e execução de } \\
\text { projetos }\end{array}$ & $\begin{array}{l}\text { Zwikael e } \\
\text { Globerson }\end{array}$ & $\begin{array}{l}\text { Survey aplicado com } \\
\text { 282 gestores de } \\
\text { projetos }\end{array}$ & $\begin{array}{l}\text { Maiores níveis de maturidade em } \\
\text { empresas de construção e engenharia } \\
\text { (3,6) se comparado a empresas de } \\
\text { outros setores: software (3,4), } \\
\text { serviços (3,3) e manufatura (3,0) }\end{array}$ \\
\hline $\begin{array}{l}\text { Verificação se os setores } \\
\text { econômicos relacionados à } \\
\text { construção possuem } \\
\text { maiores níveis de } \\
\text { maturidade na gestão de } \\
\text { projetos }\end{array}$ & Byde (2008) & $\begin{array}{l}\text { Survey envolvendo } \\
\text { 238 empresas no } \\
\text { Reino Unido }\end{array}$ & $\begin{array}{l}\text { Apontou um maior nível de } \\
\text { maturidade na gestão de projetos em } \\
\text { empresas relacionadas a construção se } \\
\text { comparadas a outros setores } \\
\text { tecnologia de informação, projetos } \\
\text { estratégicos e projetos de mudança } \\
\text { organizacional) }\end{array}$ \\
\hline $\begin{array}{l}\text { Identificação de fatores } \\
\text { contribuintes para } \\
\text { impulsionar a maturidade de } \\
\text { gestão de projetos }\end{array}$ & Silveira (2008) & $\begin{array}{l}\text { Survey envolvendo } \\
\text { diretamente } \\
\text { envolvidas em gestão } \\
\text { de projetos }\end{array}$ & $\begin{array}{l}\text { Verificado maiores níveis de } \\
\text { maturidade em empresas de origem } \\
\text { estrangeira, empresas de grande porte } \\
\text { e empresas de dependência } \\
\text { tecnológica }\end{array}$ \\
\hline
\end{tabular}

\subsubsection{KPMMM - Kerzner Project Management Maturity Model}

Kerzner (2000) estabelece um modelo de análise da maturidade em gerenciamento de projetos através de um modelo composto por cinco fases que ilustradas pela Figura 8.

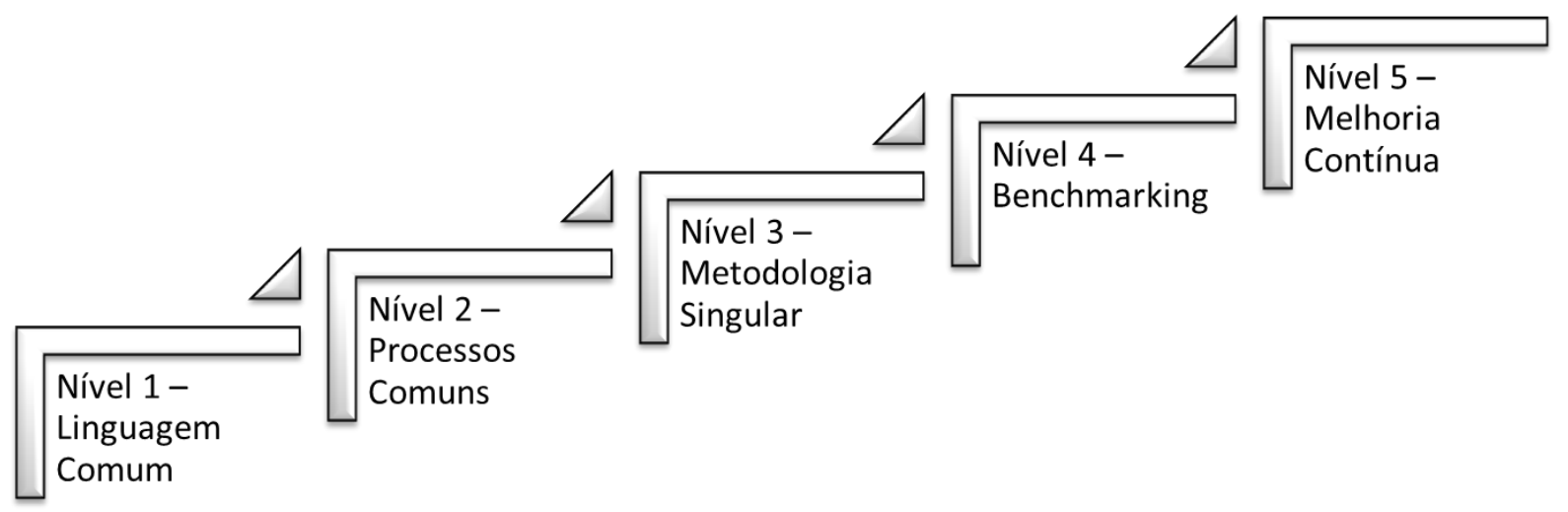

Figura 8. Modelo de Maturidade KPMMM

FONTE: KERZNER, 2001.

A primeira fase é denominada embrionária e ocorre quando a empresa ainda está vivenciando as primeiras experiências em gestão de projetos. A segunda fase ocorre quando a alta 
administração da organização reconhece a importância da gestão de projetos. A terceira fase, por sua vez, se refere ao reconhecimento do papel do gerente de projetos pela empresa. A quarta fase ocorre quando há um crescimento da função de gestão de projetos. Por fim, a última fase está relacionada à maturidade do gerenciamento de projetos.

\subsubsection{Modelo de Maximiano e Rabechini}

Maximiano e Rabechini (2002) propuseram um modelo de avaliação de maturidade em gerenciamento de projetos dividido em três estágios ou níveis como ilustrado na Figura 9.

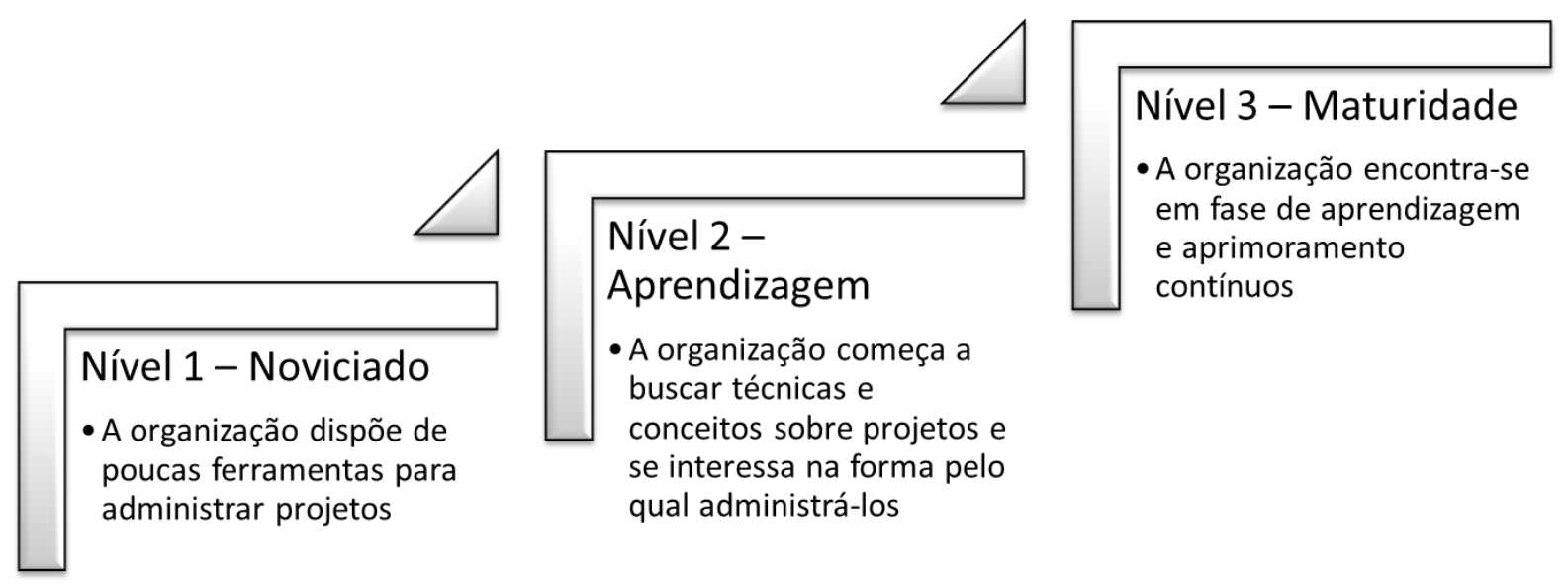

Figura 9. Modelo de Maximiano e Rabechini

De acordo com os autores, o primeiro estágio é denominado Noviciado e ocorre quando a organização dispõe de poucas ferramentas para administrar projetos. A organização sente a necessidade de aprimorar suas ferramentas de gestão de projetos e não se encontra mais na fase de total alienação em relação ao gerenciamento de projetos.

A segunda fase é denominada Aprendizagem e ocorre quando a organização começa a buscar técnicas e conceitos sobre projetos e se interessa na forma pelo qual administrá-los. A alta administração começa a se preocupar com o potencial de vantagem competitiva que a gestão de projetos pode proporcionar a organização.

Por fim, o terceiro estágio é denominado Maturidade e ocorre quando a organização encontrase em fase de aprendizagem e aprimoramento contínuos. Há um contingente significativo de 
pessoas preparadas para gerenciar projetos e participar de equipes. Os procedimentos são claramente definidos e há uma preocupação de aprender com outras experiências em projetos.

\subsubsection{MMGP - Modelo de Maturidade em Gerenciamento de Projetos}

O Modelo de Maturidade em Gerenciamento de Projetos (MMGP) é um modelo brasileiro e foi criado pelo consultor Darci Prado. Esse modelo é voltado tanto para setores internos de uma organização como para o ambiente corporativo como um todo e foi aplicado a diversas organizações brasileiras (PRADO, 2010a). Além disso, é aderente à terminologia utilizada no PMBOK do PMI e no RBC do IPMA/ABGP, segundo Prado (2010b).

O MMGP destaca os fatores determinantes da maturidade, denominados de dimensões da maturidade.

Essas dimensões são as capacidades organizacionais que precisam ser desenvolvidas e implantadas e são agrupadas em seis por Prado (2008): Competência Técnica em Gerenciamento de Projetos; Uso de Metodologia; Uso de Informatização; Uso de Adequada Estrutura Organizacional; Relacionamentos humanos ou Competência Comportamental; Alinhamento com as Estratégias/Negócios da Organização. Assim, tais fatores aparecem em maior ou menor intensidade dependendo do nível de maturidade, conforme o Quadro 9.

O modelo apresenta cinco níveis de maturidade (1-Inicial; 2-Conhecido; 3-Padronizado; 4Gerenciado; 5-Otimizado).

Quadro 9. Relacionamentos entre as Dimensões de Maturidade e os Níveis de Maturidade

\begin{tabular}{|l|c|c|c|c|c|}
\hline \multirow{2}{*}{$\begin{array}{c}\text { Dimensão da } \\
\text { maturidade }\end{array}$} & $\begin{array}{c}\mathbf{1} \\
\text { Inicial }\end{array}$ & $\begin{array}{c}\mathbf{2} \\
\text { Conhecido }\end{array}$ & $\begin{array}{c}\mathbf{3} \\
\text { Padronizado }\end{array}$ & $\begin{array}{c}\mathbf{4} \\
\text { Gerenciado }\end{array}$ & $\begin{array}{c}\mathbf{5} \\
\text { Otimizado }\end{array}$ \\
\cline { 2 - 6 } & Dispersos & Básicos & Básicos & Avançados & Avançados \\
\hline Metodologia & Não há & $\begin{array}{c}\text { Tentativas } \\
\text { isoladas }\end{array}$ & $\begin{array}{c}\text { Implantada e } \\
\text { padronizada }\end{array}$ & Estabilizada & Otimizada \\
\hline Informatização & $\begin{array}{c}\text { Tentativas } \\
\text { isoladas }\end{array}$ & $\begin{array}{c}\text { Tentativas } \\
\text { isoladas }\end{array}$ & Implantada & Estabilizada & Otimizada \\
\hline Estrutura & Não há & Não há & Implantada & Estabilizada & Otimizada \\
\hline
\end{tabular}




\begin{tabular}{|l|c|c|c|c|c|}
\hline Organizacional & & & & & \\
\hline $\begin{array}{l}\text { Relacionamentos } \\
\text { Humanos }\end{array}$ & Boa vontade & Algum avanço & Algum avanço & Algum avanço & Maduros \\
\hline $\begin{array}{l}\text { Alinhamento } \\
\text { com a Estratégia }\end{array}$ & Não há & Não há & Iniciado & Alinhado & Alinhado \\
\hline
\end{tabular}

FONTE: PRADO, 2010a.

Para avaliar a maturidade das organizações é aplicado um questionário com 40 questões fechadas, podendo obter resultados fracionados, o que pode demonstrar diferenças entre os setores da mesma organização (PRADO, 2008). Desse modo, é possível avaliar o valor global da maturidade de uma organização e também dos setores, o que pode auxiliar em um plano de ação mais adequado para a empresa, aplicando determinadas ações na empresa como um todo ou de forma individualizada dependendo da avaliação.

\subsubsection{Organizational Project Maturity Management Model (OPM3)}

A criação do modelo Organizational Project Maturity Management Model levou em consideração o conceito de Quality Function Deployment (QFD), em específico a abordagem house of quality, que utiliza matrizes para organizar e relacionar dados. A função básica do modelo é auxiliar as organizações a entender e avaliar o seu nível de maturidade em gerenciamento de projetos. Através do reconhecimento das competências que devem ser desenvolvidas, o modelo prevê um caminho para o melhoramento do gerenciamento de projetos da empresa (LUKOSEVICIUS, 2005). A segunda edição do OPM3 foi reconhecida pela American National Standards Institute (ANSI) como um American National Standard (ANSI/PMI 08-004-2008).

O OPM3 é composto pelas melhores práticas de processos, capacidades que são as competências específicas necessárias à gestão de projetos, resultados tangíveis ou intangíveis que comprovam a existências das capacidades e, finalmente, indicadores de desempenho como ilustrado na Figura 10 (RODRIGUES, RABECHINI JR. \& CSILLAG, 2006). 


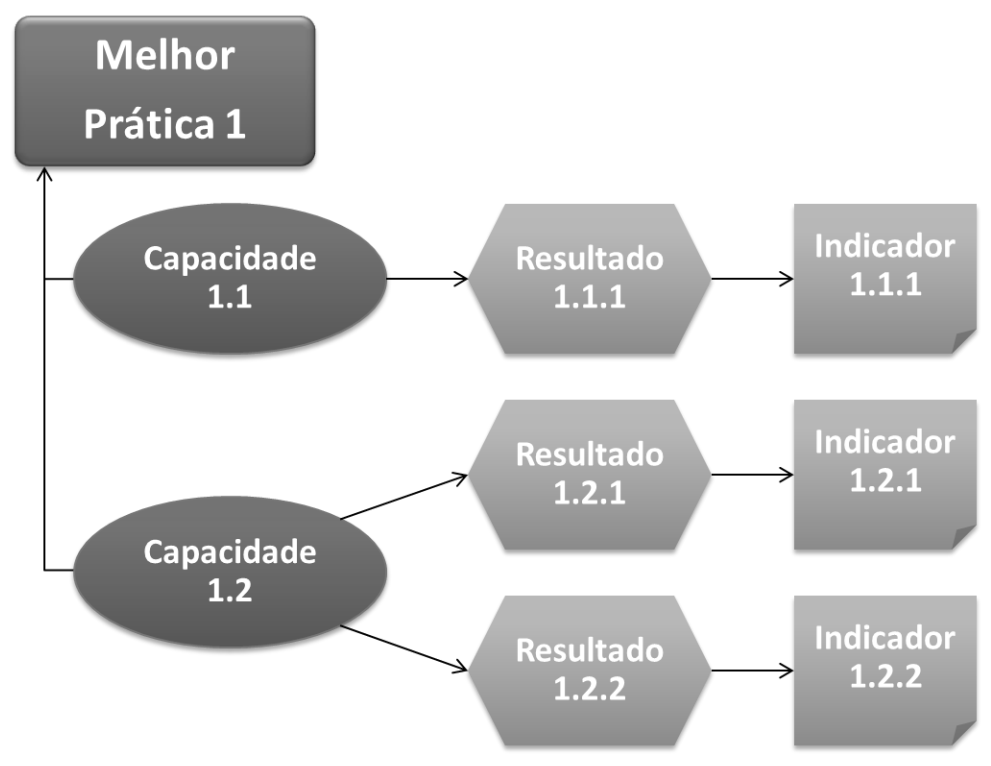

Figura 10. Relação entre Melhores Práticas, Capacidades, Resultados e Indicadores do OPM3. FONTE: PMI, 2008b.

Segundo Silva Jr (2009), o OPM3 trabalha com quatro domínios definidos: organizacional, portfólio, programas e projetos. Assim o modelo inova ao trazer uma característica importante que é a avalição não só da maturidade em gestão de projetos, mas em gestão de portfólio, programas e projetos, bem como os elementos organizacionais e, algumas vezes, culturais que reforçam e exercem influencia sobre a orientação à projetos.

O OPM3 também introduz um olhar mais abrangente incluindo a avaliação dos programas e portfólios, pois enquanto o projeto é um esforço para criar um produto ou serviço, o programa é um conjunto de projetos relacionados e o portfólio é um conjunto de projetos ou programas agrupados com outros trabalhos, que visa facilitar o gerenciamento dos trabalhos a fim de atender aos objetivos estratégicos da organização (SILVA JR, 2009).

Além de colocar uma proposta de um processo de melhoria contínua semelhante aos ciclos de PDCA e de DMAIC seguinte um conjunto de passos como ilustrado Figura 11. 


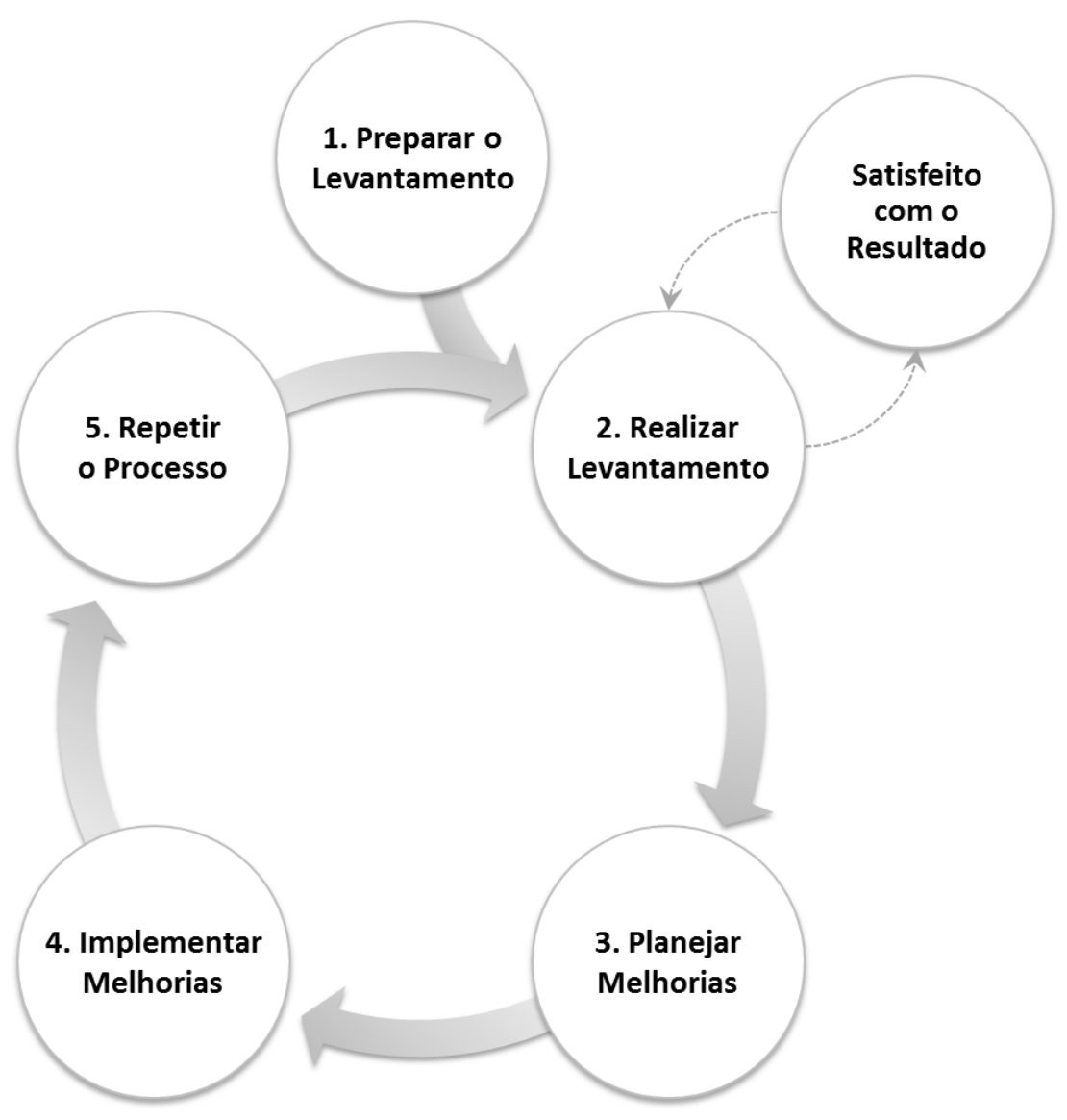

Figura 11. Processo de Implantação e Melhoria Contínua FONTE: PMI, 2008b.

Segundo Silveira (2008), o modelo OPM3® é uma combinação do mais compreensivo conjunto das melhores práticas organizado por meio de algumas dimensões. Esse estudo explora as dimensões organizacionais e de gestão de projetos, excluindo as dimensões de programas e portfolio. Ainda para fins deste estudo são avaliados os quatro estágios progressivos da maturidade: 1) padronização - identificar o processo-problema; 2) aferição identificar as entradas/saídas; priorizar e definir indicadores; 3) controle - identificar indicadores e variações; analisar causas raízes e 4) melhoria contínua - identificar e implementar as mudanças nos processos.

Diferentemente de outros modelos, o OPM3® classifica a maturidade em níveis, em uma escala, o que beneficia a empresa no sentindo de medir e trabalhar nas práticas que trouxerem maiores benefícios estratégicos, em vez de trabalhar nas práticas exclusivas de um nível (KANUP, 2009).

Buscou-se exemplificar a estrutura das dimensões, grupos de processo e níveis de maturidade 
do OMP3 no Quadro 10.

Quadro 10. Dimensões, Grupos de Processos e Níveis do OPM3

\begin{tabular}{|c|c|c|c|c|c|c|}
\hline Dimensões & $\begin{array}{l}\text { Grupos de } \\
\text { Processos }\end{array}$ & Padronizado & Mensurável & Controlado & $\begin{array}{l}\text { Melhoria } \\
\text { Contínua }\end{array}$ & $\begin{array}{c}\text { Facilitadores } \\
\text { organiza- } \\
\text { cionais }\end{array}$ \\
\hline \multirow{2}{*}{$\begin{array}{l}\text { Gestão de } \\
\text { Portfolio }\end{array}$} & Alinhamento & & & & & \\
\hline & $\begin{array}{l}\text { Monitoramento } \\
\text { e Controle }\end{array}$ & & & & & \\
\hline \multirow{5}{*}{$\begin{array}{l}\text { Gestão de } \\
\text { Programa }\end{array}$} & Iniciação & & & & & \\
\hline & Planejamento & & & & & \\
\hline & Execução & & & & & \\
\hline & $\begin{array}{c}\text { Monitoramento } \\
\text { e Controle }\end{array}$ & & & & & \\
\hline & Encerramento & & & & & \\
\hline \multirow{5}{*}{$\begin{array}{c}\text { Gestão de } \\
\text { Projeto }\end{array}$} & Iniciação & & & & & \\
\hline & Planejamento & & & & & \\
\hline & Execução & & & & & \\
\hline & $\begin{array}{c}\text { Monitoramento } \\
\text { e Controle }\end{array}$ & & & & & \\
\hline & Encerramento & & & & & \\
\hline
\end{tabular}

\subsubsection{Análise Crítica dos Modelos de Maturidade}

Cooper, Edgett e Kleinschimidt (2001a e b) argumentam que há duas maneiras de uma empresa ser bem sucedida em relação a sua carteira de projetos: realizar os projetos corretamente e realizar os projetos corretos. Assim, entendemos que auferir a maturidade das práticas de gestão de projetos corroboram com a realização dos projetos corretamente.

Muito embora existam trabalhos que demonstrem resultados divergentes analisamos a seguir, a utilização de estudos empíricos na aferição da maturidade na gestão de projetos, além de encontrar um primeiro obstáculo na forma de medição, derivado dos diversos instrumentos e 
existentes, que encontra dificuldade na obtenção de um parâmetro único que não sofra alteração ao longo do tempo.

A própria necessidade de gestão de projetos sofre influências diversas, seja em função do setor de atividade, da tecnologia na qual a organização está inserida, do tamanho da empresa e da experiência profissional do seu grupo de gestão, justificando, sobremaneira, a elaboração de estudos exploratórios a fim de identificar essas influências e para justificar ou mesmo aprimorar sua utilização.

O modelo KPMMM de Kerzner (2001) e o modelo de Maximiano e Rabechini (2002) são propostas de avaliação geral da maturidade de gestão de projetos em uma única dimensão induzindo ao entendimento de que a organização amadurece por estágios seguindo uma certa sequência ou padrão.

O MMGP de Prado (2010a) avalia a maturidade de gestão de projetos em seis dimensões distintas que estão mais associadas a características específicas facilitadores da gestão de projetos do que um modelo de maturidade de processos.

Já o OPM3® de PMI (2008b) avalia tanto a maturidade dos processos de gestão de projetos de Kerzner (2001) e de Maximiano e Rabechini (2002) quanto às características facilitadoras como vistas em Prado (2010a) além de avaliar também a maturidade dos processos de gestão de portfolio e programas.

Assim, o estudo enfocou a aplicação do Modelo de Maturidade Organizacional de Gestão de Projetos OPM3® (Organizational Project Management Maturity Model) e não se pretende exaurir o assunto ou mesmo identificar o melhor ou pior modelo de maturidade em gerenciamento de projetos que determine o melhor desempenho das organizações.

Esse enfoque deu-se pelo entendimento de que o OPM3® incorpora os elementos chave de avaliação de maturidade em gestão de projetos mais amplos ao compararmos os diversos modelos em nossa revisão bibliográfica. Também pode-se constatar pelo número de membros e Chapters do PMI® no Brasil que ele é o padrão mais difundido e, portanto, o que seria mais adequado para uso nesse estudo. 
Entretanto, considerando os modelos nacionais Prado (2008), Prado (2010a, b) e Maximiano e Rabechini (2002) notamos uma particularidade que os diferencia do OPM3® e outros modelos internacionais. Os dois modelos de avaliação de maturidade em gestão de projetos nacionais que estudamos apontam a existência de um grau embrionário. Dessa forma, em nosso estudo adicionamos um nível de maturidade que precede o nível inicial do OPM3 que é a padronização como ilustrado no Quadro 11.

Quadro 11. Escala de Avaliação de Maturidade de Projetos Adaptada de Prado (2008) e Maximiano e Rabechini (2002)

\begin{tabular}{|c|c|c|c|c|c|}
\hline $\begin{array}{l}\text { Nos projetos que participo, } \\
\text { minha organização... }\end{array}$ & $\begin{array}{c}\text { Nenhuma ou poucas } \\
\text { vezes }\end{array}$ & $\begin{array}{r}\text { Muitas vezes mas não } \\
\text { de forma padronizada }\end{array}$ & $\begin{array}{l}\text { Muitas vezes e de } \\
\text { forma padronizada }\end{array}$ & $\begin{array}{l}\text { Gerencia a realizacão } \\
\text { no padrão }\end{array}$ & $\begin{array}{l}\text { Gerencia e promove } \\
\text { melhorias contínuas }\end{array}$ \\
\hline $\begin{array}{l}\text {...desenvolve o business case, } \\
\text { termo de abertura ou início. } \\
\text { (project charter) }\end{array}$ & $\begin{array}{l}\text { Adaptado de } \\
\text { Prado, Maximiano } \\
\text { \& Rabechini }\end{array}$ & \multicolumn{4}{|c|}{ OPM3® } \\
\hline
\end{tabular}

FONTE: PRADO, 2008; MAXIMIANO \& RABECHINI, 2002 - adaptado pelo autor 


\subsection{Abordagem Metodológica}

A abordagem metodológica desta pesquisa partiu de um sistêmico levantamento bibliográfico nas bases de dados Academic Search Premier (EBSCO), Web of Science (ISI), ABI/INFORM (ProQuest), Portal Domínio Público e Biblioteca Digital de Teses e Dissertações da USP, bem como, revistas acadêmicas Project Management Journal (PMI) e do International Project Management Journal (IPMA/Elsevier) na busca de estudos de duas naturezas, trabalhos empíricos com a proposta de avaliar comparativamente a maturidade em gestão de projetos em diversos setores e trabalhos teórico ou normativos que se propusessem a criticar e formular modelos de avaliação de maturidade em gestão de projeto.

Finalmente, revisaram-se livros técnicos e instrumentais no tema também foram identificados e pesquisados a fim de complementar o levantamento. A abordagem metodológica desta pesquisa foi ilustrada na Figura 12.

Revisão
Bibliográfica

\section{Figura 12. Abordagem Metodológica da Pesquisa}

O instrumento de pesquisa foi desenvolvido, primeiramente, por meio da composição das escalas de modelos identificados na revisão bibliográfica, pela seleção das dimensões de projeto e organização em detrimento das dimensões de programa e portfolio, bem como, pela seleção, tradução e formatação de um conjunto de perguntas derivadas diretamente do modelo de maturidade selecionada para ser à base do trabalho de campo, o OPM3. Posteriormente, 
esse instrumento sofreu pré-teste e foi ajustado com base nas recomendações e melhorias identificadas.

Já o trabalho de campo foi composto pela busca de potenciais organizações e respondentes para comporem a amostra do fenômeno em estudo. Assim, buscou-se nas redes sociais o currículo de profissionais que pudessem contribuir para a pesquisa por meio de análise de currículo e experiência publicada no LinkedIn e Facebook, bem como, fez-se uso da rede de contatos da FEA-USP e do pesquisador para envio do questionário.

Durante a análise de dados, realizou-se uma análise individual dos questionários com o intuito de excluir da amostra aqueles que não pudessem ser considerados válidos. Assim, foram realizados testes estatísticos, análise descritiva, análise estatística e, finalmente, análise de regressão.

\subsection{Instrumento de Pesquisa}

Martins e Theófilo (2009) sugerem que o pré-teste seja realizado por 3 a 10 colaboradores evidenciando possíveis falhas, inconsistências, complexidade das questões, ambiguidades e linguagem promovendo assim o aumento da confiabilidade e validade do instrumento. Ainda segundo o autor, o objetivo do pré-teste seria reformular, melhorar a redação, ampliar ou reduzir itens.

Desta forma, o questionário desse estudo sofreu pré-teste com 2 profissionais e 3 pesquisadores da área onde percebeu-se que ao enfocar as perguntas nos processo de iniciação e planejamento, o questionário daria um retrato bastante significativo do fenômeno estudado sendo mais enxuto e viável.

Abaixo elencamos, de forma reduzida, as colocações mais relevantes apontadas pelos colaboradores durante a fase de pré-teste do instrumento de pesquisa:

- Prof. Dr. Cesar Amaru Maximiano: "Deixar claro se o respondente está passando uma informação concreta ou passando uma opinião sobre a percepção dele a respeito da prática de gestão de projetos; Focar apenas em uma etapa (Planejamento por exemplo) para reduzir o tamanho; retrabalhar a linguagem formal de gerenciamento" 
- Prof. Dr Roberto Sbragia: "Garantir resposta a todas as perguntas, um survey extensivo precisa ser usado, portanto há necessidade de garantir um numero grande de respostas."

- Prof. Dr Marilson Gonçalves: "Inserir a definição operacional de "Projeto" para equalizar o entendimento; Questionou o tamanho do questionário e a viabilidade da amostra."

- Gilbeto Cheng, PMP: "Seria interessante verificar se o fato de executivos em posições mais altas terem algum tipo de certificação ou capacitação formal PMI não contribui para a maturidade das organizações de projeto. Geralmente há um suporte maior para a implantação de processos ou mesmo uma estrutura organizacional dedicada a projetos quando os próprios sponsors têm a formação. Entendo que todas as perguntas são pertinentes ou que poderiam ser respondidas sem maiores restrições."

- Eduardo Ebel, PMP: “A amplitude do questionário está realmente boa.”

Gil (2006) sugere que a técnica de survey, ou questionário, possui a vantagem de atingir um amplo número de pessoas, implica em menores custos de pesquisa, garante o anonimato das respostas, permite que as pessoas respondam no momento que lhes é mais conveniente e não expõe os respondentes às influências externas.

Ainda de acordo com o autor, teríamos como limitação dessa técnica: 1) a exclusão de pessoas que não saibam ler e escrever, 2) impede que o respondente receba auxílio quando não entende um termo ou a pergunta, 3) impede que se entenda o contexto ou momento quando o questionário foi respondido, 4) não garante que os respondentes preencham, 5) envolve um número reduzido de questões para que haja responsividade e 6) proporciona resultados bastante críticos em relação à objetividade.

Malhotra (2006, p. 291) afirma ainda que o questionário tem três objetivos específicos: transformar a informação desejada em um conjunto de perguntas específicas, motivar o respondente a se envolver na pesquisa, respondendo-o completamente, e deve sempre buscar a minimização do erro de resposta.

A coleta de dados foi realizada por meio de questionários aplicados de abril a junho/2010 via internet através do software de pesquisa QuestionPro. O convite para participar da pesquisa foi para uma amostra de conveniência de membros de redes sociais ligadas aos Chapters do Project Management Institute (PMI) de diversos Estados brasileiros, membros de redes 
sociais ligadas ao tema via LinkedIn, redes sociais de ex-alunos da FEA, alunos de MBA da FIA e do PECE da Poli-USP além da rede pessoal de contatos dos pesquisadores. O questionário aplicado encontra-se formalizado na integra no Anexo I desse relatório de pesquisa.

Nesse estudo, para analisar a maturidade em planejamento da gestão de projetos de empresas brasileiras, foi elaborado um questionário com 46 questões fechadas. Martins e Theófilo (2009) apontam que as questões fechadas têm um número de alternativas fixadas que podem se referir a fatos, atitudes e crenças, comportamento, sentimento, padrões de ação, dirigidas a comportamento presente ou passado, razões conscientes de crenças, sentimentos, orientações e comportamentos.

Dessa forma, o questionário foi estruturado em quatro partes 1) caracterização do respondente com 6 perguntas; 2) caracterização da organização ao qual o respondente pertence com 6 perguntas; 3) percepção da importância dos facilitadores organizacionais de gestão de projetos com 15 perguntas em escala de Likert de onde respostas possíveis variavam de 1 a 5, em que 1 era igual a discordo totalmente, 2 era discordo parcialmente, 3 era indiferente, 4 era concorda parcialmente e, por fim, 5 era igual a concordo totalmente; 4) percepção da maturidade em iniciação e planejamento de projetos com 19 perguntas utilizando a escala de maturidade do OPM3 com a inclusão de uma nível inicial de maturidade que encontramos nos modelos Maximiano e Rabechini (2002) e Kerzner (2000). As respostas foram caracterizadas como nenhuma ou poucas vezes (1), muitas vezes, mas de forma não padronizada (2), muitas vezes e de forma padronizada (3), gerencia a realização no padrão (4) e gerencia e promove melhorias contínuas (5).

Durante o período de coleta de dados, 468 respondentes visualizaram o questionário, 357 respondentes responderam parcialmente o questionário, 225 respondentes responderam o questionário até a última seção e 217 questionários foram considerados válidos considerando os seguintes critérios:

- foram excluídos questionários que foram respondidos com todas as respostas nos centros ou nas pontas extremas (outliers) das escalas;

- foram excluídos questionários que tiveram uma ou mais respostas nulas em qualquer pergunta da seção de percepção da importância da gestão de projetos; 
- foram excluídos questionários que tiveram uma ou mais respostas nulas em qualquer pergunta da seção percepção de maturidade na gestão de projetos.

Finalmente, dado o enfoque do trabalho, selecionou-se somente os 190 questionários oriundos de profissionais que atuam predominantemente com TI. A redução nesse último filtro foi pequena pois a pesquisa foi intencionalmente enviada somente a profissionais dessa área que atuam com projetos de sistemas de informações.

Assim, procuramos ilustrar na Figura 13 os passos do processo de filtro e seleção das respostas aos questionários que foram tratados neste estudo.

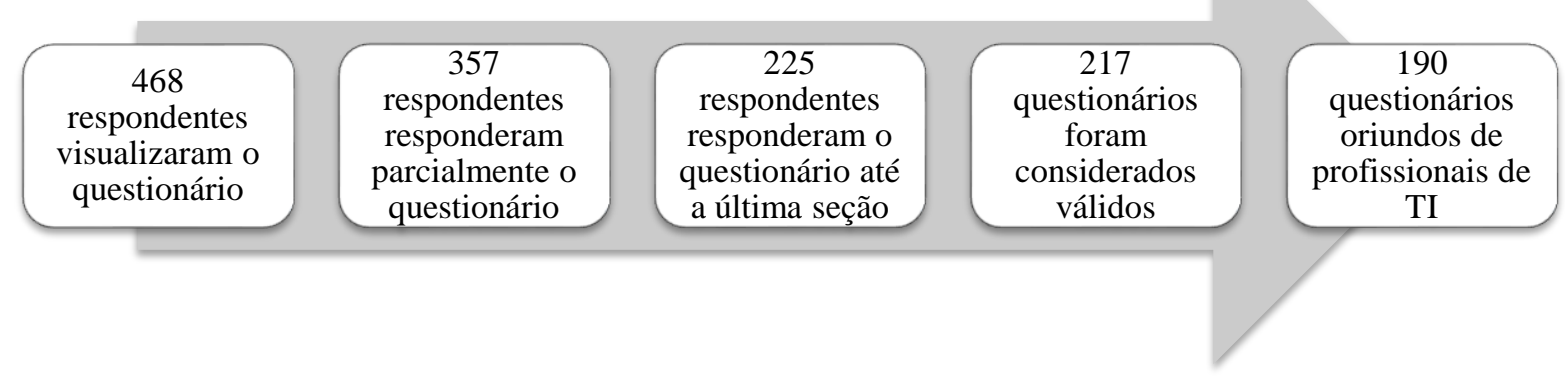

Figura 13. Processo de Seleção dos Questionários Válidos

\subsection{Metodologia de Análise de Dados}

O software estatístico SPSS na versão 18 foi utilizado para análise dos dados. Nas respostas válidas, foi aplicado o teste de Kolmogorov-Smirnov para testar a normalidade das distribuições das respostas nas partes 3 e 4 do questionário conforme ilustrado na Tabela 1.

Verificou-se que dados coletados sobre a percepção da maturidade de gestão de projetos manifestaram-se como uma distribuição não normal (Sig. 0,044) com cauda longa à esquerda: negative skewness. Enquanto os dados coletados sobre a percepção da importância dos facilitadores organizacionais da gestão de projetos, por sua vez, manifestaram as características de distribuição normal (Sig. 0,158). 
Tabela 1. Teste de Kolmogov-Smirnov de Percepção de Maturidade em Gestão de Projetos e Percepção de Importância dos Facilitadores Organizacionais da Gestão de Projetos

\begin{tabular}{|l|l|r|r|}
\hline \multicolumn{2}{|c|}{ Teste de Kolmogorov-Smirnov } & \multicolumn{1}{c|}{$\begin{array}{c}\text { Percepção de } \\
\text { Maturidade em } \\
\text { Gestão de Projetos }\end{array}$} & $\begin{array}{c}\text { Percepção de } \\
\text { Importância da } \\
\text { Gestão de Projetos }\end{array}$ \\
\hline N & Mediana & 190 & 190 \\
\hline \multirow{2}{*}{ Parâmetros Normais (a,b) } & Desvio Padrão & 54,4158 & 51,7316 \\
\cline { 2 - 4 } & Absoluta & 21,75333 &, 082 \\
\cline { 2 - 4 } Diferenças mais extremas & Positivo &, 100 &, 046 \\
\cline { 2 - 4 } & Negativo &,- 100 &,- 082 \\
\hline Kolmogorov-Smirnov Z & & 1,380 & 1,126 \\
\hline Sig. Assint. (2-tailed) &, 044 &, 158 \\
\hline
\end{tabular}

a. Distribuição Testada é Normal

b. Calculado a partir dos Dados

Dados as características das distribuições, as análises foram compostas pelo teste nãoparamétrico de Kruskal-Wallis. Segundo Fávero et al. (2009) o Teste Kruskal-Wallis pode ser aplicado quando a normalidade e igualdade das variâncias não estejam presentes e verifica a probabilidade das amostras independentes serem da mesma população.

Também verificou-se a relação entre a importância e a maturidade em gestão de projetos por meio de uma regressão linear que, segundo Fávero et. al. (2009), tem por objetivo estudar a relação entre duas ou mais variáveis explicativas que se apresentam na forma linear e uma variável dependente métrica.

Desenvolvemos um gráfico radar para visualmente identificar as diferentes médias de percepção sobre maturidade em iniciação e planejamento de projetos entre setores distintos nas nove áreas de conhecimento em gestão de projetos, segundo o PMBOK® (2008): integração, escopo, tempo, custo, qualidade, comunicação, risco, recursos humanos e aquisições.

Finalmente, elaboramos uma lista das melhores práticas aplicadas com maior maturidade e menor maturidade. 


\section{ANÁLISE DE DADOS}

\subsection{Análise Descritiva dos Dados}

A amostra de dados mostrou-se bastante robusta ao se analisar de maneira descritiva tanto as características dos respondentes quanto das empresas por eles representadas. Na Tabela 2 e Tabela 3 se pode avaliar estas características para se entender melhor a representatividade da amostra.

Tabela 2. Análise Descritiva dos Respondentes

\begin{tabular}{|c|l|c|r|r|}
\hline \multicolumn{2}{|c|}{ Função atual ou mais recente do respondente } & N & $\%$ & Mean Rank \\
\hline \multirow{2}{*}{ Estagiário ou Trainee } & 4 & $2,11 \%$ & 108,75 \\
\cline { 2 - 5 } & Analista ou Operador & 27 & $14,21 \%$ & 74,44 \\
\cline { 2 - 5 } & Líder ou Coordenador de Equipe & 66 & $34,74 \%$ & 95,22 \\
\cline { 2 - 5 } & Gerente ou Superintendente de Área & 65 & $34,21 \%$ & 102,10 \\
\cline { 2 - 5 } & Alta-Administração, Diretor, VP ou C-Level & 28 & $14,74 \%$ & 99,25 \\
\hline
\end{tabular}

Outras características relevantes dos respondentes são que $82,95 \%$ possuem Curso Universitário, MBA, Pós-Graduação ou Especialização; que 83,66\% possuem mais de 7 anos de experiência profissional; que 50,78\% possuem mais de 7 anos de experiência profissional em projetos e $17,12 \%$ possuem alguma certificação em gestão de projetos.

Tabela 3. Análise Descritiva das Organizações

\begin{tabular}{|c|c|c|c|c|c|}
\hline SETOR & FATURAMENTO & NR. DE FUNCIONÁRIOS & Mean & $\mathbf{N}$ & $\begin{array}{c}\text { Std. } \\
\text { Deviation }\end{array}$ \\
\hline \multirow{9}{*}{ SERVIÇOS } & \multirow{3}{*}{ PME $<$ R $\$ 300$ milhões } & $<499$ funcionários & 52,1094 & 64 & 19,43007 \\
\hline & & $>500$ funcionários & 54,8571 & 14 & 17,80172 \\
\hline & & Total & 52,6026 & 78 & 19,06608 \\
\hline & \multirow{3}{*}{ Grandes Empresas > R $\$ 300$ milhões } & $<499$ funcionários & 47,8000 & 5 & 18,79362 \\
\hline & & $>500$ funcionários & 61,1020 & 49 & 24,93345 \\
\hline & & Total & 59,8704 & 54 & 24,59333 \\
\hline & \multirow{3}{*}{ Total } & $<499$ funcionários & 51,7971 & 69 & 19,28241 \\
\hline & & > 500 funcionários & 59,7143 & 63 & 23,54983 \\
\hline & & Total & 55,5758 & 132 & 21,70803 \\
\hline \multirow{8}{*}{ MANUFATURA } & \multirow{3}{*}{ PME $<$ R $\$ 300$ milhões } & $<499$ funcionários & 44,8333 & 12 & 24,07878 \\
\hline & & $>500$ funcionários & 58,0000 & 1 & \\
\hline & & Total & 45,8462 & 13 & 23,34112 \\
\hline & \multirow{2}{*}{ Grandes Empresas > R $\$ 300$ milhões } & $>500$ funcionários & 56,6129 & 31 & 20,75681 \\
\hline & & Total & 56,6129 & 31 & 20,75681 \\
\hline & \multirow{3}{*}{ Total } & $<499$ funcionários & 44,8333 & 12 & 24,07878 \\
\hline & & > 500 funcionários & 56,6563 & 32 & 20,42075 \\
\hline & & Total & 53,4318 & 44 & 21,84767 \\
\hline
\end{tabular}


Outras características relevantes das organizações representadas em nosso estudo é que $84.71 \%$ atuam a mais de 7 anos no mercado; que $57.26 \%$ são multinacionais e que $71.55 \%$ têm origem latino-americana, mais significativamente, brasileiras.

As percepções de importância declaradas pelos respondentes podem ser observadas na Gráfico 1, na qual podemos destacar que as maiores importâncias aos facilitadores organizacionais de gestão de projetos associados à estratégia organizacional como a necessidade de sobrevivência da organização e da sustentação da vantagem competitiva.

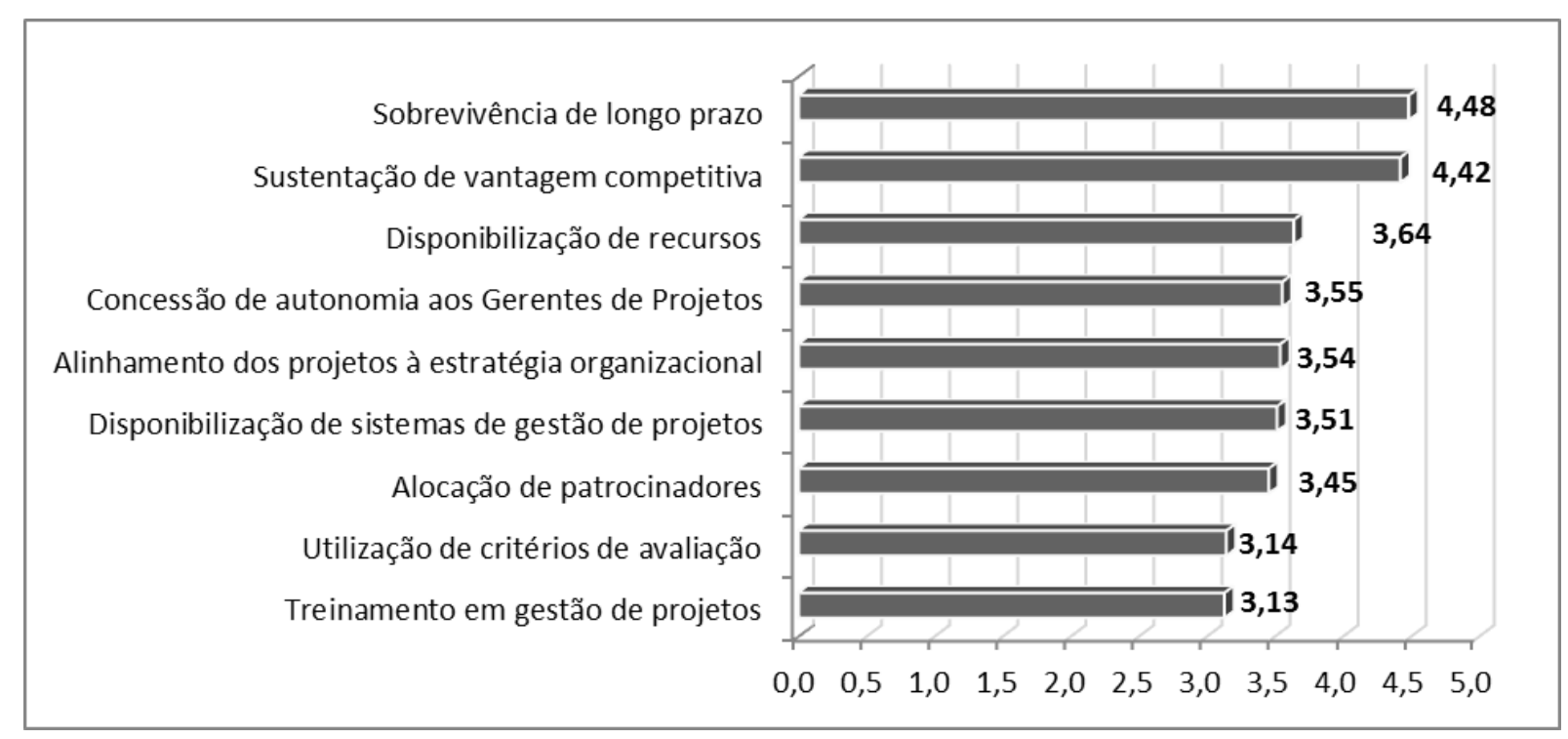

\section{Gráfico 1. Análise Descritiva das Medianas das Percepções de Importância dos Facilitadores} Organizacionais para a Gestão de Projetos

Ao se analisar a percepção de importância dos facilitadores organizacionais para gestão de projetos por setor, não foram encontradas justificativas estatísticas consistentes a ponto de determinar que o resultado da percepção da importância da gestão de projetos pudesse ser agrupado de acordo com o setor das empresas dos respondentes (Sig. 0,103) conforme ilustrado na 
Tabela 4. 
Tabela 4. Análise Descritiva da Percepção de Importância dos Facilitadores Organizacionais à Gestão de Projetos

\begin{tabular}{|c|c|c|c|c|c|c|c|c|}
\hline & \multirow[t]{2}{*}{$\mathbf{N}$} & \multirow{2}{*}{ Mediana } & \multirow{2}{*}{$\begin{array}{l}\text { Desv. } \\
\text { Padrão }\end{array}$} & \multirow{2}{*}{$\begin{array}{c}\text { Erro } \\
\text { Padrão }\end{array}$} & \multicolumn{2}{|c|}{$\begin{array}{c}\text { Interv. confiança } \\
\text { de } 95 \% \text { da } \\
\text { mediana }\end{array}$} & \multirow[t]{2}{*}{ Mínimo } & \multirow[t]{2}{*}{ Máximo } \\
\hline & & & & & $\begin{array}{l}\text { Lower } \\
\text { Bound }\end{array}$ & $\begin{array}{c}\text { Upper } \\
\text { Bound }\end{array}$ & & \\
\hline Serviços & 133 & 52,3383 & 13,17935 & 1,14279 & 50,0778 & 54,5989 & 18,00 & 75,00 \\
\hline Comercial & 3 & 62,3333 & 7,23418 & 4,17665 & 44,3626 & 80,3040 & 54,00 & 67,00 \\
\hline Manufatureira & 44 & 51,0455 & 15,76713 & 2,37698 & 46,2518 & 55,8391 & 18,00 & 75,00 \\
\hline Setor Público & 8 & 40,6250 & 6,27780 & 2,21954 & 35,3766 & 45,8734 & 29,00 & 47,00 \\
\hline Terceiro Setor & 1 & 59,0000 & & . & & & 59,00 & 59,00 \\
\hline Total & 189 & 51,7354 & 13,73084 & ,99877 & 49,7652 & 53,7057 & 18,00 & 75,00 \\
\hline
\end{tabular}

\subsection{Análise Estatística dos Dados de Importância dos Facilitadores Organizacionais para a Gestão de Projetos}

A análise da importância dos facilitadores organizacionais para a gestão de projetos apontou justificativa estatística consistente (Sig.0,015) permitindo inferir que organizações de grande porte (faturamento anual superior a $\mathrm{R} \$ 300$ milhões) parecem dar maior importância ao tema do que que organizações pequenas e de médio porte (Tabela 5).

Aponta-se, em especial, uma maior importância dada a treinamento (Sig.0,013), alinhamento do projeto à estratégia (Sig.0,013), disponibilização de sistemas de gestão de projetos (Sig.0,033), alocação de patrocinadores (Sig.0,000) e utilização de critérios múltiplos de avaliação (Sig. 0,015).

Tabela 5. Importância dos Facilitadores Organizacionais por Faturamento

\begin{tabular}{|c|c|c|c|c|c|c|}
\hline \multicolumn{4}{|l|}{ Ordens } & \multicolumn{3}{|c|}{ Testes Estatísticos ${ }^{\text {a,b }}$} \\
\hline $\begin{array}{l}\text { Facilitadores } \\
\text { Organizacionais }\end{array}$ & Faturamento & $\mathbf{N}$ & \begin{tabular}{|l|} 
Ordem \\
das \\
medianas
\end{tabular} & $\begin{array}{l}\text { Chi- } \\
\text { quad. }\end{array}$ & df & $\begin{array}{l}\text { Sig. } \\
\text { Assint. }\end{array}$ \\
\hline \multirow{3}{*}{$\begin{array}{l}\text { Importância de todos os } \\
\text { facilitadores } \\
\text { organizacionais }\end{array}$} & PME <R \$ 300 milhões & 108 & 95,63 & \multirow{3}{*}{5,885} & \multirow{3}{*}{1} & \multirow{3}{*}{, 015} \\
\hline & Grande :R\$ 300 milhões & 102 & 115,96 & & & \\
\hline & Total & 210 & & & & \\
\hline \multirow{3}{*}{$\begin{array}{l}\text { Sobrevivência de longo } \\
\text { prazo }\end{array}$} & PME <R \$ 300 milhões & 108 & 104,73 & \multirow{3}{*}{, 049} & \multirow{3}{*}{1} & \multirow{3}{*}{, 825} \\
\hline & Grande :R\$ 300 milhões & 102 & 106,32 & & & \\
\hline & Total & 210 & & & & \\
\hline \multirow{2}{*}{$\begin{array}{l}\text { Sustentação de } \\
\text { vantagem competitiva }\end{array}$} & PME <R \$ 300 milhões & 108 & 105,81 & \multirow{2}{*}{, 008} & \multirow{2}{*}{1} & \multirow{2}{*}{,930 } \\
\hline & Grande :R\$ 300 milhões & 102 & 105,17 & & & \\
\hline
\end{tabular}




\begin{tabular}{|c|c|c|c|c|c|c|}
\hline & Total & 210 & & & & \\
\hline \multirow{3}{*}{$\begin{array}{l}\text { Treinamento em gestão } \\
\text { de projetos }\end{array}$} & PME <R \$ 300 milhões & 108 & 95,72 & \multirow{3}{*}{6,190} & \multirow{3}{*}{1} & \multirow{3}{*}{013} \\
\hline & Grande :R\$ 300 milhões & 102 & 115,85 & & & \\
\hline & Total & 210 & & & & \\
\hline \multirow{3}{*}{$\begin{array}{l}\text { Alinhamento dos } \\
\text { projetos à estratégia } \\
\text { organizacional }\end{array}$} & PME <R \$ 300 milhões & 108 & 95,81 & \multirow{3}{*}{6,119} & \multirow{3}{*}{1} & \multirow{3}{*}{013} \\
\hline & Grande :R\$ 300 milhões & 102 & 115,75 & & & \\
\hline & Total & 210 & & & & \\
\hline \multirow{3}{*}{$\begin{array}{l}\text { Disponibilização de } \\
\text { recursos }\end{array}$} & PME <R \$ 300 milhões & 108 & 101,34 & \multirow{3}{*}{1,160} & \multirow{3}{*}{1} & \multirow{3}{*}{,281 } \\
\hline & Grande :R\$ 300 milhões & 102 & 109,90 & & & \\
\hline & Total & 210 & & & & \\
\hline \multirow{3}{*}{$\begin{array}{l}\text { Disponibilização de } \\
\text { sistemas de gestão de } \\
\text { projetos }\end{array}$} & PME <R \$ 300 milhões & 108 & 97,24 & \multirow{3}{*}{4,522} & \multirow{3}{*}{1} & \multirow{3}{*}{, 033} \\
\hline & Grande :R\$ 300 milhões & 102 & 114,25 & & & \\
\hline & Total & 210 & & & & \\
\hline \multirow{3}{*}{$\begin{array}{l}\text { Alocação de } \\
\text { patrocinadores }\end{array}$} & PME <R \$ 300 milhões & 108 & 89,77 & \multirow{3}{*}{15,988} & \multirow{3}{*}{1} & \multirow{3}{*}{, 000} \\
\hline & Grande :R\$ 300 milhões & 102 & 122,15 & & & \\
\hline & Total & 210 & & & & \\
\hline \multirow{3}{*}{$\begin{array}{l}\text { Utilização de critérios } \\
\text { de avaliação }\end{array}$} & PME <R \$ 300 milhões & 108 & 95,89 & \multirow{3}{*}{5,933} & \multirow{3}{*}{1} & \multirow{3}{*}{, 015} \\
\hline & Grande :R\$ 300 milhões & 102 & 115,68 & & & \\
\hline & \begin{tabular}{|l|} 
Total \\
\end{tabular} & 210 & & & & \\
\hline \multirow{3}{*}{$\begin{array}{l}\text { Concessão de autonomia } \\
\text { aos Gerentes de Projetos }\end{array}$} & PME <R \$ 300 milhões & 108 & 104,30 & \multirow{3}{*}{,095 } & \multirow{3}{*}{1} & \multirow{3}{*}{,757 } \\
\hline & Grande :R\$ 300 milhões & 102 & 106,77 & & & \\
\hline & Total & 210 & & & & \\
\hline
\end{tabular}

a. Teste de Kruskal Wallisb. Variável de Agrupamento: Faturamento

Entretanto, analisando-se um a importância dada aos facilitadores organizacionais em grandes organizações (com mais de 500 funcionários) e pequenas e médias organizações (com menos de 500 funcionários), não foram encontradas justificativas estatísticas que apontassem diferenças significativas (Sig. 0,2510).

Já a importância dada para a alocação de patrocinadores para os projetos (Sig. 0,010) mostrou-se maior em grandes organizações (com mais de 500 funcionários) do que em pequenas e médias organizações (com menos de 500 funcionários).

Quando analisada a importância dada aos facilitadores organizacionais por setor de atividade (serviços, comercial, manufatureiro, setor público e terceiro setor), também não foram encontradas justificativas estatísticas suficientes que permitissem identificar diferenças significativas entre os setores (Tabela 6). Tanto para cada setor individualmente (Sig. 0,064) quanto ao comparando manufatura com os demais setores (Sig.0,769). 
Tabela 6. Importância dos Facilitadores Organizacionais por Setor

\begin{tabular}{|c|c|c|c|c|c|c|}
\hline \multicolumn{4}{|l|}{ Ordens } & \multicolumn{3}{|c|}{ Testes Estatísticos ${ }^{\text {a,b }}$} \\
\hline & Setor & $\mathbf{N}$ & $\begin{array}{l}\text { Ordem } \\
\text { das } \\
\text { medianas }\end{array}$ & $\begin{array}{l}\text { Chi- } \\
\text { quad. }\end{array}$ & df & $\begin{array}{l}\text { Sig. } \\
\text { Assint. }\end{array}$ \\
\hline \multirow{6}{*}{$\begin{array}{l}\text { Importância } \\
\text { Geral }\end{array}$} & Serviços & 144 & 107,03 & \multirow{6}{*}{8,889} & \multirow{6}{*}{4} & \multirow{6}{*}{,064 } \\
\hline & Comercial & 3 & 151,50 & & & \\
\hline & Manufatureiro & 53 & 102,90 & & & \\
\hline & Setor Público & 8 & 55,63 & & & \\
\hline & Terceiro Setor & 1 & 180,00 & & & \\
\hline & Total & 209 & & & & \\
\hline
\end{tabular}

\begin{tabular}{|c|c|c|c|c|c|c|}
\hline \multicolumn{4}{|l|}{ Ordens } & \multicolumn{3}{|c|}{ Testes Estatísticos ${ }^{\text {a,c }}$} \\
\hline & Setor Agrupado & $\mathbf{N}$ & $\begin{array}{l}\text { Ordem } \\
\text { das } \\
\text { medianas }\end{array}$ & $\begin{array}{l}\text { Chi- } \\
\text { quad. }\end{array}$ & df & $\begin{array}{l}\text { Sig. } \\
\text { Assint. }\end{array}$ \\
\hline \multirow{3}{*}{$\begin{array}{l}\text { Importância } \\
\text { Geral }\end{array}$} & $\begin{array}{l}\text { Serviços, Comercial, } \\
\text { Setor Público e } 3^{\circ} \text { Setor }\end{array}$ & 156 & 105,71 & \multirow{3}{*}{, 086} & \multirow{3}{*}{1} & \multirow{3}{*}{,769 } \\
\hline & Manufatureira & 53 & 102,90 & & & \\
\hline & Total & 209 & & & & \\
\hline
\end{tabular}

a. Teste de Kruskal Wallis b. Variável de Agrupamento: Setor c. Variável de Agrupamento: Setor Agrupado

Da mesma forma, quando analisada a importância dos facilitadores organizacionais considerando a origem da organização do respondente (latino americana, norte americana, europeia ou asiática), também não foram encontradas justificativas estatísticas suficientes que permitissem apontar diferenças significativas (Tabela 7). Tanto para cada setor individualmente (Sig. 0,058) quanto ao comparando manufatura com os demais setores (Sig.0, 479).

Tabela 7. Importância dos Facilitadores Organizacionais por Origem da Organização

\begin{tabular}{|c|c|c|c|c|c|c|}
\hline \multicolumn{4}{|l|}{ Ordens } & \multicolumn{3}{|c|}{ Testes Estatísticos $^{\text {a,b }}$} \\
\hline $\begin{array}{l}\text { Importância dos } \\
\text { facilitadores } \\
\text { organizacionais }\end{array}$ & Origem & $\mathbf{N}$ & $\begin{array}{l}\text { Ordem } \\
\text { das } \\
\text { medianas }\end{array}$ & $\begin{array}{l}\text { Chi- } \\
\text { quad. }\end{array}$ & df & $\begin{array}{l}\text { Sig. } \\
\text { Assint. }\end{array}$ \\
\hline \multirow{5}{*}{ Importância Geral } & Latino americana & 144 & 102,53 & \multirow{5}{*}{7,479} & \multirow{5}{*}{3} & \multirow{5}{*}{, 058} \\
\hline & Norte americana & 22 & 127,32 & & & \\
\hline & Européia & 39 & 94,24 & & & \\
\hline & Asiática & 3 & 164,83 & & & \\
\hline & Total & 208 & & & & \\
\hline
\end{tabular}

\begin{tabular}{|l|l|l|l|l|l|l|}
\hline Ordens & \multicolumn{3}{|l|}{ Testes Estatísticos } \\
\hline $\begin{array}{l}\text { Importância dos } \\
\text { facilitadores }\end{array}$ & Origem Agrupada & $\mathrm{N}$ & $\begin{array}{l}\text { Ordem } \\
\text { das }\end{array}$ & $\begin{array}{l}\text { Chi- } \\
\text { quad. }\end{array}$ & df & $\begin{array}{l}\text { Sig. } \\
\text { Assint. }\end{array}$ \\
\hline
\end{tabular}




\begin{tabular}{|l|l|l|l|l|l|l|}
\hline organizacionais & & & medianas & & \\
\hline \multirow{5}{*}{ Importância Geral } & Latino americanas & 144 & 102,53 & & & \multirow{2}{*}{, 479} \\
\cline { 2 - 4 } & $\begin{array}{l}\text { Norte americanas, } \\
\text { Européias e } \\
\text { Asiáticas }\end{array}$ & 64 & 108,92 &, 500 & 1 &, 49 \\
\cline { 2 - 5 } & Total & 208 & & & \\
\hline
\end{tabular}

a. Teste de KW $\quad$ b.Variável de Agrup.: Origem $\quad$ c. Variável de Agrup.: Origem Agrupada

Ainda neste contexto, encontraram-se justificativas estatísticas para inferir que respondentes de posições de alta e média-gerência (presidência, vice-presidência, diretoria, superintendência e gerência) parecem dar maior importância aos facilitadores organizacionais que seus colegas de níveis hierárquicos tático-operacionais (coordenadores, analistas, trainees e estagiários) (Sig. 0,021)

Assim como parecem dar maior importância para sobrevivência de longo prazo (Sig.0,009), sustentação de vantagem competitiva (Sig.0,045), disponibilização de sistema de gestão de projetos (Sig.0,038) e concessão de autonomia aos gestores de projetos (Sig.0,040) Tabela 8.

Tabela 8. Importância dos Facilitadores Organizacionais por Nível Hierárquico

\begin{tabular}{|c|c|c|c|c|c|c|}
\hline \multicolumn{4}{|l|}{ Ordens } & \multicolumn{3}{|c|}{ Testes Estatísticos $^{\mathrm{a}, \mathrm{b}}$} \\
\hline $\begin{array}{l}\text { Importância dos } \\
\text { Facilitadores } \\
\text { Organizacionais }\end{array}$ & $\begin{array}{l}\text { Nível hierárquico do } \\
\text { Respondente }\end{array}$ & $\mathbf{N}$ & $\begin{array}{l}\text { Ordem } \\
\text { das } \\
\text { medianas }\end{array}$ & $\begin{array}{l}\text { Chi- } \\
\text { quad. }\end{array}$ & df & $\begin{array}{l}\text { Sig. } \\
\text { Assint. }\end{array}$ \\
\hline Importância geral & $\begin{array}{l}\text { Operacional } \\
\text { Estratégico } \\
\text { Total }\end{array}$ & $\begin{array}{l}109 \\
103 \\
212\end{array}$ & $\begin{array}{l}97,08 \\
116,47\end{array}$ & 5,299 & 1 &, 021 \\
\hline $\begin{array}{l}\text { Sobrevivência de longo } \\
\text { prazo }\end{array}$ & $\begin{array}{l}\text { Operacional } \\
\text { Estratégico } \\
\text { Total }\end{array}$ & $\begin{array}{l}109 \\
103 \\
212\end{array}$ & $\begin{array}{l}97,26 \\
116,28\end{array}$ & 6,868 & 1 & ,009 \\
\hline $\begin{array}{l}\text { Sustentação de vantagem } \\
\text { competitiva }\end{array}$ & $\begin{array}{l}\text { Operacional } \\
\text { Estratégico } \\
\text { Total }\end{array}$ & $\begin{array}{l}109 \\
103 \\
212\end{array}$ & $\begin{array}{l}99,28 \\
114,15\end{array}$ & 4,034 & 1 &, 045 \\
\hline $\begin{array}{l}\text { Treinamento em gestão de } \\
\text { projetos }\end{array}$ & $\begin{array}{l}\text { Operacional } \\
\text { Estratégico } \\
\text { Total }\end{array}$ & $\begin{array}{l}109 \\
103 \\
212\end{array}$ & $\begin{array}{l}101,45 \\
111,84\end{array}$ & 1,633 & 1 &, 201 \\
\hline $\begin{array}{l}\text { Alinhamento dos projetos à } \\
\text { estratégia organizacional }\end{array}$ & $\begin{array}{l}\text { Operacional } \\
\text { Estratégico } \\
\text { Total }\end{array}$ & $\begin{array}{l}109 \\
103 \\
212 \\
\end{array}$ & $\begin{array}{l}100,22 \\
113,15\end{array}$ & 2,552 & 1 &, 110 \\
\hline $\begin{array}{l}\text { Disponibilização de } \\
\text { recursos }\end{array}$ & $\begin{array}{l}\text { Operacional } \\
\text { Estratégico } \\
\text { Total }\end{array}$ & $\begin{array}{l}109 \\
103 \\
212\end{array}$ & $\begin{array}{l}101,00 \\
112,32\end{array}$ & 2,011 & 1 &, 156 \\
\hline $\begin{array}{l}\text { Disponibilização de } \\
\text { sistemas de gestão de }\end{array}$ & $\begin{array}{l}\text { Operacional } \\
\text { Estratégico }\end{array}$ & $\begin{array}{l}109 \\
103\end{array}$ & $\begin{array}{l}98,41 \\
115,06\end{array}$ & 4,288 & 1 &, 038 \\
\hline
\end{tabular}




\begin{tabular}{|c|c|c|c|c|c|c|}
\hline projetos & Total & 212 & & & & \\
\hline Alocação de patrocinadores & $\begin{array}{l}\text { Operacional } \\
\text { Estratégico } \\
\text { Total }\end{array}$ & \begin{tabular}{|l|}
109 \\
103 \\
212
\end{tabular} & $\begin{array}{l}103,37 \\
109,82\end{array}$ & ,629 & 1 & ,428 \\
\hline $\begin{array}{l}\text { Utilização de critérios de } \\
\text { avaliação }\end{array}$ & $\begin{array}{l}\text { Operacional } \\
\text { Estratégico } \\
\text { Total }\end{array}$ & \begin{tabular}{|l|}
109 \\
103 \\
212
\end{tabular} & $\begin{array}{l}100,27 \\
113,10\end{array}$ & 2,469 & 1 &, 116 \\
\hline $\begin{array}{l}\text { Concessão de autonomia } \\
\text { aos Gerentes de Projetos }\end{array}$ & $\begin{array}{l}\text { Operacional } \\
\text { Estratégico } \\
\text { Total }\end{array}$ & $\begin{array}{l}109 \\
103 \\
212\end{array}$ & $\begin{array}{l}98,47 \\
115,00\end{array}$ & 4,221 & 1 &, 040 \\
\hline
\end{tabular}

a. Teste de Kruskal Wallis b. Variável de Agrupamento: Nível hierárquico agrupado

Já respondentes mais experientes (com mais de 10 anos de experiência) parecem dar maior importância aos facilitadores organizacionais (Sig. 0,021) do que seus colegas menos experientes.

Esta importância é maior, em especial, para o alinhamento estratégico (Sig.0,003), sobrevivência a longo prazo (Sig.0,009), sustentação de vantagem competitiva (Sig.0,045), disponibilização de sistemas de gestão de projetos (Sig.0,038), e concessão de autonomia par aos gerentes de projeto (Sig. 0,040) como se pode notar na Tabela 9.

Tabela 9. Importância dos Facilitadores Organizacionais por Experiência

\begin{tabular}{|c|c|c|c|c|c|c|}
\hline \multicolumn{4}{|l|}{ Ordens } & \multicolumn{3}{|c|}{ Testes Estatísticos $^{\mathbf{a}, \mathrm{b}}$} \\
\hline $\begin{array}{l}\text { Importância dos } \\
\text { Facilitadores } \\
\text { Organizacionais }\end{array}$ & $\begin{array}{l}\text { Experiência Total } \\
\text { do Respondente }\end{array}$ & $\mathbf{N}$ & $\begin{array}{l}\text { Ordem } \\
\text { das } \\
\text { medianas }\end{array}$ & $\begin{array}{l}\text { Chi- } \\
\text { quad. }\end{array}$ & df & $\begin{array}{l}\text { Sig. } \\
\text { Assint. }\end{array}$ \\
\hline Importância geral & $\begin{array}{l}\text { Menor que } 10 \text { anos } \\
\text { Maior que } 10 \text { anos } \\
\text { Total }\end{array}$ & $\begin{array}{l}62 \\
149 \\
211\end{array}$ & $\begin{array}{l}86,37 \\
114,17\end{array}$ & 9,095 & 1 &, 003 \\
\hline $\begin{array}{l}\text { Sobrevivência de longo } \\
\text { prazo }\end{array}$ & $\begin{array}{l}\text { Menor que } 10 \text { anos } \\
\text { Maior que } 10 \text { anos } \\
\text { Total }\end{array}$ & $\begin{array}{l}62 \\
149 \\
211\end{array}$ & $\begin{array}{l}93,04 \\
111,39\end{array}$ & 5,350 & 1 &, 021 \\
\hline $\begin{array}{l}\text { Sustentação de vantagem } \\
\text { competitiva }\end{array}$ & $\begin{array}{l}\text { Menor que } 10 \text { anos } \\
\text { Maior que } 10 \text { anos } \\
\text { Total }\end{array}$ & $\begin{array}{l}62 \\
149 \\
211\end{array}$ & $\begin{array}{l}96,40 \\
110,00\end{array}$ & 2,811 & 1 &, 003 \\
\hline $\begin{array}{l}\text { Treinamento em gestão } \\
\text { de projetos }\end{array}$ & $\begin{array}{l}\text { Menor que } 10 \text { anos } \\
\text { Maior que } 10 \text { anos } \\
\text { Total }\end{array}$ & $\begin{array}{l}62 \\
149 \\
211\end{array}$ & $\begin{array}{l}95,56 \\
110,35\end{array}$ & 2,765 & 1 & ,096 \\
\hline $\begin{array}{l}\text { Alinhamento dos } \\
\text { projetos à estratégia } \\
\text { organizacional }\end{array}$ & $\begin{array}{l}\text { Menor que } 10 \text { anos } \\
\text { Maior que } 10 \text { anos } \\
\text { Total }\end{array}$ & $\begin{array}{l}62 \\
149 \\
211\end{array}$ & $\begin{array}{l}94,72 \\
110,69\end{array}$ & 3,246 & 1 &, 072 \\
\hline $\begin{array}{l}\text { Disponibilização de } \\
\text { recursos }\end{array}$ & $\begin{array}{l}\text { Menor que } 10 \text { anos } \\
\text { Maior que } 10 \text { anos }\end{array}$ & \begin{tabular}{|l|}
62 \\
149
\end{tabular} & $\begin{array}{l}91,45 \\
112,05\end{array}$ & 5,551 & 1 &, 018 \\
\hline
\end{tabular}




\begin{tabular}{|c|c|c|c|c|c|c|}
\hline & Total & | 211 & & & & \\
\hline $\begin{array}{l}\text { Disponibilização de } \\
\text { sistemas de gestão de } \\
\text { projetos }\end{array}$ & $\begin{array}{l}\text { Menor que } 10 \text { anos } \\
\text { Maior que } 10 \text { anos } \\
\text { Total }\end{array}$ & $\begin{array}{l}62 \\
149 \\
211\end{array}$ & \begin{tabular}{|l|}
87,28 \\
113,79
\end{tabular} & 9,051 & 1 & ,003 \\
\hline $\begin{array}{l}\text { Alocação de } \\
\text { patrocinadores }\end{array}$ & $\begin{array}{l}\text { Menor que } 10 \text { anos } \\
\text { Maior que } 10 \text { anos } \\
\text { Total }\end{array}$ & \begin{tabular}{|l|}
62 \\
149 \\
211 \\
\end{tabular} & \begin{tabular}{|l|}
87,00 \\
113,91
\end{tabular} & 9,152 & 1 & ,002 \\
\hline $\begin{array}{l}\text { Utilização de critérios de } \\
\text { avaliação }\end{array}$ & $\begin{array}{l}\text { Menor que } 10 \text { anos } \\
\text { Maior que } 10 \text { anos } \\
\text { Total }\end{array}$ & $\begin{array}{l}62 \\
149 \\
211\end{array}$ & $\begin{array}{l}90,64 \\
112,39\end{array}$ & 5,926 & 1 &, 015 \\
\hline $\begin{array}{l}\text { Concessão de autonomia } \\
\text { aos Gerentes de Projetos }\end{array}$ & $\begin{array}{l}\text { Menor que } 10 \text { anos } \\
\text { Maior que } 10 \text { anos } \\
\text { Total }\end{array}$ & $\begin{array}{l}62 \\
149 \\
211\end{array}$ & $\begin{array}{l}93,83 \\
111,06\end{array}$ & 3,828 & 1 & ,050 \\
\hline
\end{tabular}

a. Teste de Kruskal Wallis b. Variável de Agrupamento: Experiência total agrupada

O respondente possuir ou não certificações em gestão de projetos (PMI, CAPM, PMP, OGG, PRINCE2), gestão de qualidade (SixSigma), ou outras relacionadas à gestão, não provoca diferenças estatisticamente justificáveis em relação à importância dos facilitadores organizacionais em geral (Sig. 0,938) ou mesmo para nenhum dos itens individualmente.

Separando-se as organizações em dois grupos distintos considerando a percepção de maturidade de gestão de projetos: 1) organizações com baixo grau de maturidade (níveis inferiores à mediana) e, 2) organizações com alto grau de maturidade (níveis superiores à mediana). Com base neste agrupamento, realizou-se uma análise para verificar a importância dada aos facilitadores organizacionais pelas organizações dada sua maturidade em gestão de projetos.

Assim, encontraram-se justificativas estatísticas para afirmar que organizações dão maior importância aos facilitadores organizacionais, possuem maior maturidade em gestão de projetos (Sig. 0,000), como pode ser observado na

Tabela 10.

Tabela 10. Importância dos Facilitadores Organizacionais por Nível de Maturidade em Gestão de Projetos

\begin{tabular}{|l|l|l|l|l|l|l|}
\hline Ordens & \multicolumn{3}{|c|}{ Testes Estatísticosa, } \\
\hline $\begin{array}{l}\text { Importância dos Facilitadores } \\
\text { Organizacionais }\end{array}$ & Maturidade & $\mathbf{N}$ & $\begin{array}{l}\text { Ordem } \\
\text { das } \\
\text { medianas }\end{array}$ & $\begin{array}{l}\text { Chi- } \\
\text { quad. }\end{array}$ & df & $\begin{array}{l}\text { Sig. } \\
\text { Assint. }\end{array}$ \\
\hline Importância geral & Baixa Maturidade & 97 & 66,53 & 58,150 & 1,000 &, 000 \\
\cline { 2 - 8 } & Alta Maturidade & 96 & 127,79 & \\
\hline
\end{tabular}




\begin{tabular}{|c|c|c|c|c|c|c|}
\hline & Total & 193 & & & & \\
\hline \multirow{3}{*}{$\begin{array}{l}\text { Reconhece a importância dos } \\
\text { projetos para a sobrevivência no } \\
\text { longo prazo }\end{array}$} & Baixa Maturidade & 97 & 79,39 & \multirow{3}{*}{26,161} & \multirow{3}{*}{1,000} & \multirow{3}{*}{, 000} \\
\hline & Alta Maturidade & 96 & \begin{tabular}{|l|}
114,79 \\
\end{tabular} & & & \\
\hline & Total & 193 & & & & \\
\hline \multirow{3}{*}{$\begin{array}{l}\text { Reconhece a importância dos } \\
\text { projetos para a criação e } \\
\text { sustentação de vantagem } \\
\text { competitiva }\end{array}$} & Baixa Maturidade & 97 & 78,00 & \multirow{3}{*}{29,876} & \multirow{3}{*}{1,000} & \multirow{3}{*}{, 000} \\
\hline & Alta Maturidade & 96 & 116,20 & & & \\
\hline & Total & 193 & & & & \\
\hline \multirow{3}{*}{$\begin{array}{l}\text { Treina as partes interessadas ou } \\
\text { impactadas stakeholders em } \\
\text { gestão de projetos }\end{array}$} & Baixa Maturidade & 97 & 72,21 & \multirow{3}{*}{41,189} & \multirow{3}{*}{1,000} & \multirow{3}{*}{, 000} \\
\hline & Alta Maturidade & 96 & 122,05 & & & \\
\hline & Total & 193 & & & & \\
\hline \multirow{3}{*}{$\begin{array}{l}\text { Promove o alinhamento dos } \\
\text { projetos estratégia organizacional }\end{array}$} & Baixa Maturidade & 97 & 75,83 & \multirow{3}{*}{30,522} & \multirow{3}{*}{1,000} & \multirow{3}{*}{, 000} \\
\hline & Alta Maturidade & 96 & 118,39 & & & \\
\hline & Total & 193 & & & & \\
\hline \multirow{3}{*}{$\begin{array}{l}\text { Disponibiliza os recursos } \\
\text { necessários ao sucesso dos } \\
\text { projetos }\end{array}$} & Baixa Maturidade & 97 & 79,24 & \multirow{3}{*}{22,142} & \multirow{3}{*}{1,000} & \multirow{3}{*}{,000 } \\
\hline & Alta Maturidade & 96 & 114,95 & & & \\
\hline & Total & 193 & & & & \\
\hline \multirow{3}{*}{$\begin{array}{l}\text { Disponibiliza os sistemas de } \\
\text { gestão de projetos necessários ao } \\
\text { sucesso dos projetos }\end{array}$} & Baixa Maturidade & 97 & 75,30 & \multirow{3}{*}{32,102} & \multirow{3}{*}{1,000} & \multirow{3}{*}{, 000} \\
\hline & Alta Maturidade & 96 & 118,92 & & & \\
\hline & Total & 193 & & & & \\
\hline \multirow{3}{*}{$\begin{array}{l}\text { Aloca patrocinadores necessários } \\
\text { ao projeto }\end{array}$} & Baixa Maturidade & 97 & 81,51 & \multirow{3}{*}{16,110} & \multirow{3}{*}{1,000} & \multirow{3}{*}{, 000} \\
\hline & Alta Maturidade & 96 & 112,65 & & & \\
\hline & Total & 193 & & & & \\
\hline \multirow{3}{*}{$\begin{array}{l}\text { Usa critérios múltiplos para } \\
\text { avaliar o resultado dos projetos } \\
\text { como benefício retorno do } \\
\text { investimento ou sustentabilidade }\end{array}$} & Baixa Maturidade & 97 & 68,21 & \multirow{3}{*}{55,163} & \multirow{3}{*}{1,000} & \multirow{3}{*}{,000 } \\
\hline & Alta Maturidade & 96 & \begin{tabular}{|l|}
126,09 \\
\end{tabular} & & & \\
\hline & Total & 193 & & & & \\
\hline Dá autonomia necessária ao & Baixa Maturidade & 97 & 78,10 & & & \\
\hline gerente e equipe para alcançar os & Alta Maturidade & 96 & 116,09 & 24,306 & 1,000 & ,000 \\
\hline objetivos do projeto & Total & 193 & & & & \\
\hline
\end{tabular}

a. Teste de Kruskal Wallis

b. Variável de Agrupamento: Maturidade agrupada

Resumidamente, pode-se afirmar que os facilitadores organizacionais para a gestão de projetos são mais apreciados em organizações de grande porte (faturamento anual superior a R\$ 300 milhões) e que esta importância é indiferente ao setor ou a origem da organização.

Também se pode inferir que respondente mais experiente (com mais de 10 anos de experiência) e da alta e média-gerência dão maior importância aos facilitadores organizacionais do que seus colegas.

Finalmente, aponta-se uma relevante correlação entre a importância dada aos facilitadores organizacionais e a maturidade sendo que se pode verificar que organizações que dão maior importância aos facilitadores possuem maior maturidade em gestão de projetos.

\subsection{Análise Estatística dos Dados de Maturidade em Gestão de Projetos}


Como se pode verificar na Tabela 11, há justificativas estatísticas para afirmar que parece não existirem diferenças da maturidade de gestão de projetos de tecnologia da informação entres as organizações dos setores de serviços, manufatura/indústria, comercial/varejo, setor público e $3^{\circ}$ setor (Sig. 0,407).

Tabela 11. Maturidade por Setor de Atividade

\begin{tabular}{|c|l|r|r|}
\hline \multirow{2}{*}{ Percepção de Maturidade } & \multicolumn{1}{|c|}{ Setor de Atividade } & N & \multicolumn{1}{c|}{$\begin{array}{c}\text { Ordem das } \\
\text { medianas }\end{array}$} \\
\hline \multirow{4}{*}{$\begin{array}{l}\text { Grupos de Processos de Iniciação e } \\
\text { Planejamento }\end{array}$} & Serviços & 133 & 97,40 \\
\cline { 2 - 4 } & Comercial & 3 & 78,33 \\
\cline { 2 - 4 } & Sanufatureira & 44 & 93,42 \\
\cline { 2 - 4 } & Setor Público & 8 & 63,81 \\
\cline { 2 - 4 } & Terceiro Setor & 1 & 144,50 \\
\cline { 2 - 4 } & Total & $\mathbf{1 8 9}$ & \\
\hline
\end{tabular}

\begin{tabular}{|l|r|}
\hline \multicolumn{1}{|c|}{ Teste Estatístico(a,b) } & \multicolumn{2}{c|}{$\begin{array}{c}\text { Percepção de } \\
\text { Maturidade }\end{array}$} \\
\hline Chi-quad. & 3,993 \\
df & 4 \\
Sig. Assint. &, 407 \\
\hline
\end{tabular}

a. Teste de Kruskal Wallis

b. Variável de Agrupamento: Setor

Da mesma forma, há justificativas estatísticas para afirmar que parece não existirem diferenças entre a maturidade de gestão de projetos de tecnologia da informação das organizações de diversos tamanhos considerando-se faixas de faturamento (Sig. 0,132), como se pode verificar na Tabela 12.

Tabela 12. Maturidade por Faturamento Anual

\begin{tabular}{|l|l|r|r|}
\hline \multirow{2}{*}{ Percepção de Maturidade } & \multicolumn{1}{|c|}{$\begin{array}{c}\text { Faturamento ou Orçamento } \\
\text { Anual da Organização }\end{array}$} & N & $\begin{array}{c}\text { Ordem das } \\
\text { medianas }\end{array}$ \\
\hline \multirow{4}{*}{$\begin{array}{l}\text { Grupos de Processos de } \\
\text { Iniciação e Planejamento }\end{array}$} & Microempresa & 16 & 90,78 \\
\cline { 2 - 4 } & Pequena Empresa & 30 & 77,90 \\
\cline { 2 - 4 } & Média Empresa & 35 & 84,66 \\
\cline { 2 - 4 } & Média-Grande Empresa & 18 & 106,06 \\
\cline { 2 - 4 } & Grande Empresa & 90 & 103,26 \\
\cline { 2 - 4 } & Total & $\mathbf{1 8 9}$ & \\
\hline
\end{tabular}

\begin{tabular}{|l|r|}
\hline \multicolumn{1}{|c|}{ Teste Estatístico (a,b) } & Percepção de Maturidade \\
\hline Chi-quad. & 7,069 \\
df & 4 \\
Sig. Assint. &, 132 \\
\hline
\end{tabular}

a. Teste de Kruskal Wallis

b. Variável de Agrupamento: Faturamento Anual 
Assim, há justificativas estatísticas para afirmar que parece não existirem diferenças entre a maturidade de gestão de projetos de tecnologia da informação das organizações de diversos tamanhos considerando-se número de funcionários (Sig. 0,124), conforme Tabela 13.

Tabela 13. Maturidade por Quantidade de Funcionários

\begin{tabular}{|l|l|r|r|}
\hline \multirow{2}{*}{ Percepção de Maturidade } & \multicolumn{1}{|c|}{ Quantidade de funcionários } & N & \multicolumn{1}{c|}{$\begin{array}{c}\text { Ordem das } \\
\text { medianas }\end{array}$} \\
\hline \multirow{4}{*}{$\begin{array}{l}\text { Grupos de Processos de Iniciação e } \\
\text { Planejamento }\end{array}$} & de 0 a 9 funcionários & 11 & 97,05 \\
\cline { 2 - 4 } & de 10 a 49 funcionários & 21 & 87,45 \\
\cline { 2 - 4 } & de 50 a 249 funcionários & 34 & 79,56 \\
\cline { 2 - 4 } & de 250 a 499 funcionários & 24 & 84,77 \\
\cline { 2 - 4 } & 500 funcionários ou mais & 100 & 105,02 \\
\cline { 2 - 4 } & Total & $\mathbf{1 9 0}$ & \\
\hline
\end{tabular}

\begin{tabular}{|l|r|}
\hline \multicolumn{1}{|c|}{ Teste Estatístico (a,b) } & \multicolumn{2}{|c|}{ Maturidade } \\
\hline Chi-quad. & 7,226 \\
df & 4 \\
Sig. Assint. &, 124 \\
\hline
\end{tabular}

a. Teste de Kruskal Wallis

b. Variável de Agrupamento: Quantidade de funcionários

Entretanto, ao se dividir as organizações em dois agrupamentos distintos sendo o primeiro composto por organizações de grande porte com faturamento anual maior que $\mathrm{R} \$ 300$ milhões e o segundo com as demais, encontrou-se evidências estatísticas para afirmar que as grandes organizações parecem ter maior maturidade em gestão de projetos de tecnologia da informação do que as demais (Sig. 0,048), conforme Tabela 14.

Tabela 14. Maturidade por Agrupamento de Faturamento

\begin{tabular}{|c|c|c|c|}
\hline Percepção de Maturidade & $\begin{array}{l}\text { Tamanho das empresas por } \\
\text { faturamento (agrup.) }\end{array}$ & $\mathbf{N}$ & $\begin{array}{c}\text { Ordem das } \\
\text { medianas }\end{array}$ \\
\hline \multirow{3}{*}{$\begin{array}{l}\text { Grupos de Processos de } \\
\text { Iniciação e Planejamento }\end{array}$} & $\begin{array}{l}\text { Microempresa, Pequena Empresa, } \\
\text { Média Empresa e Média-Grande } \\
\text { Empresa }\end{array}$ & 99 & 87,49 \\
\hline & Grande Empresa & 90 & 103,26 \\
\hline & Total & 189 & \\
\hline
\end{tabular}

\begin{tabular}{|l|r|}
\hline \multicolumn{1}{|c|}{ Teste Estatístico (a,b) } & Percepção de Maturidade \\
\hline Chi-quad. & 3,920 \\
df & 1 \\
Sig. Assint. &, 048 \\
\hline
\end{tabular}


Tal qual se aferiu, ao se dividir as mesmas organizações em dois agrupamentos distintos sendo o primeiro composto por grandes organizações com mais de 500 funcionários e o segundo grupo com as que possuem menos de 499 funcionários, apontou-se evidências estatísticas para afirmar que organizações com mais de 500 funcionários parecem apresentar maior maturidade em gestão de projetos de tecnologia da informação do que as que possuem menos funcionários (Sig. 0,012), como apresentado na Tabela 15.

Tabela 15. Maturidade por Agrupamento de Quantidade de Funcionários

\begin{tabular}{|l|l|r|r|}
\hline \multicolumn{1}{|c|}{ Percepção de Maturidade } & \multicolumn{1}{|c|}{$\begin{array}{c}\text { Quantidade de Funcionários } \\
\text { (agrup.) }\end{array}$} & $\begin{array}{c}\text { Ordem } \\
\text { das } \\
\text { medianas }\end{array}$ \\
\hline \multirow{2}{*}{$\begin{array}{l}\text { Grupos de Processos de Iniciação e } \\
\text { Planejamento }\end{array}$} & de 0 a 499 funcionários & 90 & 84,93 \\
\cline { 2 - 4 } & 500 funcionários ou mais & 100 & 105,02 \\
\cline { 2 - 4 } & Total & 190 & \\
\hline
\end{tabular}

\begin{tabular}{|l|r|}
\hline \multicolumn{1}{|c|}{ Teste Estatístico (a,b) } & \multicolumn{2}{|c|}{ Percepção de Maturidade } \\
\hline Chi-quad. & 6,323 \\
Df & 1 \\
Sig. Assint. &, 012 \\
\hline
\end{tabular}

a. Teste de Kruskal Wallis b. Variável de Agrupamento: Quantidade de funcionários agrupados

Subsequentemente, buscou-se analisar o impacto do tamanho das organizações, por meio das variáveis faturamento e quantidade de funcionários, na percepção da maturidade organizacional de gestão de projetos de tecnologia de informação. Tanto nas faixas propostas pelo IBGE e que foram utilizadas na pesquisa quanto em agrupamentos destas faixas feitos por conveniência.

Ao analisar as organizações de setores de atividade e de tamanhos semelhantes em termos de número de funcionários ou faturamento, não foi encontrada justificativa estatística para afirmar que a maturidade de gestão de projetos de tecnologia de informação fosse semelhante em organizações do mesmo tamanho e setor como será demonstrado a seguir.

Como se pode verificar na Tabela 16, há justificativas estatísticas para afirmar que parece não existirem diferenças da maturidade de gestão de projetos de tecnologia da informação entres as organizações de tamanhos semelhantes (faturamento) no seu setor de atividade (Sig. 0,182). 


\begin{tabular}{|c|c|c|c|c|}
\hline $\begin{array}{l}\text { Percepção de } \\
\text { Maturidade } \\
\end{array}$ & $\begin{array}{c}\text { Setor de } \\
\text { Atividade }\end{array}$ & $\begin{array}{c}\text { Tamanho da organização } \\
\text { por faturamento }\end{array}$ & $\mathbf{N}$ & $\begin{array}{l}\text { Ordem das } \\
\text { medianas }\end{array}$ \\
\hline \multirow{19}{*}{$\begin{array}{l}\text { Grupos de Processos } \\
\text { de Iniciação e } \\
\text { Planejamento }\end{array}$} & \multirow{5}{*}{ Serviços } & Microempresa & 13 & 86,77 \\
\hline & & Pequena Empresa & 24 & 85,69 \\
\hline & & Média Empresa & 28 & 86,29 \\
\hline & & Média-Grande Empresa & 13 & 115,77 \\
\hline & & Grande Empresa & 54 & 105,75 \\
\hline & \multirow{3}{*}{ Comercial } & Pequena Empresa & 1 & 30,00 \\
\hline & & Média Empresa & 1 & 184,50 \\
\hline & & Grande Empresa & 1 & 17,50 \\
\hline & \multirow{5}{*}{ Manufatureira } & Microempresa & 2 & 88,00 \\
\hline & & Pequena Empresa & 3 & 77,50 \\
\hline & & Média Empresa & 5 & 56,20 \\
\hline & & Média-Grande Empresa & 3 & 77,50 \\
\hline & & Grande Empresa & 31 & 101,56 \\
\hline & \multirow{4}{*}{ Setor Público } & Pequena Empresa & 2 & 5,50 \\
\hline & & Média Empresa & 1 & 77,00 \\
\hline & & Média-Grande Empresa & 2 & 83,75 \\
\hline & & Grande Empresa & 3 & 82,83 \\
\hline & Terceiro Setor & Microempresa & 1 & 143,50 \\
\hline & & Total & 188 & \\
\hline
\end{tabular}

\begin{tabular}{|l|r|}
\hline Teste Estatístico $^{(a, b)}$ & \multicolumn{1}{|c|}{$\begin{array}{c}\text { Percepção de } \\
\text { Maturidade }\end{array}$} \\
\hline Chi-quad. & 22,072 \\
Df & 17 \\
Sig. Assint. &, 182 \\
\hline
\end{tabular}

a. Teste de Kruskal Wallis b. Variável de Agrupamento: Setor e faturamento

Há justificativas estatísticas para afirmar que parece não existirem diferenças da maturidade de gestão de projetos de tecnologia da informação entres as organizações de tamanhos semelhantes (número de funcionários) no seu setor de atividade (Sig. 0,217), como se pode verificar na Tabela 17.

Tabela 17. Maturidade por Setor e Quantidade de Funcionários

\begin{tabular}{|c|c|c|c|c|}
\hline $\begin{array}{l}\text { Percepção de } \\
\text { Maturidade }\end{array}$ & $\begin{array}{c}\text { Setor de } \\
\text { Atividade }\end{array}$ & $\begin{array}{l}\text { Tamanho da organização por } \\
\text { quantidade de funcionários }\end{array}$ & $\mathbf{N}$ & $\begin{array}{c}\text { Ordem das } \\
\text { medianas }\end{array}$ \\
\hline \multirow{10}{*}{$\begin{array}{l}\text { Percepção de } \\
\text { Maturidade nos } \\
\text { Grupos de Processos } \\
\text { de Iniciação e } \\
\text { Planejamento }\end{array}$} & \multirow{5}{*}{ Serviços } & de 0 a 9 funcionários & 10 & 92,00 \\
\hline & & de 10 a 49 funcionários & 18 & 89,42 \\
\hline & & de 50 a 249 funcionários & 29 & 81,53 \\
\hline & & de 250 a 499 funcionários & 13 & 100,19 \\
\hline & & 500 funcionários ou mais & 63 & 107,27 \\
\hline & \multirow{2}{*}{ Comercial } & de 10 a 49 funcionários & 2 & 108,25 \\
\hline & & 500 funcionários ou mais & 1 & 18,50 \\
\hline & \multirow{3}{*}{ Manufatureira } & de 10 a 49 funcionários & 1 & 5,50 \\
\hline & & de 50 a 249 funcionários & 4 & 83,38 \\
\hline & & de 250 a 499 funcionários & 7 & 67,71 \\
\hline
\end{tabular}




\begin{tabular}{|l|l|l|r|r|}
\hline & & 500 funcionários ou mais & 32 & 103,05 \\
\cline { 2 - 5 } & \multirow{4}{*}{ Setor Público } & de 50 a 249 funcionários & 1 & 1,50 \\
\cline { 3 - 5 } & & de 250 a 499 funcionários & 4 & 63,75 \\
\cline { 2 - 5 } & 500 funcionários ou mais & 3 & 84,67 \\
\cline { 2 - 5 } & Terceiro Setor & de 0 a 9 funcionários & 1 & 144,50 \\
\cline { 2 - 5 } & & Total & 189 & \\
\hline
\end{tabular}

\begin{tabular}{|l|r|}
\hline Teste Estatístico $^{(\mathbf{a}, \mathbf{b})}$ & \multicolumn{1}{|c|}{ Maturidade } \\
\hline Chi-quad. & 17,787 \\
Df & 14 \\
Sig. Assint. &, 217 \\
\hline
\end{tabular}

a. Teste de Kruskal Wallis

b. Variável de Agrupamento: Setor e quantidade de funcionários

Da mesma forma, ao se dividir as organizações em dois agrupamentos distintos, dentro de seus setores, sendo o deles primeiro composto por organizações de grande porte com faturamento anual maior que R\$ 300 milhões e o segundo com as demais não foram encontradas evidências estatísticas para afirmar que havia diferença significativa entre a maturidade em gestão de projetos de tecnologia da informação (Sig. 0,159), conforme Tabela 18.

Tabela 18. Maturidade por Setor e Agrupamento de Faturamento Agrupado

\begin{tabular}{|c|c|c|c|c|}
\hline Percepção de Maturidade & $\begin{array}{l}\text { Setor de } \\
\text { Atividade }\end{array}$ & $\begin{array}{l}\text { Tamanho da organização por } \\
\text { nível de faturamento (agrup.) }\end{array}$ & $\mathbf{N}$ & $\begin{array}{c}\text { Ordem } \\
\text { das } \\
\text { medianas }\end{array}$ \\
\hline \multirow{10}{*}{$\begin{array}{l}\text { Grupos de Processos de Iniciação e } \\
\text { Planejamento }\end{array}$} & \multirow[t]{2}{*}{ Serviços } & $\begin{array}{l}\text { Micro, Pequena, Média e Média- } \\
\text { Grande Empresa }\end{array}$ & 78 & 91,10 \\
\hline & & Grande Empresa & 54 & 105,75 \\
\hline & \multirow{2}{*}{ Comercial } & $\begin{array}{l}\text { Micro, Pequena, Média e Média- } \\
\text { Grande Empresa }\end{array}$ & 2 & 107,25 \\
\hline & & Grande Empresa & 1 & 17,50 \\
\hline & \multirow[t]{2}{*}{ Manufatureira } & $\begin{array}{l}\text { Micro, Pequena, Média e Média- } \\
\text { Grande Empresa }\end{array}$ & 13 & 70,92 \\
\hline & & Grande Empresa & 31 & 101,56 \\
\hline & \multirow[t]{2}{*}{ Setor Público } & $\begin{array}{l}\text { Micro, Pequena, Média e Média- } \\
\text { Grande Empresa }\end{array}$ & 5 & 51,10 \\
\hline & & Grande Empresa & 3 & 82,83 \\
\hline & Terceiro Setor & $\begin{array}{l}\text { Microempresa, Pequena } \\
\text { Empresa, Média Empresa e } \\
\text { Média-Grande Empresa }\end{array}$ & 1 & 143,50 \\
\hline & & Total & 188 & \\
\hline
\end{tabular}

\begin{tabular}{|l|r|}
\hline \multicolumn{1}{|c|}{ Teste Estatístico $^{(\text {a,b) }}$} & $\begin{array}{c}\text { Percepção de } \\
\text { Maturidade }\end{array}$ \\
\hline Chi-quad. & 11,824 \\
\hline
\end{tabular}




\begin{tabular}{|l|r|}
\hline Df & 8 \\
\hline Sig. Assint. &, 159 \\
\hline
\end{tabular}

a. Teste de Kruskal Wallis $\quad$ b. Variável de Agrupamento: Setor e Faturamento Agrupado

O mesmo se pode verificar ao se separar as organizações em dois agrupamentos distintos, dentro de seus setores de atividade, sendo o primeiro deles composto por grandes organizações com mais de 500 funcionários e o segundo grupo com as que possuem menos de 499 funcionários não foram identificadas evidências estatísticas para afirmar que organizações com mais de 500 funcionários apresentam maior maturidade em gestão de projetos de tecnologia da informação do que as demais (Sig. 0,081), como apresentado na

Tabela 19.

Tabela 19. Maturidade por Setor e Agrupamento de Quantidade de Funcionários

\begin{tabular}{|c|c|c|c|c|}
\hline $\begin{array}{l}\text { Percepção de } \\
\text { maturidade }\end{array}$ & Setor de atividade & $\begin{array}{l}\text { Tamanho da organização por } \\
\text { quantidade de funcionários (agrup.) }\end{array}$ & $\mathbf{N}$ & $\begin{array}{c}\text { Ordem das } \\
\text { medianas }\end{array}$ \\
\hline \multirow{10}{*}{$\begin{array}{l}\text { Grupos de Processos } \\
\text { de Iniciação e } \\
\text { Planejamento }\end{array}$} & \multirow{2}{*}{ Serviços } & de 0 a 499 funcionários & 70 & 88,52 \\
\hline & & 500 funcionários ou mais & 63 & 107,27 \\
\hline & \multirow{2}{*}{ Comercial } & de 0 a 499 funcionários & 2 & 108,25 \\
\hline & & 500 funcionários ou mais & 1 & 18,50 \\
\hline & \multirow{2}{*}{ Manufatureira } & de 0 a 499 funcionários & 12 & 67,75 \\
\hline & & 500 funcionários ou mais & 32 & 103,05 \\
\hline & \multirow{2}{*}{ Setor Público } & de 0 a 499funcionários & 5 & 51,30 \\
\hline & & 500 funcionários ou mais & 3 & 84,67 \\
\hline & Terceiro Setor & de 0 a 499 funcionários & 1 & 144,50 \\
\hline & & Total & 189 & \\
\hline
\end{tabular}

\begin{tabular}{|l|r|}
\hline Teste Estatístico $^{(a, b)}$ & \multicolumn{1}{|c|}{$\begin{array}{c}\text { Percepção de } \\
\text { maturidade }\end{array}$} \\
\hline Chi-quad. & 14,018 \\
Df & 8 \\
Sig. Assint. &, 081 \\
\hline
\end{tabular}

a. Teste de Kruskal Wallisb. Variável de Agrupamento: Setor e Quantidade de Funcionários Agrupado

Analisando-se a percepção dos profissionais de níveis hierárquicos distintos, não foram encontradas justificativas estatísticas para afirmar que os respondentes de níveis hierárquicos diferentes têm percepções divergentes em relação a maturidade de gestão de projetos de tecnologia da informação em suas organizações (Sig. 0,262) conforme Tabela 20.

Tabela 20. Maturidade por Função Hierárquica 


\begin{tabular}{|l|l|r|r|}
\hline \multirow{4}{*}{$\begin{array}{l}\text { Grupos de Processos de } \\
\text { Iniciação e Planejamento }\end{array}$} & Estagiário ou Trainee & 4 & 108,75 \\
\cline { 2 - 3 } & Analista ou Operador & 27 & 74,44 \\
\cline { 2 - 3 } & Líder ou Coordenador de Equipe & 66 & 95,22 \\
\cline { 2 - 4 } & Gerente ou Superintendente de Área & 65 & 102,10 \\
\cline { 2 - 4 } & Alta Administração, Diretor, VP ou C-Level & 28 & 99,25 \\
\cline { 2 - 4 } & Total & 190 & \\
\hline
\end{tabular}

\begin{tabular}{|l|r|}
\hline \multicolumn{1}{|c|}{ Teste Estatístico $^{(\mathbf{a}, \mathbf{b})}$} & \multicolumn{2}{c|}{ Percepção de maturidade } \\
\hline Chi-quad. & 5,261 \\
Df & 4 \\
Sig. Assint. &, 262 \\
\hline
\end{tabular}

a. Teste de Kruskal Wallis

b. Variável de Agrupamento: Função hierárquica

Ao realizar esta análise promovendo o agrupamento dos respondentes em dois conjuntos sendo um deles composto por profissionais de alta e média-gerência e o outro conjunto de profissionais do nível tático-operacional, encontraram-se evidências estatísticas que apontam não haver divergência de percepções também (Sig. 0,159) como na

Tabela 21.

Os resultados apresentados nas Tabela $20 \mathrm{e}$

Tabela 21 corroboram a consistência das respostas e a robustez da amostra e resultados em relação ao método de análise indireta do fenômeno por meio da percepção dos profissionais envolvidos em projetos de tecnologia da informação.

Tabela 21. Maturidade por Função Hierárquica Agrupada

\begin{tabular}{|l|l|l|r|r|}
\hline \multirow{2}{*}{ Percepção de maturidade } & \multicolumn{2}{|c|}{ Nível Hierárquico dos Respondentes Agrupado } & \multicolumn{1}{|c|}{$\begin{array}{c}\text { Ordem } \\
\text { das } \\
\text { medianas }\end{array}$} \\
\hline \multirow{2}{*}{$\begin{array}{l}\text { Grupos de Processos de } \\
\text { Iniciação e Planejamento }\end{array}$} & $\begin{array}{c}\text { Inferior: tático } \\
\text { e operacional }\end{array}$ & $\begin{array}{l}\text { Estagiário ou Trainee, Analista ou } \\
\text { Operador, Líder ou Coordenador de } \\
\text { Equipe }\end{array}$ & 97 & 89,99 \\
\cline { 2 - 5 } & $\begin{array}{c}\text { Superior: média } \\
\text { e alta-gerência }\end{array}$ & $\begin{array}{l}\text { Gerente ou Superintendente de Área, } \\
\text { Alta Administração, Diretor, VP ou C- } \\
\text { level (Executivo) }\end{array}$ & 93 & 101,24 \\
\cline { 2 - 5 } & & Total & 190 & \\
\hline
\end{tabular}

\begin{tabular}{|l|r|}
\hline \multicolumn{1}{|c|}{ Teste Estatístico $^{(\mathbf{a}, \mathbf{b})}$} & $\begin{array}{c}\text { Percepção de } \\
\text { maturidade }\end{array}$ \\
\hline Chi-quad. & 1,987 \\
Df & 1 \\
Sig. Assint. &, 159 \\
\hline
\end{tabular}

a. Teste de Kruskal Wallis

b. Variável de Agrupamento: Nível Hierárquico Agrupado 
Buscando entender se as empresas latino-americanas apresentavam menor maturidade de gestão de projetos de tecnologia da informação, agruparam-se as um conjunto com as organizações em organizações de origem em países latino-americana e outros com as demais para realizar análises estatísticas não paramétricas.

Assim, não foram identificadas diferenças estatisticamente significativas para afirmar que a maturidade de gestão de projetos de tecnologia da informação de organizações de origem latino-americana é diferente da maturidade das demais (Sig. 0,171) como apresentado na

Tabela 22.

Tabela 22. Maturidade por Origem Agrupada

\begin{tabular}{|c|c|c|c|}
\hline Percepção de maturidade & Origem da Organização (agrupada) & $\mathbf{N}$ & $\begin{array}{l}\text { Ordem das } \\
\text { medianas }\end{array}$ \\
\hline \multirow{3}{*}{$\begin{array}{l}\text { Grupos de Processos de Iniciação } \\
\text { e Planejamento }\end{array}$} & Latino-americana & 133 & 91,47 \\
\hline & $\begin{array}{l}\text { Outas (Norte Americana, Européia, } \\
\text { Asiática) }\end{array}$ & 56 & 103,38 \\
\hline & Total & 189 & \\
\hline
\end{tabular}

\begin{tabular}{|l|r|}
\hline \multicolumn{1}{|c|}{ Teste Estatístico ${ }^{(\mathbf{a}, \mathbf{b})}$} & \multicolumn{2}{c|}{ Percepção de maturidade } \\
\hline Chi-quad. & 1,870 \\
Df & 1 \\
Sig. Assint. &, 171 \\
\hline
\end{tabular}

a. Teste de Kruskal Wallis

b. Variável de Agrupamento: Origem Agrupada

O mesmo se passou ao analisar a maturidade de gestão de projetos de tecnologia da informação considerando a origem da organização de maneira específica. Assim, não há relevância estatística significativa capaz de afirmar que a maturidade de gestão de projetos está de alguma forma relacionada com a origem da organização (Sig. 0,147), conforme Tabela 23.

Tabela 23. Maturidade por Origem

\begin{tabular}{|l|l|r|r|}
\hline \multirow{2}{*}{ Percepção de maturidade } & \multicolumn{1}{|c|}{ Origem da Organização } & N & \multicolumn{1}{c|}{$\begin{array}{c}\text { Ordem das } \\
\text { medianas }\end{array}$} \\
\hline \multirow{4}{*}{$\begin{array}{l}\text { Grupos de Processos de Iniciação } \\
\text { e Planejamento }\end{array}$} & Latino Americana & 133 & 91,47 \\
\cline { 2 - 4 } & Norte Americana & 21 & 112,55 \\
\cline { 2 - 4 } & Européia & 32 & 93,36 \\
\cline { 2 - 4 } & Asiática & 3 & 146,17 \\
\hline
\end{tabular}




\begin{tabular}{|l|l|r|r|}
\hline & Total & 189 & \\
\hline
\end{tabular}

\begin{tabular}{|l|r|}
\hline \multicolumn{1}{|c|}{ Teste Estatístico ${ }^{(\mathbf{a}, \mathbf{b})}$} & \multicolumn{2}{c|}{ Percepção de maturidade } \\
\hline Chi-quad. & 5,371 \\
Df & 3 \\
Sig. Assint. &, 147 \\
\hline
\end{tabular}

a. Teste de Kruskal Wallis

b. Variável de Agrupamento: Origem

Supondo que organizações com maior tempo de vida pudessem estar à frente da curva de aprendizagem e, assim, terem processos mais maduros, buscou-se identificar possíveis diferenças de maturidade considerando o tempo de atuação da organização no mercado.

Esta análise, no entanto, não mostrou evidências estatísticas que permitissem afirmar que a maturidade de gestão de projetos de tecnologia da informação estivesse associada ao tempo de atuação da organização no mercado (Sig. 0,893) conforme Tabela 24.

Tabela 24. Maturidade por Tempo de Atuação no Mercado

\begin{tabular}{|l|l|r|r|}
\hline \multicolumn{1}{|c|}{ Percepção de maturidade } & \multicolumn{1}{|c|}{ Tempo de Atuação no Mercado } & \multicolumn{1}{c|}{$\begin{array}{c}\text { Ordem das } \\
\text { medianas }\end{array}$} \\
\hline \multirow{4}{*}{$\begin{array}{l}\text { Grupos de Processos de } \\
\text { Iniciação e Planejamento }\end{array}$} & Menor que 3 anos & 6 & 83,00 \\
\cline { 2 - 4 } & Entre 3 e 5 anos & 11 & 106,73 \\
\cline { 2 - 4 } & Entre 5 e 7 anos & 12 & 87,79 \\
\cline { 2 - 4 } & Entre 7 e 10 anos & 17 & 99,26 \\
\cline { 2 - 4 } & Maior que 10 anos & 143 & 94,70 \\
\cline { 2 - 4 } & Total & 189 & \\
\hline
\end{tabular}

\begin{tabular}{|l|r|}
\hline \multicolumn{1}{|c|}{ Teste Estatístico $^{(a, b)}$} & Percepção de maturidade \\
\hline Chi-quad. & 1,111 \\
df & 4 \\
Sig. Assint. &, 893 \\
\hline
\end{tabular}

a. Teste de Kruskal Wallis

b. Variável de Agrupamento: Tempo de atuação

No entanto, ao se avaliar a maturidade de gestão de projetos de tecnologia da informação em organizações com amplitude atuação distinta em termos de escopo geográfico (Sig. 0,018), pode-se afirmar que empresas de atuação internacional ou multinacional parecem apresentar maior maturidade, seguidas por empresas com atuação nacional, e por último, empresas de atuação local ou regional conforme 
Tabela 25. 
Tabela 25. Maturidade por Escopo Geográfico

\begin{tabular}{|l|l|r|r|}
\hline Percepção de maturidade & \multicolumn{1}{|c|}{ Escopo Geográfico (amplitude) da Organização } & N & $\begin{array}{c}\text { Ordem das } \\
\text { medianas }\end{array}$ \\
\hline \multirow{3}{*}{$\begin{array}{l}\text { Grupos de Processos de } \\
\text { Iniciação e Planejamento }\end{array}$} & Local e/ou regional (um ou mais municípios/estados) & 29 & 77,28 \\
\cline { 2 - 4 } & Nacional (dois ou mais regiões) & 47 & 83,28 \\
\cline { 2 - 4 } & Internacional ou multinacional (dois ou mais países) & 112 & 103,67 \\
\cline { 2 - 4 } & Total & 188 & \\
\hline
\end{tabular}

\begin{tabular}{|l|r|}
\hline \multicolumn{1}{|c|}{ Teste Estatístico ${ }^{(a, b)}$} & \multicolumn{2}{|c|}{ Percepção de maturidade } \\
\hline Chi-quad. & 8,089 \\
df & 2 \\
Sig. Assint. &, 018 \\
\hline
\end{tabular}

a. Teste de Kruskal Wallis / b. Variável de Agrupamento: Escopo geográfico

Tendo em vista que a maturidade de gestão de projetos é um fenômeno com diversas nuances ou perspectivas compostas, resolveu-se avaliar de maneira distinta a maturidade por área de conhecimento.

Assim, os testes estatísticos que subsequentes buscam investigar possíveis diferenças de maturidade em uma área de conhecimento em específico, ao invés de somente avaliar a maturidade de maneira geral.

Conforme ilustrado na Tabela 26, primeiramente se analisou a maturidade de gestão de projetos para cada setor de atividade, dada certa área do conhecimento. Nesta análise não se encontraram justificativas estatísticas para afirmar a maturidade de gestão de projeto de tecnologia da informação de cada uma das nove áreas de conhecimento é diferente de um setor de atividade para outro.

Tabela 26. Maturidade das Áreas de Conhecimento por Setor de Atividade

\begin{tabular}{|l|l|c|c|}
\hline $\begin{array}{l}\text { Percepção de maturidade nos grupos de } \\
\text { processos de iniciação e planejamento por } \\
\text { área de conhecimento }\end{array}$ & Setor de Atividade & $\mathbf{N}$ & $\begin{array}{c}\text { Ordem das } \\
\text { medianas }\end{array}$ \\
\hline \multirow{5}{*}{ INTEGRAÇÃO } & Serviços & 133 & 96,17 \\
\cline { 2 - 4 } & Comercial & 3 & 88,50 \\
\cline { 2 - 4 } & Manufatureira & 44 & 96,76 \\
\cline { 2 - 4 } & Setor Público & 8 & 60,50 \\
\cline { 2 - 4 } & Terceiro Setor & 1 & 158,00 \\
\cline { 2 - 4 } & Total & 189 & \\
\hline \multirow{5}{*}{ ESCOPO } & Serviços & 133 & 99,03 \\
\cline { 2 - 4 } & Comercial & 3 & 83,00 \\
\cline { 2 - 4 } & Manufatureira & 8 & 90,74 \\
\cline { 2 - 4 } & Setor Público & 1 & 56,63 \\
\cline { 2 - 4 } & Terceiro Setor & & 90,00 \\
\hline
\end{tabular}




\begin{tabular}{|c|c|c|c|}
\hline $\begin{array}{l}\text { Percepção de maturidade nos grupos de } \\
\text { processos de iniciação e planejamento por } \\
\text { área de conhecimento }\end{array}$ & Setor de Atividade & $\mathbf{N}$ & $\begin{array}{l}\text { Ordem das } \\
\text { medianas }\end{array}$ \\
\hline & Total & 189 & \\
\hline \multirow{6}{*}{ TEMPO } & Serviços & 133 & 98,48 \\
\hline & Comercial & 3 & 71,00 \\
\hline & Manufatureira & 44 & 91,70 \\
\hline & Setor Público & 8 & 54,63 \\
\hline & Terceiro Setor & 1 & 172,00 \\
\hline & Total & 189 & \\
\hline \multirow{6}{*}{ CUSTO } & Serviços & 133 & 96,34 \\
\hline & Comercial & 3 & 71,67 \\
\hline & Manufatureira & 44 & 96,43 \\
\hline & Setor Público & 8 & 64,44 \\
\hline & Terceiro Setor & 1 & 168,50 \\
\hline & Total & 189 & \\
\hline \multirow{6}{*}{ QUALIDADE } & Serviços & 133 & 96,99 \\
\hline & Comercial & 3 & 86,83 \\
\hline & Manufatureira & 44 & 93,15 \\
\hline & Setor Público & 8 & 65,25 \\
\hline & Terceiro Setor & 1 & 174,00 \\
\hline & Total & 189 & \\
\hline \multirow{6}{*}{ RECURSOS HUMANOS } & Serviços & 133 & 97,92 \\
\hline & Comercial & 3 & 108,33 \\
\hline & Manufatureira & 44 & 89,11 \\
\hline & Setor Público & 8 & 71,13 \\
\hline & Terceiro Setor & 1 & 116,00 \\
\hline & Total & 189 & \\
\hline \multirow{6}{*}{ COMUNICAÇÕES } & Serviços & 133 & 96,63 \\
\hline & Comercial & 3 & 96,33 \\
\hline & Manufatureira & 44 & 91,44 \\
\hline & Setor Público & 8 & 83,50 \\
\hline & Terceiro Setor & 1 & 122,50 \\
\hline & Total & 189 & \\
\hline \multirow{6}{*}{ RISCOS } & Serviços & 133 & 96,74 \\
\hline & Comercial & 3 & 92,17 \\
\hline & Manufatureira & 44 & 91,85 \\
\hline & Setor Público & 8 & 79,63 \\
\hline & Terceiro Setor & 1 & 133,50 \\
\hline & Total & 189 & \\
\hline \multirow{6}{*}{ AQUISIÇÕES } & Serviços & 133 & 92,55 \\
\hline & Comercial & 3 & 82,17 \\
\hline & Manufatureira & 44 & 105,44 \\
\hline & Setor Público & 8 & 72,94 \\
\hline & Terceiro Setor & 1 & 176,50 \\
\hline & Total & 189 & \\
\hline
\end{tabular}

\begin{tabular}{|l|r|r|r|r|r|r|r|r|r|}
\hline $\begin{array}{c}\text { Teste } \\
\text { Estatístico } \\
\text { (a,b) }\end{array}$ & $\begin{array}{c}\text { Integra- } \\
\text { ção }\end{array}$ & Escopo & Tempo & Custo & Qualidade & RH & $\begin{array}{c}\text { Comunica- } \\
\text { ções }\end{array}$ & Riscos & Aquisições \\
\hline $\begin{array}{l}\text { Chi-quad. } \\
\text { df }\end{array}$ & 4,709 & 5,125 & 7,764 & 5,209 & 4,970 & 2,878 &, 966 & 1,429 & 5,821 \\
\end{tabular}


Sig. Assint.

, 319

, 275

, 101

a. Teste de Kruskal Wallis

b. Variável de Agrupamento: Setor

Assim, foi analisada maturidade de gestão de projeto de tecnologia da informação por área do conhecimento se dividindo as organizações em dois agrupamentos distintos, sendo o primeiro deles composto por organizações de grande porte com faturamento anual maior que $\mathrm{R} \$ 300$ milhões e o segundo com as demais.

Desta análise, foram identificadas evidências estatísticas que permitem afirmar que parecer haver maior maturidade em integração (Sig. 0,020) nas grandes organizações, enquanto há maior maturidade em comunicações (Sig. 0,030) e riscos $(0,012)$ nas organizações menores como pode ser verificado na Tabela 27.

Tabela 27. Maturidade das Áreas de Conhecimento por Faturamento

\begin{tabular}{|c|c|c|c|}
\hline $\begin{array}{l}\text { Percepção de maturidade nos grupos de } \\
\text { processos de iniciação e planejamento por } \\
\text { área de conhecimento }\end{array}$ & $\begin{array}{l}\text { Tamanho da organização por } \\
\text { faturamento }\end{array}$ & $\mathbf{N}$ & $\begin{array}{c}\text { Ordem } \\
\text { das } \\
\text { medianas }\end{array}$ \\
\hline \multirow{3}{*}{ INTEGRAÇÃO } & Faturamento abaixo de $\mathrm{R} \$ 300$ milhões & 99 & 86,24 \\
\hline & $\begin{array}{l}\text { Grande Empresa (acima de R\$ } 300 \\
\text { milhões) }\end{array}$ & 90 & 104,64 \\
\hline & Total & 189 & \\
\hline \multirow{3}{*}{ ESCOPO } & Faturamento abaixo de $\mathrm{R} \$ 300$ milhões & 99 & 89,01 \\
\hline & $\begin{array}{l}\text { Grande Empresa (acima de R\$ } 300 \\
\text { milhões) }\end{array}$ & 90 & 101,59 \\
\hline & Total & 189 & \\
\hline \multirow{3}{*}{ TEMPO } & Faturamento abaixo de $\mathrm{R} \$ 300$ milhões & 99 & 89,57 \\
\hline & $\begin{array}{l}\text { Grande Empresa (acima de R\$ } 300 \\
\text { milhões) }\end{array}$ & 90 & 100,98 \\
\hline & Total & 189 & \\
\hline \multirow{3}{*}{ CUSTO } & Faturamento abaixo de $\mathrm{R} \$ 300$ milhões & 99 & 90,47 \\
\hline & $\begin{array}{l}\text { Grande Empresa (acima de R\$ } 300 \\
\text { milhões) }\end{array}$ & 90 & 99,98 \\
\hline & Total & 189 & \\
\hline \multirow{3}{*}{ QUALIDADE } & Faturamento abaixo de $\mathrm{R} \$ 300$ milhões & 99 & 90,30 \\
\hline & $\begin{array}{l}\text { Grande Empresa (acima de R\$ } 300 \\
\text { milhões) }\end{array}$ & 90 & 100,17 \\
\hline & Total & 189 & \\
\hline \multirow{3}{*}{ RECURSOS HUMANOS } & Faturamento abaixo de $\mathrm{R} \$ 300$ milhões & 99 & 90,89 \\
\hline & $\begin{array}{l}\text { Grande Empresa (acima de R\$ } 300 \\
\text { milhões) }\end{array}$ & 90 & 99,52 \\
\hline & Total & 189 & \\
\hline \multirow{3}{*}{ COMUNICAÇÕES } & Faturamento abaixo de $\mathrm{R} \$ 300$ milhões & 99 & 86,98 \\
\hline & $\begin{array}{l}\text { Grande Empresa (acima de R\$300 } \\
\text { milhões) }\end{array}$ & 90 & 103,82 \\
\hline & Total & 189 & \\
\hline RISCOS & Faturamento abaixo de $\mathrm{R} \$ 300$ milhões & 99 & 85,53 \\
\hline
\end{tabular}




\begin{tabular}{|l|l|r|r|}
\hline $\begin{array}{l}\text { Percepção de maturidade nos grupos de } \\
\text { processos de iniciação e planejamento por } \\
\text { área de conhecimento }\end{array}$ & $\begin{array}{l}\text { Tamanho da organização por } \\
\text { faturamento }\end{array}$ & N & \multicolumn{1}{c|}{$\begin{array}{c}\text { Ordem } \\
\text { das } \\
\text { medianas }\end{array}$} \\
\hline & $\begin{array}{l}\text { Grande Empresa (acima de R\$300 } \\
\text { milhões) }\end{array}$ & 90 & 105,42 \\
\cline { 2 - 5 } & Total & 189 & \\
\hline \multirow{3}{*}{ AQUISIÇÕES } & Faturamento abaixo de R\$ 300 milhões & 99 & 89,51 \\
\cline { 2 - 4 } & $\begin{array}{l}\text { Grande Empresa (acima de R\$ 300 } \\
\text { milhões) }\end{array}$ & 90 & 101,04 \\
\cline { 2 - 5 } & Total & 189 & \\
\hline
\end{tabular}

\begin{tabular}{|l|r|r|r|r|r|r|r|r|r|}
\hline $\begin{array}{c}\text { Teste } \\
\text { Estatístico } \\
(\mathbf{a}, \mathbf{b})\end{array}$ & $\begin{array}{c}\text { Integra- } \\
\text { ção }\end{array}$ & Escopo & Tempo & Custo & Qualidade & RH & $\begin{array}{c}\text { Comuni- } \\
\text { cações }\end{array}$ & Riscos & Aquisições \\
\hline Chi-quad. & 5,395 & 2,516 & 2,093 & 1,496 & 1,604 & 1,233 & 4,727 & 6,294 & 2,194 \\
df & 1 & 1 & 1 & 1 & 1 & 1 & 1 & 1 & 1 \\
Sig. Assint. &, 020 &, 113 &, 148 &, 221 &, 205 &, 267 &, 030 &, 012 &, 139 \\
\hline
\end{tabular}

a. Teste de Kruskal Wallis

b. Variável de Agrupamento: Faturamento Agrupado

Ainda neste contexto, foi analisada maturidade de gestão de projeto de tecnologia da informação por área do conhecimento se dividindo as organizações por tamanho segundo o número de funcionários.

Nesta análise, foram encontradas evidências estatísticas que permitem afirmar que parecer haver diferença na maturidade em integração (Sig. 0,029), comunicações (Sig. 0,049) e riscos (Sig. 0,025) entre as diversas organizações conforme Tabela 28.

Tabela 28. Maturidade das Áreas de Conhecimento por Quantidade de Funcionários

\begin{tabular}{|c|c|c|c|}
\hline $\begin{array}{l}\text { Percepção de maturidade nos grupos de } \\
\text { processos de iniciação e planejamento por área } \\
\text { de conhecimento }\end{array}$ & $\begin{array}{l}\text { Tamanho da organização por } \\
\text { número de funcionários }\end{array}$ & $\mathbf{N}$ & $\begin{array}{l}\text { Ordem das } \\
\text { medianas }\end{array}$ \\
\hline \multirow{6}{*}{ INTEGRAÇÃO } & de 0 a 9 funcionários & 11 & 105,68 \\
\hline & de 10 a 49 funcionários & 21 & 77,57 \\
\hline & de 50 a 249 funcionários & 34 & 78,90 \\
\hline & de 250 a 499 funcionários & 24 & 84,44 \\
\hline & 500 funcionários ou mais & 100 & 106,45 \\
\hline & Total & 190 & \\
\hline \multirow{6}{*}{ ESCOPO } & de 0 a 9 funcionários & 11 & 87,05 \\
\hline & de 10 a 49 funcionários & 21 & 86,21 \\
\hline & de 50 a 249 funcionários & 34 & 87,79 \\
\hline & de 250 a 499 funcionários & 24 & 81,21 \\
\hline & 500 funcionários ou mais & 100 & 104,43 \\
\hline & Total & 190 & \\
\hline \multirow{2}{*}{ TEMPO } & de 0 a 9 funcionários & 11 & 96,05 \\
\hline & de 10 a 49 funcionários & 21 & 99,76 \\
\hline
\end{tabular}




\begin{tabular}{|c|c|c|c|}
\hline $\begin{array}{l}\text { Percepção de maturidade nos grupos de } \\
\text { processos de iniciação e planejamento por área } \\
\text { de conhecimento }\end{array}$ & $\begin{array}{l}\text { Tamanho da organização por } \\
\text { número de funcionários }\end{array}$ & $\mathbf{N}$ & $\begin{array}{l}\text { Ordem das } \\
\text { medianas }\end{array}$ \\
\hline & de 50 a 249 funcionários & 34 & 86,75 \\
\hline & de 250 a 499 funcionários & 24 & 83,08 \\
\hline & 500 funcionários ou mais & 100 & 100,50 \\
\hline & Total & 190 & \\
\hline \multirow{6}{*}{ CUSTO } & de 0 a 9 funcionários & 11 & 84,36 \\
\hline & de 10 a 49 funcionários & 21 & 100,05 \\
\hline & de 50 a 249 funcionários & 34 & 88,24 \\
\hline & de 250 a 499 funcionários & 24 & 93,19 \\
\hline & 500 funcionários ou mais & 100 & 98,80 \\
\hline & Total & 190 & \\
\hline \multirow{6}{*}{ QUALIDADE } & de 0 a 9 funcionários & 11 & 103,82 \\
\hline & de 10 a 49 funcionários & 21 & 98,95 \\
\hline & de 50 a 249 funcionários & 34 & 81,65 \\
\hline & de 250 a 499 funcionários & 24 & 85,35 \\
\hline & 500 funcionários ou mais & 100 & 101,01 \\
\hline & Total & 190 & \\
\hline \multirow{6}{*}{ RECURSOS HUMANOS } & de 0 a 9 funcionários & 11 & 104,55 \\
\hline & de 10 a 49 funcionários & 21 & 89,60 \\
\hline & de 50 a 249 funcionários & 34 & 79,68 \\
\hline & de 250 a 499 funcionários & 24 & 95,15 \\
\hline & 500 funcionários ou mais & 100 & 101,21 \\
\hline & Total & 190 & \\
\hline \multirow{6}{*}{ COMUNICAÇÕES } & de 0 a 9 funcionários & 11 & 82,86 \\
\hline & de 10 a 49 funcionários & 21 & 93,26 \\
\hline & de 50 a 249 funcionários & 34 & 74,74 \\
\hline & de 250 a 499 funcionários & 24 & 90,60 \\
\hline & 500 funcionários ou mais & 100 & 105,60 \\
\hline & Total & 190 & \\
\hline \multirow{6}{*}{ RISCOS } & de 0 a 9 funcionários & 11 & 98,68 \\
\hline & de 10 a 49 funcionários & 21 & 85,12 \\
\hline & de 50 a 249 funcionários & 34 & 73,25 \\
\hline & de 250 a 499 funcionários & 24 & 87,81 \\
\hline & 500 funcionários ou mais & 100 & 106,74 \\
\hline & Total & 190 & \\
\hline \multirow{6}{*}{ AQUISIÇÕES } & de 0 a 9 funcionários & 11 & 94,09 \\
\hline & de 10 a 49 funcionários & 21 & 81,52 \\
\hline & de 50 a 249 funcionários & 34 & 88,26 \\
\hline & de 250 a 499 funcionários & 24 & 89,46 \\
\hline & 500 funcionários ou mais & 100 & 102,50 \\
\hline & Total & 190 & \\
\hline
\end{tabular}

\begin{tabular}{|l|r|r|r|r|r|r|r|r|r|}
\hline $\begin{array}{c}\text { Teste } \\
\text { Estatístico } \\
\text { (a,b) }\end{array}$ & $\begin{array}{c}\text { Integra- } \\
\text { ção }\end{array}$ & Escopo & Tempo & Custo & Qualidade & RH & $\begin{array}{c}\text { Comuni- } \\
\text { cações }\end{array}$ & Riscos & Aquisições \\
\hline Chi-quad. & 10,760 & 5,840 & 3,098 & 1,670 & 4,513 & 4,657 & 9,549 & 11,102 & 4,046 \\
df & 4 & 4 & 4 & 4 & 4 & 4 & 4 & 4 & 4 \\
Sig. Assint. &, 029 &, 211 &, 542 &, 796 &, 341 &, 324 &, 049 &, 025 &, 400 \\
\hline
\end{tabular}

a. Teste de Kruskal Wallis

b. Variável de Agrupamento: Quantidade de funcionários da organização no Brasil 
No entanto, analisando-se a maturidade de gestão de projetos por área do conhecimento, parece que o variável tempo de atuação da organização no mercado não tem influência. Ao menos esta influência não pode ser detectada por meio do teste não-paramétrico realizado e que encontra-se na Tabela 29.

Tabela 29. Maturidade das Áreas de Conhecimento por Tempo de Atuação

\begin{tabular}{|c|c|c|c|}
\hline $\begin{array}{l}\text { Percepção de maturidade nos grupos de processos de } \\
\text { iniciação e planejamento por área de conhecimento }\end{array}$ & $\begin{array}{l}\text { Tempo de atuação da } \\
\text { organização }\end{array}$ & $\mathbf{N}$ & $\begin{array}{l}\text { Ordem das } \\
\text { medianas }\end{array}$ \\
\hline \multirow{6}{*}{ INTEGRAÇÃO } & Menor que 3 anos & 6 & 93,58 \\
\hline & Entre 3 e 5 anos & 11 & 104,91 \\
\hline & Entre 5 e 7 anos & 12 & 81,50 \\
\hline & Entre 7 e 10 anos & 17 & 98,53 \\
\hline & Maior que 10 anos & 143 & 95,01 \\
\hline & Total & 189 & \\
\hline \multirow{6}{*}{ ESCOPO } & Menor que 3 anos & 6 & 81,25 \\
\hline & Entre 3 e 5 anos & 11 & 111,50 \\
\hline & Entre 5 e 7 anos & 12 & 88,17 \\
\hline & Entre 7 e 10 anos & 17 & 86,88 \\
\hline & Maior que 10 anos & 143 & 95,85 \\
\hline & Total & 189 & \\
\hline \multirow{6}{*}{ TEMPO } & Menor que 3 anos & 6 & 109,75 \\
\hline & Entre 3 e 5 anos & 11 & 97,27 \\
\hline & Entre 5 e 7 anos & 12 & 103,96 \\
\hline & Entre 7 e 10 anos & 17 & 95,29 \\
\hline & Maior que 10 anos & 143 & 93,42 \\
\hline & Total & 189 & \\
\hline \multirow{6}{*}{ CUSTO } & Menor que 3 anos & 6 & 80,25 \\
\hline & Entre 3 e 5 anos & 11 & 112,27 \\
\hline & Entre 5 e 7 anos & 12 & 112,96 \\
\hline & Entre 7 e 10 anos & 17 & 107,50 \\
\hline & Maior que 10 anos & 143 & 91,30 \\
\hline & Total & 189 & \\
\hline \multirow{6}{*}{ QUALIDADE } & Menor que 3 anos & 6 & 89,75 \\
\hline & Entre 3 e 5 anos & 11 & 110,09 \\
\hline & Entre 5 e 7 anos & 12 & 87,13 \\
\hline & Entre 7 e 10 anos & 17 & 108,94 \\
\hline & Maior que 10 anos & 143 & 93,06 \\
\hline & Total & 189 & \\
\hline \multirow{3}{*}{ RECURSOS HUMANOS } & Menor que 3 anos & 6 & 91,83 \\
\hline & Entre 3 e 5 anos & 11 & 104,50 \\
\hline & Entre 5 e 7 anos & 12 & 77,50 \\
\hline
\end{tabular}




\begin{tabular}{|c|c|c|c|}
\hline $\begin{array}{l}\text { Percepção de maturidade nos grupos de processos de } \\
\text { iniciaçâo e planejamento por área de conhecimento }\end{array}$ & $\begin{array}{l}\text { Tempo de atuação da } \\
\text { organização }\end{array}$ & $\mathbf{N}$ & $\begin{array}{l}\text { Ordem das } \\
\text { medianas }\end{array}$ \\
\hline & Entre 7 e 10 anos & 17 & 89,12 \\
\hline & Maior que 10 anos & 143 & 96,57 \\
\hline & Total & 189 & \\
\hline \multirow{6}{*}{ COMUNICAÇÕES } & Menor que 3 anos & 6 & 61,67 \\
\hline & Entre 3 e 5 anos & 11 & 103,95 \\
\hline & Entre 5 e 7 anos & 12 & 74,04 \\
\hline & Entre 7 e 10 anos & 17 & 105,44 \\
\hline & Maior que 10 anos & 143 & 96,23 \\
\hline & Total & 189 & \\
\hline \multirow{6}{*}{ RISCOS } & Menor que 3 anos & 6 & 75,58 \\
\hline & Entre 3 e 5 anos & 11 & 103,41 \\
\hline & Entre 5 e 7 anos & 12 & 82,58 \\
\hline & Entre 7 e 10 anos & 17 & 99,06 \\
\hline & Maior que 10 anos & 143 & 95,73 \\
\hline & Total & 189 & \\
\hline \multirow{6}{*}{ AQUISIÇÕES } & Menor que 3 anos & 6 & 55,25 \\
\hline & Entre 3 e 5 anos & 11 & 112,18 \\
\hline & Entre 5 e 7 anos & 12 & 74,33 \\
\hline & Entre 7 e 10 anos & 17 & 104,15 \\
\hline & Maior que 10 anos & 143 & 95,99 \\
\hline & Total & 189 & \\
\hline
\end{tabular}

\begin{tabular}{|l|r|r|r|r|r|r|r|r|r|}
\hline $\begin{array}{c}\text { Teste } \\
\text { Estatístico } \\
\text { (a,b) }\end{array}$ & $\begin{array}{c}\text { Integra } \\
\text {-ção }\end{array}$ & Escopo & Tempo & Custo & $\begin{array}{c}\text { Quali- } \\
\text { dade }\end{array}$ & RH & $\begin{array}{c}\text { Comuni- } \\
\text { cações }\end{array}$ & Riscos & $\begin{array}{c}\text { Aquisi- } \\
\text { ções }\end{array}$ \\
\hline Chi-quad. & 1,180 & 1,995 &, 915 & 4,590 & 2,538 & 1,989 & 5,262 & 1,770 & 6,795 \\
\hline df & 4 & 4 & 4 & 4 & 4 & 4 & 4 & 4 & 4 \\
\hline Sig. Assint. &, 881 &, 737 &, 922 &, 332 &, 638 &, 738 &, 261 &, 778 &, 147 \\
\hline
\end{tabular}

a. Teste de Kruskal Wallis / b. Variável de Agrupamento: Tempo de atuação da organização no mercado

Já, ao analisar o reflexo do escopo geográfico de atuação da organização na maturidade de gestão de projetos de tecnologia da informação, foram encontradas evidências estatísticas que permitem afirmar que parecer haver maior maturidade nas áreas de conhecimento de integração (Sig. 0,021), escopo (Sig. 0,007), tempo (Sig. 0,041) e riscos (Sig. 0,016). Isto significa dizer que organizações com maior amplitude de escopo geográfico possuem maior maturidade nas as áreas de conhecimento de integração, escopo, tempo e riscos como apresentado na 
Tabela 30. 
Tabela 30. Maturidade das Áreas de Conhecimento por Escopo de Atuação

\begin{tabular}{|c|c|c|c|}
\hline $\begin{array}{l}\text { Percepção de Maturidade nos Grupos de } \\
\text { Processos de Iniciação e Planejamento para } \\
\text { a Área de Conhecimento }\end{array}$ & Escopo de atuação & $\mathbf{N}$ & $\begin{array}{l}\text { Ordem das } \\
\text { medianas }\end{array}$ \\
\hline \multirow{4}{*}{ INTEGRAÇÃO } & $\begin{array}{l}\text { Local e/ou regional (um ou mais } \\
\text { municípios/estados) }\end{array}$ & 29 & 78,31 \\
\hline & Nacional (dois ou mais regiões) & 47 & 83,21 \\
\hline & $\begin{array}{l}\text { Internacional ou multinacional (dois ou } \\
\text { mais países) }\end{array}$ & 112 & 103,43 \\
\hline & Total & 188 & \\
\hline \multirow{4}{*}{ ESCOPO } & $\begin{array}{l}\text { Local e/ou regional (um ou mais } \\
\text { municípios/estados) }\end{array}$ & 29 & 75,24 \\
\hline & Nacional (dois ou mais regiões) & 47 & 82,48 \\
\hline & $\begin{array}{l}\text { Internacional ou multinacional (dois ou } \\
\text { mais países) }\end{array}$ & 112 & 104,53 \\
\hline & Total & 188 & \\
\hline \multirow{4}{*}{ TEMPO } & $\begin{array}{l}\text { Local e/ou regional (um ou mais } \\
\text { municípios/estados) }\end{array}$ & 29 & 74,74 \\
\hline & Nacional (dois ou mais regiões) & 47 & 89,33 \\
\hline & $\begin{array}{l}\text { Internacional ou multinacional (dois ou } \\
\text { mais países) }\end{array}$ & 112 & 101,79 \\
\hline & Total & 188 & \\
\hline \multirow{4}{*}{ CUSTO } & $\begin{array}{l}\text { Local e/ou regional (um ou mais } \\
\text { municípios/estados) }\end{array}$ & 29 & 84,60 \\
\hline & Nacional (dois ou mais regiões) & 47 & 84,29 \\
\hline & $\begin{array}{l}\text { Internacional ou multinacional (dois ou } \\
\text { mais países) }\end{array}$ & 112 & 101,35 \\
\hline & Total & 188 & \\
\hline \multirow{4}{*}{ QUALIDADE } & $\begin{array}{l}\text { Local e/ou regional (um ou mais } \\
\text { municípios/estados) }\end{array}$ & 29 & 87,79 \\
\hline & Nacional (dois ou mais regiões) & 47 & 89,28 \\
\hline & $\begin{array}{l}\text { Internacional ou multinacional (dois ou } \\
\text { mais países) }\end{array}$ & 112 & 98,43 \\
\hline & Total & 188 & \\
\hline \multirow{4}{*}{ RECURSOS HUMANOS } & $\begin{array}{l}\text { Local e/ou regional (um ou mais } \\
\text { municípios/estados) }\end{array}$ & 29 & 89,78 \\
\hline & Nacional (dois ou mais regiões) & 47 & 83,34 \\
\hline & $\begin{array}{l}\text { Internacional ou multinacional (dois ou } \\
\text { mais países) }\end{array}$ & 112 & 100,41 \\
\hline & Total & 188 & \\
\hline \multirow{4}{*}{ COMUNICAÇÕES } & $\begin{array}{l}\text { Local e/ou regional (um ou mais } \\
\text { municípios/estados) }\end{array}$ & 29 & 78,55 \\
\hline & Nacional (dois ou mais regiões) & 47 & 89,01 \\
\hline & $\begin{array}{l}\text { Internacional ou multinacional (dois ou } \\
\text { mais países) }\end{array}$ & 112 & 100,93 \\
\hline & Total & 188 & \\
\hline \multirow{4}{*}{ RISCOS } & $\begin{array}{l}\text { Local e/ou regional (um ou mais } \\
\text { municípios/estados) }\end{array}$ & 29 & 78,72 \\
\hline & Nacional (dois ou mais regiões) & 47 & 82,11 \\
\hline & $\begin{array}{l}\text { Internacional ou multinacional (dois ou } \\
\text { mais países) }\end{array}$ & 112 & 103,79 \\
\hline & Total & 188 & \\
\hline AQUISIÇÕES & $\begin{array}{l}\text { Local e/ou regional (um ou mais } \\
\text { municípios/estados) }\end{array}$ & 29 & 89,16 \\
\hline
\end{tabular}




\begin{tabular}{|l|l|r|r|}
\hline $\begin{array}{l}\text { Percepção de Maturidade nos Grupos de } \\
\text { Processos de Iniciação e Planejamento para } \\
\text { a Área de Conhecimento }\end{array}$ & Escopo de atuação & N & \multicolumn{1}{c|}{$\begin{array}{c}\text { Ordem das } \\
\text { medianas }\end{array}$} \\
\hline & Nacional (dois ou mais regiões) & 47 & 83,38 \\
\cline { 2 - 4 } & $\begin{array}{l}\text { Internacional ou multinacional (dois ou } \\
\text { mais países) }\end{array}$ & 112 & 100,55 \\
\cline { 2 - 4 } & Total & 188 & \\
\hline
\end{tabular}

\begin{tabular}{|l|r|r|r|r|r|r|r|r|r|}
\hline $\begin{array}{c}\text { Teste } \\
\text { Estatístico } \\
(\mathbf{a}, \mathbf{b})\end{array}$ & $\begin{array}{c}\text { Integra- } \\
\text { ção }\end{array}$ & Escopo & Tempo & Custo & $\begin{array}{c}\text { Qualidad } \\
\text { e }\end{array}$ & RH & $\begin{array}{c}\text { Comuni } \\
\text {-cações }\end{array}$ & Riscos & Aquisições \\
\hline Chi-quad. & 7,691 & 9,826 & 6,377 & 4,611 & 1,526 & 3,695 & 4,805 & 8,216 & 3,799 \\
Df & 2 & 2 & 2 & 2 & 2 & 2 & 2 & 2 & 2 \\
Sig. Assint. &, 021 &, 007 &, 041 &, 100 &, 466 &, 158 &, 091 &, 016 &, 150 \\
\hline
\end{tabular}

a. Teste de Kruskal Wallis

b. Variável de Agrupamento: Escopo de atuação

Resumidamente, este estudo pode afirma que maturidade de gestão de projetos de tecnologia da informação parece ser maior em grandes organizações que possuem faturamento maior que R\$300 milhões ou com mais de 500 funcionários.

Também parecer haver certa correlação positiva da maturidade de gestão de projetos de tecnologia da informação em relação à amplitude do escopo geográfico de atuação da organização. Assim, organizações internacionais ou multinacionais apresentaram maior maturidade que organizações regionais ou nacionais que, por sua vez, apresentaram maior maturidade que organizações locais.

Avaliando-se as áreas de conhecimento este trabalho permite afirmar que parecer haver certa diferença na maturidade de gestão de projetos nas áreas de conhecimento de integração, comunicação e riscos dado o tamanho da organização, seja falando-se em faturamento ou número de funcionários.

Finalmente, pode-se afirmar que organizações com maior amplitude de escopo geográfico de atuação parecem apresentar maior maturidade em gestão de projetos de tecnologia da informação nas áreas de conhecimento de integração, escopo, tempo e riscos.

Prosseguindo, procurou-se estudar possíveis correlações entre a importância dos facilitadores organizacionais com a maturidade de gestão de projetos de tecnologia da informação. 
Assim, foi projetada uma regressão linear tomando como variável independente a maturidade de gestão de projetos de tecnologia da informação e como variável dependente a importância dos facilitadores organizacionais como apresentado na Tabela 31, Tabela 32, Tabela 33.

Tabela 31. Resumo da Regressão Linear (Variável Independente Maturidade)

\begin{tabular}{|r|r|r|r|}
\hline \multicolumn{1}{|c|}{ R } & R Quadrado & $\begin{array}{c}\text { R Quadrado } \\
\text { Ajustado }\end{array}$ & $\begin{array}{c}\text { Erro padrão } \\
\text { da estimativa }\end{array}$ \\
\hline, 690 &, 476 &, 474 & 9,936 \\
\hline
\end{tabular}

Tabela 32. ANOVA da Regressão Linear (Variável Independente Maturidade)

\begin{tabular}{|l|r|r|r|r|r|}
\hline & $\begin{array}{c}\text { Soma dos } \\
\text { quadrados }\end{array}$ & df & $\begin{array}{c}\text { Mediana dos } \\
\text { quadrado }\end{array}$ & F & Sig. \\
\hline Regressão & 16885,714 & 1 & 16885,714 & 171,044 &, 000 \\
Residual & 18559,597 & 188 & 98,721 & & \\
Total & 35445,311 & 189 & & & \\
\hline
\end{tabular}

Tabela 33. Coeficientes da Regressão Linear (Variável Independente Maturidade)

\begin{tabular}{|l|r|r|r|r|r|}
\hline & \multicolumn{2}{|c|}{ Coeficientes não padronizados } & $\begin{array}{c}\text { Coeficientes } \\
\text { padronizados }\end{array}$ & \multirow{2}{*}{ t } & \multirow{2}{*}{ Sig. } \\
\cline { 2 - 5 } & \multicolumn{1}{|c|}{ B } & Std. Error & \multicolumn{1}{c|}{ Beta } & &, 000 \\
\hline Maturidade &, 435 &, 033 &, 690 & 13,078 &, 000 \\
(Constante) & 28,087 & 1,946 & & 14,431 & \\
\hline
\end{tabular}

Embora se note um baixo nível de explicação $\left(\mathrm{R}^{2}\right.$ Ajustado $\left.=0,474\right)$ da variável independente pela dependente, ainda é possível notar certa correlação dos dois fatores como ilustrado no Gráfico 2.

Desta forma, a maturidade está fortemente associada com o papel estratégico dos projetos para a sobrevivência de longo prazo e sustentação de vantagem competitiva, a realização de alinhamento dos projetos à estratégia organizacional, assim como, utilização de múltiplos critérios de avaliação do sucesso dos projetos.

Além, é claro, da disponibilização de capacidade como recursos, treinamento, sistemas, patrocinadores e autonomia para realizar os projetos. 
Pode-se assim explorar que a maturidade de gestão de projetos de tecnologia da informação está positivamente correlacionada com o papel estratégico dos projetos e a base estrutura que para eles for viabilizada.

Assim, é possível inferir que quase $47,4 \%$, ou seja, quase metade da maturidade é explicada pelos facilitadores organizacionais que são o papel estratégico dos projetos e a disponibilização de capacidade.

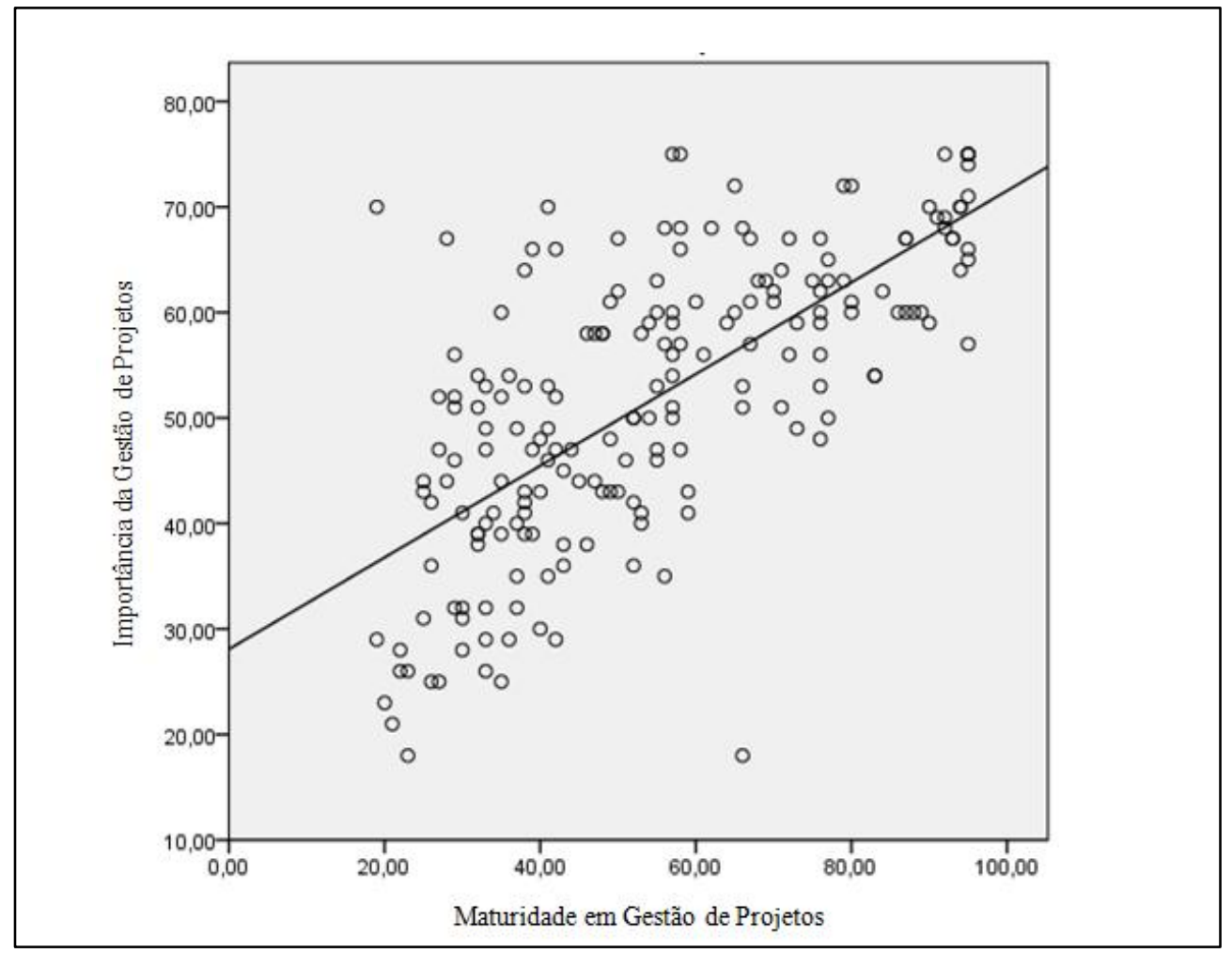

Gráfico 2. Regressão Linear (Variável Independente Maturidade)

Finalmente, é possível notar uma ampla dispersão dos pontos em relação à curva, no entanto, quanto maior a maturidade de gestão de projetos menor se torna esta dispersão.

Assim, pode-se até mesmo visualizar certo afunilamento dos pontos como ilustrado no Gráfico 3 que parece permitir afirmar que embora os facilitadores organizacionais não determinem a maturidade de gestão de projetos, a ausência deles, determina uma baixa maturidade.

Logo, também seria possível afirmar que a presença dos facilitadores organizacionais fomenta o aumento da maturidade. 


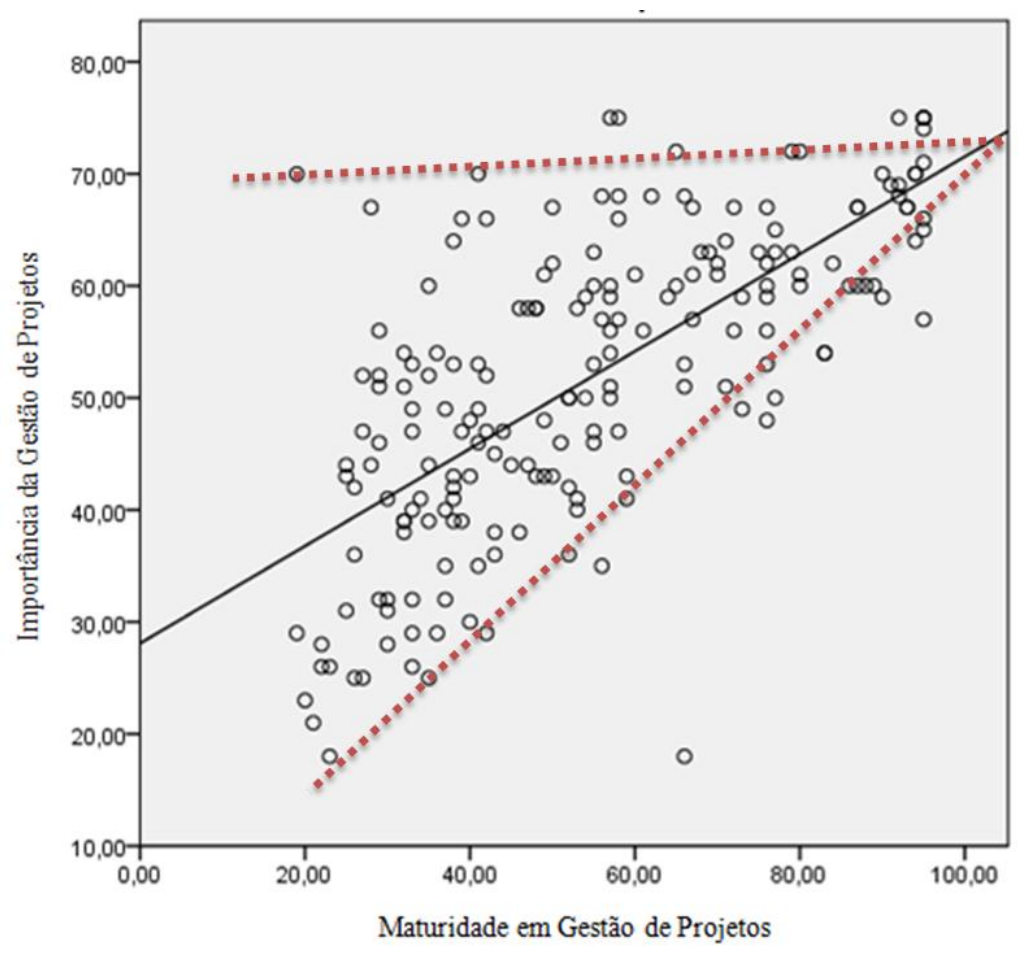

Gráfico 3. Regressão Linear com Afunilamento 


\section{CONSIDERAÇÕES FINAIS}

Primeiramente, ao realizarmos o teste Kolmogorov-Smirnov para testar a normalidade da distribuição da percepção de maturidade, identificamos uma distribuição não-normal o que pode sinalizar que o uso de médias não seria o mais apropriado para retratar o fenômeno como utilizado nos estudos empíricos.

Assim, os trabalhos de Levene, Bentley e Jarvis (1995), Ibbs e Kwak (2000), Cooke-Davies e Arzymanow (2003), Crawford (2005), Mullaly (2006), Zwikael e Globerson (2006) e Byde (2008) poderiam ser questionados quanto a simples comparação de médias de maturidades como determinante para afirmar que um setor ou outro tem maior maturidade em gestão de projetos.

Estes trabalhos comparam a maturidade de gestão de projetos das diversos setores de maneira geral, ou seja, sem analisar as maturidades por categorias de projeto (ARCHIBALD, 2004). Assim, a comparação multi-setorial pode estar enviesada ou mesmo indevida, pois pode comparar a maturidade de projetos de tipos distintos entre si.

Os resultados da análise de dados deste estudo não mostram evidências estatísticas da maturidade de gestão de projetos das organizações estar relacionada com o setor de atividade assim como em Levene, Bentley e Jarvis (1995).

Finalmente, compilou-se no Gráfico 4 as práticas de gestão de projetos aplicadas com maior maturidade e menor maturidade nas organizações representadas pela nossa amostra. Cabe ressaltar a baixa maturidade das organizações nas áreas de conhecimento de riscos, comunicações e recursos humanos encontrada no estudo enquanto nota-se claramente uma forte maturidade no tratamento das áreas de tempo e custos. 


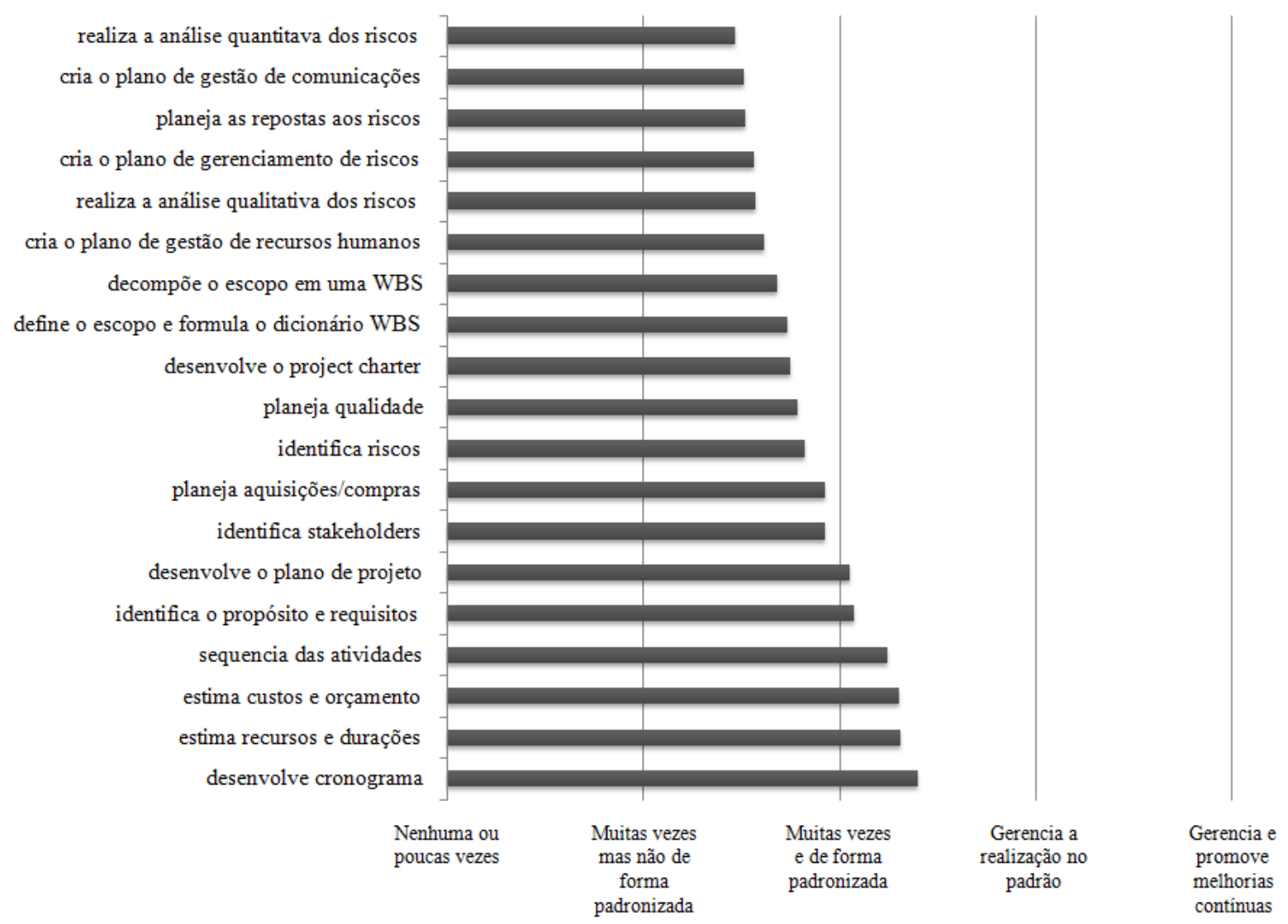

Gráfico 4. Percepção de Maturidade dos Grupos de Processos de Iniciação e Planejamento de Gestão de Projetos

A análise de variância e das distribuições de maturidade entre as organizações nos seus próprios setores. Assim, poder-se-ia questionar se a maturidade de gestão de projetos estaria associada ao papel da TI dentro das organizações estudadas e como os projetos de TI seriam utilizados para geração de vantagem competitiva.

Considerando a literatura revisada, é possível inferir As diferentes maturidades de gestão de projetos nas organizações estudadas poderiam levar de alguma forma a construção mais eficiente de ativos estratégicos (RBV) ou no posicionamento diferenciado por criação de valor meio de serviços de sistemas de informação.

Elaborou-se um sumário dos resultados do trabalho considerando as perguntas de pesquisa, hipóteses levantadas e respostas que se pode inferir com base a análise de dados realizada (Quadro 12). 
Quadro 12. Sumários dos Resultados das Hipóteses

\begin{tabular}{|c|c|c|c|c|}
\hline \# & Pergunta de Pesquisa & \# & Hipóteses & esultados \\
\hline \multirow[t]{4}{*}{$\mathrm{P} 1$} & \multirow{4}{*}{$\begin{array}{l}\text { A maturidade de gestão de } \\
\text { projetos de tecnologia da } \\
\text { informação entre os distintos } \\
\text { setores é diferente? } \\
\text { Como isso muda quando } \\
\text { comparamos os setores } \\
\text { dividindo as organizações de } \\
\text { tamanhos semelhantes? }\end{array}$} & $\mathrm{H} 1$ & $\begin{array}{l}\text { Organizações do mesmo setor } \\
\text { tendem a ter maturidades } \\
\text { semelhantes }\end{array}$ & $\begin{array}{l}\text { HIPÓTESE P1.H1 FOI ACEITA } \\
\text { A maturidade de gestão de projetos de tecnologia da informação é semelhante ao } \\
\text { compararmos organizações do mesmo setor de atividade (Tabela 16, 17, } 18 \text { e 19). }\end{array}$ \\
\hline & & $\mathrm{H} 2$ & $\begin{array}{l}\text { Organizações de serviços ou } \\
\text { comerciais têm maior de } \\
\text { maturidade que manufatureiras }\end{array}$ & $\begin{array}{l}\text { HIPÓTESE P1.H2 FOI REJEITADA } \\
\text { A maturidade de gestão de projetos de tecnologia da informação das organizações de } \\
\text { diversos setores é semelhante (Tabela 11). }\end{array}$ \\
\hline & & $\mathrm{H} 3$ & $\begin{array}{l}\text { Organizações maiores têm maior } \\
\text { maturidade que organizações } \\
\text { menores }\end{array}$ & $\begin{array}{l}\text { HIPÓTESE P1.H3 FOI ACEITA } \\
\text { A maturidade de gestão de projetos de tecnologia da informação é maior em grandes } \\
\text { organizações, ou seja, que possuem mais de } 500 \text { funcionários ou faturam mais de } \\
\text { R } \$ 300 \text { milhões (Tabela } 14,15 \text { e } 25 \text { ). }\end{array}$ \\
\hline & & $\mathrm{H} 4$ & $\begin{array}{l}\text { Organizações do mesmo setor e } \\
\text { de tamanhos distintos possuem } \\
\text { maturidades semelhantes }\end{array}$ & $\begin{array}{l}\text { HIPÓTESE P1.H4 FOI REJEITADA } \\
\text { A maturidade de gestão de projetos de tecnologia da informação é semelhante ao } \\
\text { compararmos organizações do mesmo setor de atividade (Tabela 16, 17, } 18 \text { e 19). }\end{array}$ \\
\hline \multirow[t]{2}{*}{$\mathrm{P} 2$} & \multirow{2}{*}{$\begin{array}{l}\text { A maturidade de gestão de } \\
\text { projetos de tecnologia da } \\
\text { informação entre os distintos } \\
\text { setores é diferente quando } \\
\text { analisamos por área do } \\
\text { conhecimento (integração, }\end{array}$} & $\mathrm{H} 1$ & $\begin{array}{l}\text { Organizações de setores } \\
\text { diferentes têm maturidades } \\
\text { semelhantes }\end{array}$ & $\begin{array}{l}\text { HIPÓTESE P2. H1 FOI ACEITA } \\
\text { A maturidade de gestão de projetos de tecnologia da informação das organizações de } \\
\text { diversos setores é semelhante, mesmo, por área de conhecimento (Tabela 26). }\end{array}$ \\
\hline & & $\mathrm{H} 2$ & $\begin{array}{l}\text { Organizações de serviços ou } \\
\text { comerciais têm maior de } \\
\text { maturidade que manufatureiras }\end{array}$ & $\begin{array}{l}\text { HIPÓTESE P2. H2 FOI REJEITADA } \\
\text { A maturidade de gestão de projetos de tecnologia da informação das organizações de } \\
\text { diversos setores é semelhante, mesmo, por área de conhecimento (Tabela 26). }\end{array}$ \\
\hline
\end{tabular}




\begin{tabular}{|c|c|c|c|c|}
\hline$\#$ & Pergunta de Pesquisa & \# & Hipóteses & Resultados \\
\hline & $\begin{array}{l}\text { escopo, tempo, custo, risco, } \\
\begin{array}{l}\text { comunicação, qualidade, } \\
\text { recursos humanos, aquisições)? }\end{array} \\
\text { Como isso muda quando } \\
\text { comparamos os setores } \\
\text { dividindo as organizações de } \\
\text { tamanhos semelhantes? }\end{array}$ & $\mathrm{H} 3$ & $\begin{array}{l}\text { Organizações do mesmo } \\
\text { tamanho possuem maturidades } \\
\text { semelhantes }\end{array}$ & $\begin{array}{l}\text { HIPÓTESE P2. H3 FOI REJEITADA } \\
\text { Grandes organizações (faturamento acima de } \mathrm{R} \$ 300 \text { milhões ou mais de } 500 \\
\text { funcionários) possuem maturidade nas áreas de conhecimento de integração, } \\
\text { comunicações e riscos diferentes das demais organizações (Tabela } 27 \text { e 28) } \\
\text { Organizações com atuação internacional possuem maiores níveis de maturidade, } \\
\text { seguidas por empresas nacionais e por último, empresas locais ou regionais nas áreas de } \\
\text { conhecimento de áreas de conhecimento de integração, escopo, tempo e riscos (Tabela } \\
\text { 30) }\end{array}$ \\
\hline P3 & $\begin{array}{l}\text { A maturidade de gestão de } \\
\text { projetos percebida pelos } \\
\text { respondentes é diferente quando } \\
\text { comparamos as respostas de } \\
\text { profissionais com características } \\
\text { distintas? }\end{array}$ & H1 & $\begin{array}{l}\text { Os facilitadores organizacionais } \\
\text { são percebidos da mesma forma } \\
\text { por profissionais de } \\
\text { características distintas }\end{array}$ & $\begin{array}{l}\text { HIPÓTESE P3. H1 FOI REJEITADA. } \\
\text { Profissionais de alta e média-gerência dão maior importância aos facilitadores } \\
\text { organizacionais do que seus colegas de níveis hierárquicos tático-operacionais (Tabela } \\
\text { 8). Esta diferença é notada em especial em alguns itens como sobrevivência de longo } \\
\text { prazo, sustentação de vantagem competitiva, disponibilização de sistema de gestão de } \\
\text { projetos e concessão de autonomia aos gestores de projetos. } \\
\text { Profissionais mais experientes dão maior importância aos facilitadores organizacionais } \\
\text { que seus colegas menos experientes (Tabela 9). Esta diferença é notada em especial em } \\
\text { alguns itens como alinhamento estratégico, sobrevivência a longo prazo, sustentação de } \\
\text { vantagem competitiva, disponibilização de sistemas de gestão de projetos e concessão } \\
\text { de autonomia par aos gerentes de projeto. }\end{array}$ \\
\hline
\end{tabular}




\begin{tabular}{|c|c|c|c|c|}
\hline \# & Pergunta de Pesquisa & \# & Hipóteses & Resultados \\
\hline P4 & $\begin{array}{l}\text { Os facilitadores organizacionais } \\
\text { disponíveis nos distintos setores } \\
\text { são diferentes? } \\
\text { Como isso muda quando } \\
\text { comparamos os setores } \\
\text { dividindo as organizações por }\end{array}$ & H1 & $\begin{array}{l}\text { Organizações de origem latino- } \\
\text { americana dão menos } \\
\text { importância para os facilitadores } \\
\text { organizacionais para a gestão de } \\
\text { projetos do que as empresas de } \\
\text { outros países. }\end{array}$ & $\begin{array}{l}\text { HIPÓTESE P4. H1 FOI REJEITADA } \\
\text { As organizações de origem latino-americana e demais dão a mesma importância aos } \\
\text { facilitadores organizacionais (Tabela 7). }\end{array}$ \\
\hline
\end{tabular}


De uma forma geral, a missão e os objetivos estratégicos PMI (2008) da organização direcionam o processo de gerenciamento do planejado em realidade para, com isso, determinar a posição estratégica futura. Embora grande parte dos estudos acadêmicos considerem a formulação da estratégia o fator-chave de sucesso no direcionamento futuro, a implementação é caracterizada pelos gestores como a fase crítica ao sucesso para a gestão estratégica (HREBINIAK, 2005).

Ao longo do tempo esta abordagem despertou o interesse de alguns acadêmicos Shenhar, (1999), Kathuria et al. (2007), Artto e Dietrich (2004), Jamieson e Morris (2004), Srivannaboon e Milosevic (2004), Dietrich e Lehtonen (2005) e Srivannaboon (2006) que buscavam explicar como a gestão competente do portfólio de projetos poderia ser considerada fator crítico para construção e manutenção de vantagens competitivas para as organizações. Podemos inferir que as características necessárias para suportar e fomentar uma gestão integrada da execução da estratégia deliberada e emergente podem estar mais presentes em grandes organizações ou com maior maturidade em gestão de projetos.

O alinhamento estratégico dos projetos é facilitado pela a existência de alguns fatores facilitadores, os organizational enablers (PMI, 2008). Sendo assim, a gestão de portfolio e o alinhamento estratégico são facilitadores à difusão da estratégia nos diversos níveis organizacionais, conforme discutido por Mintzberg (1994), Miller (2002), IPMA (2006) e PMI (2008).

Os resultados indicam que os facilitadores organizacionais parecem ser mais valorizados por membros da alta e média-gerencia e profissionais mais experientes e que os respondentes em posições estratégicas (presidência, diretoria e gerência) dão maior importância que respondentes em níveis hierárquicos em posições operacionais (coordenadores, analistas, trainees e estagiários) enquanto sobrevivência no longo prazo, sustentação de vantagem competitiva, disponibilização de sistema de gestão de projetos e concessão de autonomia aos gestores de projetos.

Os respondentes mais experientes dão maior importância à gestão de projetos como fator que pode auxiliar o alinhamento estratégico para a sobrevivência no longo prazo, sustentação de vantagem competitiva, disponibilização de sistemas de gestão de projetos, e concessão de autonomia para os gerentes de projeto. 
Este resultado confirma as ponderações de Mintzberg (1984) no sentido de que essas configurações buscam melhorar a integração entre as áreas e unidades de negócio para que o conhecimento coletivo direcione os processos de ruptura da organização em prol dos seus objetivos. Por estas razões, o perfil do gestor destaca-se como uma importante variável motivacional: ele indica as prioridades em relação à gestão e incentivos ao desenvolvimento de competências internas e externas para atingir metas estratégicas e de desempenho.

A análise de dados sugere evidências de uma possível correlação positiva entre a importância dada aos facilitadores organizacionais e a maturidade sendo que se pode verificar que organizações que dão maior importância aos facilitadores possuem maior maturidade em gestão de projetos.

Este estudo pode afirma que maturidade de gestão de projetos de tecnologia da informação parece ser maior em grandes organizações que possuem faturamento maior que $\mathrm{R} \$ 300$ milhões ou com mais de 500 funcionários.

Também parecer haver certa correlação positiva da maturidade de gestão de projetos de tecnologia da informação em relação à amplitude do escopo geográfico de atuação da organização. Assim, organizações internacionais ou multinacionais apresentaram maior maturidade que organizações regionais ou nacionais que, por sua vez, apresentaram maior maturidade que organizações locais.

Avaliando-se as áreas de conhecimento este trabalho permite afirmar que parecer haver certa diferença na maturidade de gestão de projetos nas áreas de conhecimento de integração, comunicação e riscos dado o tamanho da organização, seja falando-se em faturamento ou número de funcionários.

Finalmente, pode-se afirmar que organizações com maior amplitude de escopo geográfico de atuação parecem apresentar maior maturidade em gestão de projetos de tecnologia da informação nas áreas de conhecimento de integração, escopo, tempo e riscos.

Desta forma, a maturidade está fortemente associada com o papel estratégico dos projetos para a sobrevivência de longo prazo e sustentação de vantagem competitiva, a realização de alinhamento dos projetos à estratégia organizacional, assim como, utilização de múltiplos 
critérios de avaliação do sucesso dos projetos. Além, é claro, da disponibilização de capacidade como recursos, treinamento, sistemas, patrocinadores e autonomia para realizar os projetos.

Pode-se assim explorar que a maturidade de gestão de projetos de tecnologia da informação está positivamente correlacionada com o papel estratégico dos projetos e a base estrutura que para eles for viabilizada. Assim, é possível inferir que quase 47,4\%, ou seja, quase metade da maturidade é explicada pelos facilitadores organizacionais que são o papel estratégico dos projetos e a disponibilização de capacidade.

Embora nos últimos anos muitas empresas estejam adotando a gestão de portfolio que ajuda a promover o alinhamento estratégico, o estudo indica que este processo formalizado e estruturado é mais presente nas grandes empresas em função das dificuldades de monitoramento e alinhamento do portfolio de projetos. Contudo, estas características ainda são pouco marcantes em empresas de pequeno e médio porte.

Questiona-se também, com base em Blichfeldt e Eskerod (2008), uma possível lacuna nos modelos normativos de alinhamento estratégico do portfolio de projeto ao lidar com os projetos extraoficiais inferindo as teorias (MINTZBERG, 1984; COLLINS, 2001) que entendem a estratégia como um processo menos deliberado e muitas vezes emergente da execução e implementação.

Este estudo permite afirmar que a maturidade de gestão de projetos está longe de ser uma commodity mesmo dentro do mesmo setor, no entanto, os modelos de maturidade não podem ser visto como as balas de prata (JUGDEV \& THOMAS, 2002). Desenvolver a maturidade em gestão de projetos é somente parte da equação, sendo que complementarmente se deve buscar alavancar os fatores críticos de sucesso (FORTUNE \& WHITE, 2006) e facilitadores organizacionais.

Cabe ressaltar que não foram encontradas diferenças estatísticas significativas quando avaliamos a maturidade de todas as áreas de conhecimento de gestão de projeto de tecnologia da informação conjuntamente (Explorando-se assim as fronteiras da gestão de projetos de tecnologia para a gestão de projetos em geral, poder-se-ia afirmar a maturidade de gestão de 
projetos é a forma pela qual se busca uma execução mais eficiente dos projetos para obter uma melhor taxa de sucesso.

Desta forma, seria possível assumir que muitos, se não a maioria, dos ativos estratégicos é criada por meio de um projeto. Assim sendo, os facilitadores organizacionais, fatores críticos de sucesso e a maturidade de gestão de projetos podem ser considerados a plataforma para ), no entanto, este estudo não pode ser considerando conclusivo e tem suas limitações.

Tabela 34. Mediana da Maturidade de Gestão e Projeto por Setor de Atividade e Área do Conhecimento

\begin{tabular}{|c|c|c|c|c|c|c|c|c|c|c|}
\hline \multicolumn{2}{|l|}{ Setor } & $\begin{array}{l}\text { Integra- } \\
\text { ção }\end{array}$ & Escopo & Tempo & Custo & Qualidade & Recursos & $\begin{array}{c}\text { Comunica- } \\
\text { ções }\end{array}$ & Riscos & $\begin{array}{l}\text { Aquisi- } \\
\text { çöes }\end{array}$ \\
\hline \multirow{3}{*}{ Serviços } & Mean & 2,9398 & 2,9348 & 3,4135 & 3,3459 & 2,8346 & 2,6992 & 2,5639 & 2,6346 & 2,8647 \\
\hline & $\mathrm{N}$ & 133 & 133 & 133 & 133 & 133 & 133 & 133 & 133 & 133 \\
\hline & Std. Deviation & 1,24102 & 1,22024 & 1,13273 & 1,21259 & 1,34941 & 1,32565 & 1,35038 & 1,34221 & 1,27791 \\
\hline \multirow{3}{*}{ Comercial } & Mean & 2,8889 & 2,6667 & 2,7778 & 2,6667 & 2,6667 & 3,0000 & 2,6667 & 2,6000 & 2,6667 \\
\hline & $\mathrm{N}$ & 3 & 3 & 3 & 3 & 3 & 3 & 3 & 3 & 3 \\
\hline & Std. Deviation & 1,83586 & 2,02759 & 1,95316 & 2,08167 & 2,08167 & 1,73205 & 2,08167 & 2,07846 & 2,08167 \\
\hline \multirow{3}{*}{ Manufatura } & Mean & 2,9318 & 2,7500 & 3,2500 & 3,3182 & 2,7500 & 2,5000 & 2,4545 & 2,4955 & 3,1591 \\
\hline & $\mathrm{N}$ & 44 & 44 & 44 & 44 & 44 & 44 & 44 & 44 & 44 \\
\hline & Std. Deviation & 1,17374 & 1,26598 & 1,24748 & 1,34290 & 1,44874 & 1,40597 & 1,40522 & 1,26967 & 1,27486 \\
\hline \multirow{3}{*}{ Setor Público } & Mean & 2,0833 & 2,0000 & 2,4167 & 2,5000 & 2,0000 & 2,0000 & 2,1250 & 2,1000 & 2,3750 \\
\hline & $\mathrm{N}$ & 8 & 8 & 8 & 8 & 8 & 8 & 8 & 8 & 8 \\
\hline & Std. Deviation & ,88641 & 1,15470 & 1,06533 & 1,51186 & ,92582 & ,92582 & ,83452 & ,77828 & 1,06066 \\
\hline \multirow{3}{*}{ 30 Setor } & Mean & 4,3333 & 2,6667 & 5,0000 & 5,0000 & 5,0000 & 3,0000 & 3,0000 & 3,2000 & 5,0000 \\
\hline & $\mathrm{N}$ & 1 & 1 & 1 & 1 & 1 & 1 & 1 & 1 & 1 \\
\hline & Std. Deviation & & & & & & & & & \\
\hline \multirow{3}{*}{ Total } & Mean & 2,9083 & 2,8466 & 3,3316 & 3,3016 & 2,7884 & 2,6296 & 2,5238 & 2,5820 & 2,9206 \\
\hline & $\mathrm{N}$ & 189 & 189 & 189 & 189 & 189 & 189 & 189 & 189 & 189 \\
\hline & Std. Deviation & 1,22564 & 1,24270 & 1,18376 & 1,27540 & 1,37519 & 1,33304 & 1,34707 & 1,31063 & 1,28785 \\
\hline
\end{tabular}

Entretanto, plotou-se em formato de radar os resultados das medianas de maturidade de gestão de projetos de tecnologia de informação para estudos futuros e para demonstrar que, graficamente, é possível identificar diferenças mesmo que estas não sejam estatisticamente significativas (Gráfico 5). 


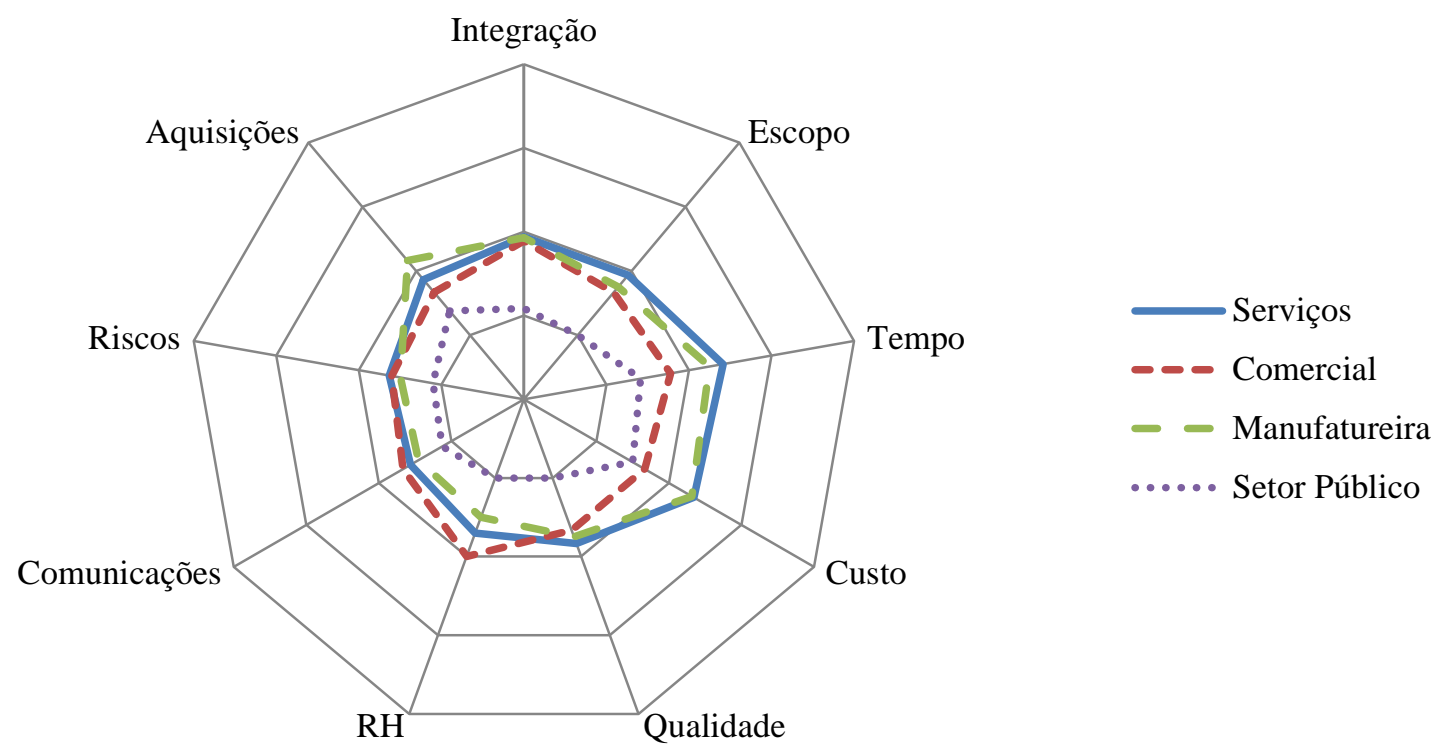

Gráfico 5. Mediana de Maturidade das Áreas de Conhecimento por Setor de Atividade

Explorando-se assim as fronteiras da gestão de projetos de tecnologia para a gestão de projetos em geral, poder-se-ia afirmar a maturidade de gestão de projetos é a forma pela qual se busca uma execução mais eficiente dos projetos para obter uma melhor taxa de sucesso.

Desta forma, seria possível assumir que muitos, se não a maioria, dos ativos estratégicos é criada por meio de um projeto. Assim sendo, os facilitadores organizacionais, fatores críticos de sucesso e a maturidade de gestão de projetos podem ser considerados a plataforma para criar e sustentar vantagens competitivas por meio da criação eficiente de ativos estratégicos ou competência essenciais da organização.

Concluindo, não seria assim, a própria maturidade de gestão de projetos, uma competência essencial chave para o sucesso das organizações em um ambiente em constante evolução e revolução?

Sugere-se que novos trabalhos possam investigar a maturidade na gestão de projetos introduzindo as práticas de execução, monitoramento, controle e encerramento.

Também se propõem que estudos posteriores investiguem as práticas e maturidade na gestão de projetos dentro do mesmo setor e ou entre setores distintos comparando-as entre os projetos de diferentes categorias de Archibald (2004) (P\&D, TI, Operações/Produção), além 
de pesquisar possíveis diferenças nas práticas e maturidade da gestão de projetos corporativos (internos) dos projetos realizados subcontratado (externos) em empresas baseadas em projetos.

São limitações do estudo a amostra por conveniência, concentrada em grandes empresas nos setores de serviços e manufatura - interpretações são mais seguras na análise deste tipo de indústria, onde a prática é mais disseminada e também concentrada em respondentes advindos das áreas de TI, serviços e finanças - interpretações são mais seguras na análise de projetos predominantemente dessas áreas.

Também é limitação da pesquisa seus métodos no que tange a aplicação de questionários para avaliar de maneira indireta a maturidade de projetos, ou seja, a percepção dos respondentes sobre a maturidade de projetos considerando os projetos nos quais estes atuaram de alguma forma. Portanto pode haver distorções de interpretação por parte de alguns pesquisados.

6 REFERÊNCIAS

ANDERSEN, E. S. Rethinking Project Management. Harlow: Pearson Education Limited. 2008.

ANSELMO, J. L., MAXIMIANO, A.C.A. Gerenciamento Estratégico em Negócios Baseados em Projetos. SIMPOI 2010, XIII Simpósio de Administração da Produção, Logística e Operações Internacionais. 2010.

ARCHIBALD, R. D. A Global System for Categorizing Projects: The Need for, Recommended Approach to, and Practical Uses of the System. 2nd Latin American Forum: PM in Government, Brasilia, Brazil, 21-22 September 2004.

ARTTO, K.; DIETRICH, P. Strategic business management through multiple projects. In: MORRIS, P.W.G.; PINTO, J.K.. The Wiley Guide to Managing Projects. New Jersey: John Wiley \& Sons, 2004.

AUBRY, M. HOBBS, B. A Fresh Look at the Contribution of Project Management to Organizational Performance. Project Management Journal. Wiley InterScience, vol. 42, n. 1, p. 3-16, 2011. 
AUSTIN, R. D.; NOLAN, R. L. Bridging the Gap Between Stewards and Creators. MITSloan Management Review. vol. 48, n. 2. 2007.

BAETS, W. Aligning Information Systems with Business Strategy. Journal of Strategic Information Systems. vol. 1, n. 4, p. 205-213. 1992.

BAETS, W. Some Empirical Evidence on IS Strategy, Alignment in Banking. Information \& Management. vol. 30, n. 4, p. 155-177. 1996.

BAI, S.; LI, S.; FENG, R.; GUO, Y. Organizational Project Selection Based on Fuzzy MultiIndex Evaluation and BP Neural Network. IEEE - International Conference on Management and Service Science MASS, 2010.

BANKER, R. D.; HU, N.; PAVLOU, P. A. LUFTMAN, J. CIO Reporting Structure, Strategic Positioning, and Firm Performance. MIS Quartely. vol, 35, n. 2, p. 487-504. 2011.

BARNEY; HESTERLY. Administração estratégica e vantagem competitiva

BERSSANETI, F. T.; CARVALHO, M. M.; LOPES, F. B.; MUSCAT, A. R. N. Maturity and Performance in Project Management: a survey of information technology professional. POMS 19th Annual Conference. 2008.

BESANKO D.; DRANOVE D.; SHANLEY M.; SCHAEFER S. A economia da estratégia. 3. ed. Porto Alegre: Bookman, 2006

BLICHFELDT, B. S.; ESKEROD, P. Project portfolio management-There's more to it than what management enacts. International Journal of Project Management, v. 26, p. 357$365,2008$.

BOSSIDY, L.; CHARAN, R.; BURCK, C. Execution: The Discipline of Getting Things Done. New York: Crown Business, 2002.

BOUTINET, J. P. Psychologie des conduites a projet. Paris: Presses Universitaires de France, 2006.

BREDILlET, C. N. Blowing Hot and Cold on Project Management. Project Management Journal. Wiley InterScience, vol. 41, n. 3, p. 4-20. 2010. 
BYDE, D. J., Is construction different? A comparison of perceptions of project management performance and practices by business sector and project type. Construction Management and Economics. n. 26, 2008.

CALLAHAN, K.; BROOKS, L., Essentials of strategic Project Management. New Jersey: John Wiley \& Sons, 2004.

CAMPBELL, B.; KAY, R.; AVISON, D. Strategic Alignment: a practitioner's perspective. Journal of Enterprise Information Management. vol. 18, n. 5/6, p. 653-664. 2005.

CARVAlHO, M. M.; RABECHINI JR, R. Construindo Competências para gerenciar projetos. 2 ed. São Paulo : Atlas, v. 1. 2007.

CARVALHO, M.M.; RABECHINI JR., R.; PESSÔA, M. S. P.; LAURINDO, F. J. B. Equivalência e completeza: análise de dois modelos de maturidade em gestão de projetos. RAUSP - Revista de Administração. São Paulo, vol. 40, n. 3, p. 289-300. 2005.

CHAN, Y. E.; HUFF, S. L. Investigating Informations Systems Strategic Alignment. Procedings of the 14th International Conference on Information Systems. Orlando, p. 345-363. 1993.

CHAN, Y. E.; HUFF, S. L.; BARCLAY, D. W. COPELAND, D. G. Business Strategic Orientations, Infromation Systems Strategic Orientation, and Strategic Alignment. Information Systems Research. vol. 8, n. 2, p. 125-150. 1997.

CHAN, Y. E.; REICH, B. H. IT Alignment: what have we learned? Journal of Information Technology. vol. 22, p. 297-315, set. 2007.

CHAN, Y. E.; SABHERWAL, R.; THATCHER, J. B. Antecedents and Outcomes of Strategic IS Alignment: an empirical investigation. IEEE Transactions on Engineering Management. vol. 51, n. 3, p. 27-47. 2006.

CIBORRA, C. U. De Profundis? Deconstructing the Concept of Strategic Alignment. Scandinavian Journal of Information Systems. vol. 9, n. 1, p. 57-82. 1997.

CIBORRA, C. U. Groupware and Teamwork. New York: John Wiley and Sons. 1996. 
COLlinS, J. Good To Great: Why Some Companies Make The Leap And Other's Don't. New York: HarperBusiness Publishers Inc., 2001.

COLLINS, J. How The Mighty Fall: And Why Some Companies Never Give In. 2009.

COLLINS, J.; HANSEN, M. T. Great by Choice: Uncertainty, Chaos, and Luck--Why Some Thrive Despite Them All. New York: HarperBusiness. 2011.

COllyer, S.; WARREN, C.; HEMSley, B.; STEVEnS, C. Aim Fire Aim - Project Planning Styles in Dynamic Environments. PMI Research and Education Conference. Washington, USA. 2010.

COOKE-DAVIES, T. J.; ARZYMANOW, A. The maturity of project management in different industries: an investigation into variations between project management models. International Journal of Project Management. n. 21, p. 471-478. 2003.

COOPER, R, EDGETT, S., KLEINSCHMIDT, E. Portfolio Management - Fundamental to New Product Success. Product Development Institute: Working Paper n.12, 2001a.

COOPER, R, EDGETT, S., KLEINSCHMIDT, E. Portfolio Management of New Product Development: results of an industry. Practices, study. R\&D Management. Oxford, n.31, $2001 b$.

CRAWFORD, L., Senior management perceptions of project management competence. International Journal of Project Management. n. 23, 2005.

DE LEEDE, J.; LOOISE, J. C.; ALDERS, B. Innovation, Improvement and Operations: na exploration of management of alignment. International Journal of Technology Management. vol. 23, n. 4, p. 353-368. 2002.

DEMING, W. E. Out of the Crisis. The MIT Press. 1986.

DIETRICH, P.; LEHTONEN, P. Successful management of strategic intentions through multiple projects - reflections from empirical study. International Journal of Project Management. n. 23, 2005. 
DIETRICH, P.; LEHTONEN, P. Successful management of strategic intentions through multiple projects - reflections from empirical study. International Journal of Project Management, v. 23, n. 5, p. 386-391, 2005.

DINSMORE, P.C. Transformando Estratégias Empresariais em Resultados Através da Gerência por Projetos - Rio de Janeiro: Qualitymark Ed., 1999.

FÁVERO. L. P.; BELFIORE, P.; SILVA, F. L.; CHAN, B. L. Análise de Dados: modelagem multivariada para tomada de decisões. Rio de Janeiro: Elsevier. 2009.

FLYVBJERG, B.; BUDZIER, A. Why Your IT Project May Be Riskier Than You Think. Harvard Business Review. 2011.

FORTUNE, J.; WHITE, D. Framing of project critical success factors by a systems model. International Journal of Project Management. n. 24. 2006.

FRAME, J. D. Project Management Competence: building key skills for individuals, teams and organizations. San Francisco: Josey-Bass. 1999.

GIL, A. C. Métodos e técnicas de pesquisa social. São Paulo: Atlas, 2006

GOVInDARAJAN, V.; TRIMBLE, C. The Other Side of Innovation: Solving the Execution Challenge. Boston: Harvard Business Press, 2010.

GRANT, K. P; PENNYPACKER, J. S. Project Management Maturity: an assessment of project management capabilities among and between selected industries. IEEE Transactions of Engineering Management. vol. 53, n. 1. 2006.

GUANGSHE, J., LI, C., JIANGUO, C., SHUISEN, Z., JIN, W. Application of Organizational Project Management Maturity Model (OPM3) to Construction in China: An Empirical Study. Information Management Innovation Management and Industrial Engineering 2008 ICIII 08 International Conference on. Vol. 2, pp. 56-62. 2008.

HAIRE, M. Modern organizational theory. New York: John Wiley \& Sons. 1959

HARTER, D. E.; KRISHNAN, M. S.; SLAUGHTER, S. A. Effects of Process Maturity on Quality, Cycle Time, and Effort in Software Product Development. Management Science. vol. 46, n. 4, p. 451-466. 2000. 
HENDERSON, J. C.; VENKATRAMAN, N. Strategic alignment: leveraging information technology for transforming organizations. IBM Systems Journal. vol. 32, n. 1, p. 4-16. 1993.

HOBBS, B. The Multi-Project PMO: A Global Analysis of the Current State of Practice. PA: Project Management Institute. 2007.

HREBINIAK, L. G. Making Strategy Work: Leading Effective Execution and Change. Wharton School Publishing. New Jersey: Pearson Prentice Hall, 2005.

INTENATIONAL PROJECT MANAGEMENT ASSOCIATION - IMPA. IPMA Competence Baseline, Version 3.0. Nijkerk. 2006.

IRANI, Z. Information Systems Evaluation: navigating through the problem domain. Information Management. vol. 40, n. 1, p. 11-24. 2002.

JAMIESON, A.; MORRIS P. W. G. Moving from corporate strategy to project strategy. The Wiley Guide to Managing Projects. Hoboken. Wiley: NJ, 2004.

JAMIESON, A.; MORRIS P. W. G. Moving from corporate strategy to project strategy. . In: MORRIS, P.W.G.; PINTO, J.K., editors. The Wiley Guide to Managing Projects. New Jersey: John Wiley \& Sons,, 2004.

JEFFERY, M.; LELIVELD, I. Best Practices in IT Portfolio Management. Massachusetts: MITSloan Management Review, 2004.

JUGDEV, K.; THOMAS, J. Project Management Maturity Models: the silver bullets of competitive advantage? Project Management Journal. Jonh Wiley \& Sons, vol. 33, n. 4, p. 2-14. 2002.

JUGDEV, K.; THOMAS, J; DELISLE, C. L. Rethinking Project Management: old truths and new insights. International Project Management Journal, vol. 7, n. 1, 2001.

KAARST-BROWN, M. L.; ROBEY, D. More on Myth, Magic and Metaphor: cultural insights into the management of information technology in organizations. Information Technology \& People. vol. 12, n. 2, p. 192-218. 1999.

KANUP, Welérson Robaina. Modelos de maturidade: um caminho para as organizações 
alcançarem maturidade em gerenciamento de projetos como diferencial estratégico. Dissertação de Mestrado. Pontifícia Universidade Católica de São Paulo, 2009.

KAPLAN, R. S.; NORTON, D. P. The Balanced Scorecard: Measures that Drive Performance. Harvard Business Review. 1992.

KAPLAN, R. S.; NORTON, D. P. The Execution Premium: Linking Strategy to Operations for Competitive Advantage. Boston: Harvard Business Press. 2008

KAPLAN, R. S.; NORTON, D. P. Translating Strategy into Action, The Balanced Scorecard. Boston: Harvard Business Press, 1996.

KATHURIA, R.; JOSHI, M. P.; PORTH, S. J. Organizational alignment and performance: past, present and future. Management Decisison, v. 45, n.3, p.503-517, 2007.

KEARNS, G. S.; LEDERER, A. L. A Resource-Based View of Strategic IT Alignment: how knowledge sharing creates competitive advantage. Decision Science. vol. 34, n. 1, p. 1-29. 2003

KENDALL, G.; ROLLINS, S. Advanced project portfolio management and the PMO: Multiplying ROI at warp speed. Fort Lauderdale: Ross Publishing Inc, 2003.

KERZNER, H. Applied Project Management Best Practices on Implementation. New Jersey: John Wiley \& Sons. 2000.

KERZNER, H. Applied Project Management Best Practices on Implementation. John Wiley \& Sons. 2000.

KERZNER, H. Project Management: A Systems Approach to Planning, Scheduling, and Controlling. 10th ed. New Jersey: John Wiley \& Sons, 2009.

KERZNER, H. Strategic Planning for Project Management - Using a Project Management Maturity Model. New York: John Wiley \& Sons, Inc. 2001.

KWAK, Y. H.; IBBS, C. W. Assessing Project Management Maturity. Project Management Journal. Vol. 31, No. 1, 32-43. 2000a.

KWAK, Y. H.; IBBS, C. W. Calculating Project Management's Return on Investment. Project Management Journal. Vol. 31, No. 2, 38-47. $2000 \mathrm{~b}$. 
KWAK, Y. H.; IBBS, C. W. Project Management Maturity (PM)2 Model. Journal of Management in Engineering. p. 150-155. 2002.

LAURINDO, F. J. B. Investigando o Papel Estratégico Da Tecnologia Da Informação Em Empresas Brasileiras: estudo de múltiplos casos. ALTEC2005 - XI SEMINARIO LatinoIberoamericano de Gestión Tecnológica. vol. 1. p. 1-16. 2005.

LAURINDO, F. J. B.; MORAES, R. O. IT projects portfolio management: a Brazilian case study. International Journal of Management and Decision Making. Indercience Enterprises, vol. 7, n. 6, p. 586-603. 2006.

LAURINDO, F. J. B.; MORAES, R. O. Processes for Ex-ante Evaluation of IT Projects: case studies in Brazilian companies. Issues in Informing Science Information Technology, vol. 3, p. 355-369. 2006.

LAURINDO, F. J. B.; SHIMIZU, T.; CARVALHO, M. M.; RABECHINI JR, R. O Papel da Tecnologia da Informação (TI) na Estratégia das Organizações. G\&P - Gestão \& Produção. Universidade Federal de São Carlos, vol. 8, n. 2, p. 160-179. 2001.

LEE, L. S.; ANDERSON, R. M. An Exploratory Investigation of the Antecedents of the IT Project Management Capability. e-Service Journal. Indiana University Press. 2006.

LEVENE, R.J., BENTLEY, A. E. and LARVIS, G.S., The scale of project management. Proceedings of the 26th annual Project Management Institute 1995 Seminar \& Symposium. 1995.

LEVINE, H. A. Project portfolio management: A practical guide to selecting projects, managing portfolios, and maximizing benefits. San Francisco: Jossey-Bass, 2005.

LUFTMAN, J. An Update on Business-IT Alignment: "a line" has been drawn. MIS Quartely. vol. 6, n. 3, p. 165-177. 2007.

LUFTMAN, J. N.; LEWIS, P. R.; OLDACH, S. H. Transforming the Enterprise: the alignment of business and information technology strategies. IBM Systems Journal. vol. 32, n. 1, p. 198-221. 1993.

LUFTMAN, J. N.; PAPP, R.; BRIER, T. Enablers and Inhibitors of Business-IT Alignment. Communications of the Association Information Systems. 1999 
LUFTMAN, J.; BEN-ZVI, T. Key Issues for IT Executives 2011: cautions optimism in uncertain economic times. MIS Quartely. vol. 10, n. 4. 2011.

LUFTMAN, J.; BRIER, T. Achieving and Sustaining Business-IT Alignment. California Management Review. vol. 42, n. 1, p. 109-122. 1999.

LUFTMAN, J.; KEMPAIAH, R. M. The IS Organization of the Future: the IT talent challenge. Information Systems Management. vol. 24, p. 129-138. 2007.

LUKOSEVICIUS, A. P. Maturidade em Gerenciamento de Projetos e Desempenho de Projetos na Indústria Naval Brasileira de Construção de Plataformas de Petróleo Flutuantes. Dissertação de Mestrado. Faculdades IBMEC, Rio de Janeiro, 2005.

MALHOTRA, N. K. Pesquisa de marketing: uma orientação aplicada. 4.ed. São Paulo: Bookman, 2006.

MARTINS, G. A; THEÓPHILO, C. R. Metodologia da Investigação Científica para Ciências Sociais Aplicadas. 2. ed. São Paulo: Atlas, 2009.

MARTINSUO, M.; LEHTONEN, P. Role of single-project management in achieving portfolio management efficiency. International Journal of Project Management, v. 25, n.1 p. 56-65, 2007.

MAXIMIANO, A. C. A; RABECHINI. R. Maturidade em Gestão de Projetos - Análise de um Caso e Proposição de um Modelo. In: Simpósio de Gestão da Inovação Tecnológica, Salvador, Bahia, 6 a 8 de novembro de 2002.

MCFARLAN, F. W. Information Technology Changes the Way You Compete. Harvard Business Review. Boston, p. 161-166. mai./jun. 1984.

MCFARLAN, F. W. Portfolio Approach to Information Systems. Harvard Business Review. Boston, p. 142-150, set./out. 1981

MCKEEN, J. D.; SMITH, H. Making IT Happen: critical issues in IT management. New Jersey: Willey. 2003.

MICHAELIS. Moderno Dicionário da Língua Portuguesa. São Paulo: Melhoramentos. 1998. 
MILlER, J. A proven project portfolio management process. Proceedings of the Project Management Institute Annual Seminars \& Symposium, p. 347-352, 2002.

MINTZBERG, H. Rise and Fall of Strategic Planning. New York: The Free Press. 1994.

MINTZBERG, H., AHLSTRAND, B., LAMPEL, J. Safári de Estratégia: um roteiro pela selva do planejamento estratégico. Porto Alegre: Bookland. 2000.

MORAES, R. Condicionantes de Desempenho dos Projetos de Software e a Influência da Maturidade em Gestão de Projetos. Tese Doutorado. 2004.

MORAES, R. O.; KRUGLIANSKAS, I. Projetos de TI: Maturidade x Desempenho. RAI Revista de Administração e Inovação. São Paulo, vol. 7, n. 2, p. 22-33. 2010.

MORAES, R. O.; LAURINDO, F. J. B. Avaliação de Resultados de Projetos de TI. In: ENEGEP 2010 - XXX Encontro Nacional de Engenharia de Produção. Anais do ENEGEP 2010. Rio de Janeiro: ABEPRO. vol. 1. p. 1-10. 2010.

MORAES, R. O.; LAURINDO, F. J. B. Multidimensionalidade da Maturidade em Gestão de Projetos de Sistemas de Informação. Produto \& Produção. v. 9, n. 2, p. 3-20. 2008.

MORAES, R. O.; LAURINDO, F. J. B. Um Estudo de Caso de Gestão de Portfolio de Projetos de Tecnologia da Informação. G\&P - Gestão \& Produção. São Carlos: Universidade Federal de São Carlos, vol. 10, n. 3, p. 311-328. 2003.

MULlALY, M. THOMAS, J. L. Exploring the Dynamics of Value and Fit: Insights From Project Management. Project Management Journal. Wiley InterScience, vol. 40, n 1, p. 124-135, 2009.

MULLALY, M., Longitudinal analysis of project management maturity, Project Management Journal. vol. 36, n. 3, p. 62-73. 2006.

NOLAN, R. L. Managing the computer resource: a stage hypothesis. Communications of the ACM. vol. 16, n. 7, 1973.

NOLAN, R. L. Managing the crises in data processing. Harvard Business Review. Boston, vol. 57, n. 2, p. 115-116. 1979. 
NOLAN, R. L. MCFARLAN, F. W. Information Technology and the Board of Directors. Harvard Business Review. Boston. vol. 83, n. 10 p. 96-106. 2005.

NOLAN, R. L. The strategic potential of information technology. Financial Executive. vol 7 , n. 4. p. 25-27. 1991.

NOLAN, R. L.; CRONSON, D. C.; SEGER, K. N. The Stages Theory: a framework for IT adoption and organizational learning. Boston: Harvard Business School Publishing. 1993.

OFFICE OF GOVERNMENT COMMERCE - OGC. Portfolio Management Guide. London. 2008.

ORLIKOWSKI, W. Improvising Organizational Transformation Over Time: a situated change perspective. Information Systems Research. vol. 7, n. 1, p. 63-92. 1996.

PENNYPACKER, J. S.; GRANT, K. P., Project Management Maturity: An industry benchmark. Project Management Journal, vol. 34, n. 1, 2003.

PFEFFER, J.; SUTTON, R. I. The Knowing-Doing Gap: How Smart Companies Turn Knowledge into Action. Harvard Business School Press. 2000.

PINTO, J. K. Project Management 2001. Research Technology Management , v. 45, n. 2, p. 22-37, 2002.

PORTER, M. E. Competitive Strategy: Techniques for Analyzing Industries and Competitors. New York: The Free Press. 1980.

PRADO, D. Maturidade em Gerenciamento de Projetos. Nova Lima (MG), INDG Tec S, 2008.

PRADO, D. Maturidade em Gerenciamento de Projetos. Revista Mundo PM. Disponível em: <http://www.mundopm.com.br/noticia.jsp?id=259>. Acesso em: 11 jul. $2010 \mathrm{~b}$.

PRADO, D. MMGP - Um modelo brasileiro de maturidade em gerenciamento de projetos. Disponível em:< http://pontogp.wordpress.com/2006/05/06/mmgp-um-modelobrasileiro-de-maturidade-em-gerenciamento-de-projetos/>. Acesso em: 10 jul. 2010a.

PRAHALAD, C. K.; HAMEL, G. Competing for the Future. Boston: Harvard Business Press. 1995. 
PRAHALAD, C. K.; HAMEL, G. The Core Competence of the Corporation. Harvard Business Review. 1990.

PRIETO, V. C.; CARVALHO, M. M.; FISCHMANN, A. A. Análise comparativa de modelos de alinhamento estratégico. Produção. v. 19, n. 2, p. 317-331, 2009.

PROJECT MANAGEMENT INSTITUTE - PMI. A Guide to the Project Management Body of Knowledge. 4. ed. Pennsylvania, 2008a.

PROJECT MANAGEMENT INSTITUTE - PMI. Organizational project management maturity model (OPM3). 2. ed. Pennsylvania: Project Management Institute. 2008b.

PROJECT MANAGEMENT INSTITUTE - PMI. Standard of Portfolio Management. 2. ed. Pennsylvania: Project Management Institute. 2008c.

RABECHINI JR, R. Competências e maturidade em gestão de projetos: uma perspectiva estruturada. Tese de Doutorado - Departamento de Engenharia da Produção da Escola Politécnica da Universidade de São Paulo. 2003.

RABECHINI JR., R. MÜLLER, S.; RACZ, A.; SILVA, A. C. P. Maturidade e Sucesso em Projetos sob a Perspectiva do Binômio Fornecedor e Cliente. RBGN - Revista Brasileira de Gestão de Negócios. São Paulo: FECAP, vol. 12, n. 34, p. 56-72. 2010.

RAD, P., RAGHAVAN, A. Establishing an Organizational Project Office. AACE International Transactions. p. 13, 2000.

REICH, B. H.; BENBASAT, I. Factors that influence the Social Dimension of Alignment between Business and Information Technology Objectives. MIS Quartely. vol. 24, n. 1, p. 81113. 2000.

REICH, B. H.; BENBASAT, I. Measuring the Linkage between Business and Information Technology Objectives. MIS Quartely. vol. 20, n. 1, p. 55-81. 1996.

RIVARD, S. DUPRÉ, R. Information Systems Project Management in PMJ: a brief history. Project Management Journal. Wiley InterScience, vol. 40, n. 4, p. 20-30. 2009. 
RODRIGUES, I.; RABECHINI JR., R.; CSILlAG, J. M. Os Escritórios de Projetos como Indutores de Maturidade em Gestão de Projetos. RAUSP - Revista de Administração da Universidade de São Paulo. São Paulo, vol. 41, n. 3, p. 273-287. 2006.

SAlViAnO, C. F.; FIGUEIREDO, A. M. C. M. Unified Basic Concepts for Process Capability Models. SEKE 2008 - 20th International Conference on Software Engineering and Knowledge Engineering. p. 173-178. 2008.

SANCHEZ, H.; ROBERT, B.; PELLERIN, R. A Project Portfolio Risk-Opportunity Identification Framework. Project Management Journal. vol. 39, n. 3, p. 97-109. 2008.

SAUER, C.; YETTON, P. W. Steps to the Future: fresh thinking on the management of IT-based organizational information. São Francisco: Jossey-Bass. 1997

SCOTT, B. R. Stages of corporate development. Boston: Harvard Business School, Intercollegiate Case Clearing House. 1971.

SHENHAR, A. Strategic project management: the new framework. Proceedings of the Portland International Conference on Management of Engineering and Technology. PICMET, Portland (OR), vol. 2, p. 382-6. 1999.

SHENHAR, A.; DVIR, D. Reinventando Gerenciamento de Projetos: a abordagem diamante ao crescimento e inovação bem-sucedidos. São Paulo: M. Books, 2010.

SILVA JR., S. D. Relações entre os fatores críticos para a maturidade em gerenciamento de projetos e a gestão estratégica organizacional. Dissertação de Mestrado. Pontifícia Universidade Católica do Rio Grande do Sul. 2009.

SILVEIRA, G. A., Fatores Contribuintes para a Maturidade em Gerenciamento de Projeto - um estudo em empresas brasileiras. Tese de doutorado. São Paulo: Universidade de São Paulo. 2008.

SMITH, K. G., MITCHELL, T. R., \& SUMMER, C. E. Top level management priorities in diferente stages of the organizational life cycle. Academy of Management Journal. vol. 28, n. 4, p. 799-821. 1985. 
SRIVANNABOON S.; MILOSEVIC D. Z. The process of translating business strategy in project actions. Innovations Project Management Research. Philadelphia: Project Management Institute. 2004.

SRIVANNABOON, S. Linking project management with business strategy. Project Management Journal. vol. 37, n. 5, p. 88-96. 2006.

VAN DER ZEE, J. T. M.; DE LONG, B. Alignment is not Enough: integrating business and information technology management with the balanced business scoreboard. Journal of Management Information Systems. vol. 16, n. 2, p. 137-156. 1999.

VITALE, M. R.; IVES, B.; BEATH, C. M. Linking Information Technology and Corporate Strategy: an organizational view. Procedings of the 7th International Conference on Information Systems. San Diego, p. 265-276.

VON WANGENHEIM, C. G.; HAUCK, J. C. R.; SALVIANO, C. F.; VON WANGEHEIM, A. Systematic Literature Review of Software Process Capability / Maturity Models. Procedings of International Conference on Software Process Improvement and Capability dEterminiation - SPICE. Italy, Pisa. 2010.

YAZICI, H. J. The Role of Project Management Maturity and Organizational Culture in Perceived Performance. Project Management Journal. Wiley InterScience, vol. 40, n. 3, p. 14-33. 2009.

ZWIKAEL, O. and GLOBERSON, S., Benchmarking of project planning and success in selected industries. Benchmarking: An International Journal. vol. 13, n. 6. 2006. 


\section{GLOSSÁRIO}

LinkedIn - é uma rede social de negócios operada meio da internet. Fundado em dezembro de 2002 e lançado em maio de 2003, difere de outras redes sociais como Facebook por ter seu foco central em profissionais e relacionamento de negócios. Em 22 de março de 2011, o LinkedIn divulgou possuir mais de 100 milhões de usuários registrados em mais de 200 países. A Quancast divulgou que o LinkedIn possui 47,6 milhões de visitantes mensais. Fez sua oferta pública de ações (IPO) em janeiro de 2011.

Chapters do Project Management Institute - Filiais do Project Management Institute. O PMI São Paulo, por exemplo, é o Chapter regional do PMI no Estado de São Paulo. Formalizado em 1998, e pioneiro na estrutura atual de Chapters do PMI no Brasil, conta hoje com mais de 3.082 membros e mantém uma intensa atividade local, com reuniões periódicas abertas ao público, Grupo de Estudos Técnicos (GETs), cursos para os exames de certificações PMP e CAPM, wokshops e a realização de um Seminário Internacional sobre o tema.

QuestionPro - Aplicação na nuvem (SaaS / Cloud Computing) para aplicação de questionários online, via web ou via correio eletrônico (e-mail). 
APÊNDICES 
APÊNDICE I

MODELO DE QUESTIONÁRIO APLICADO 
Questionário de caracterização dos respondentes:

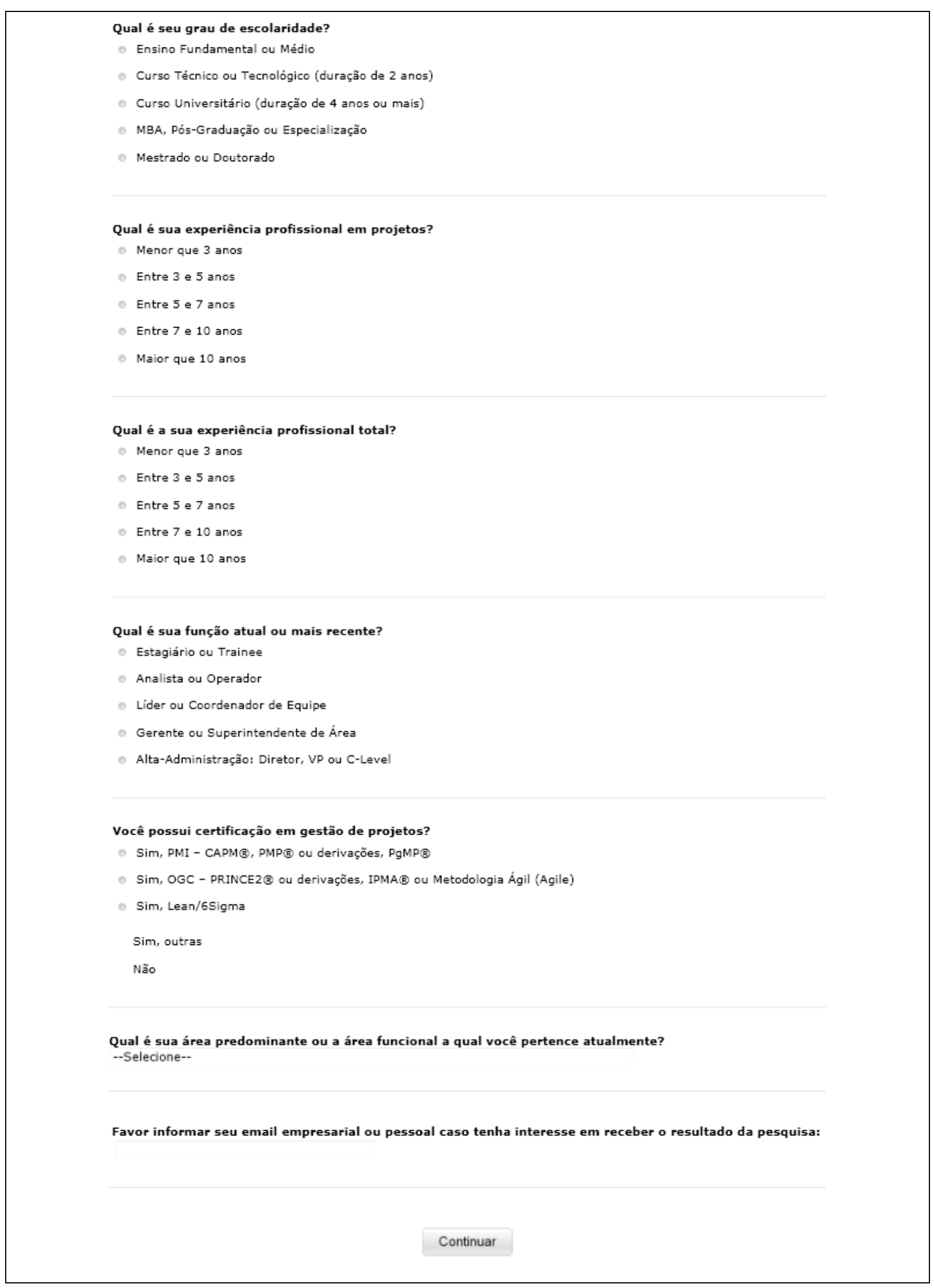


Questionário de caracterização das organizações ondes os respondentes atuam:

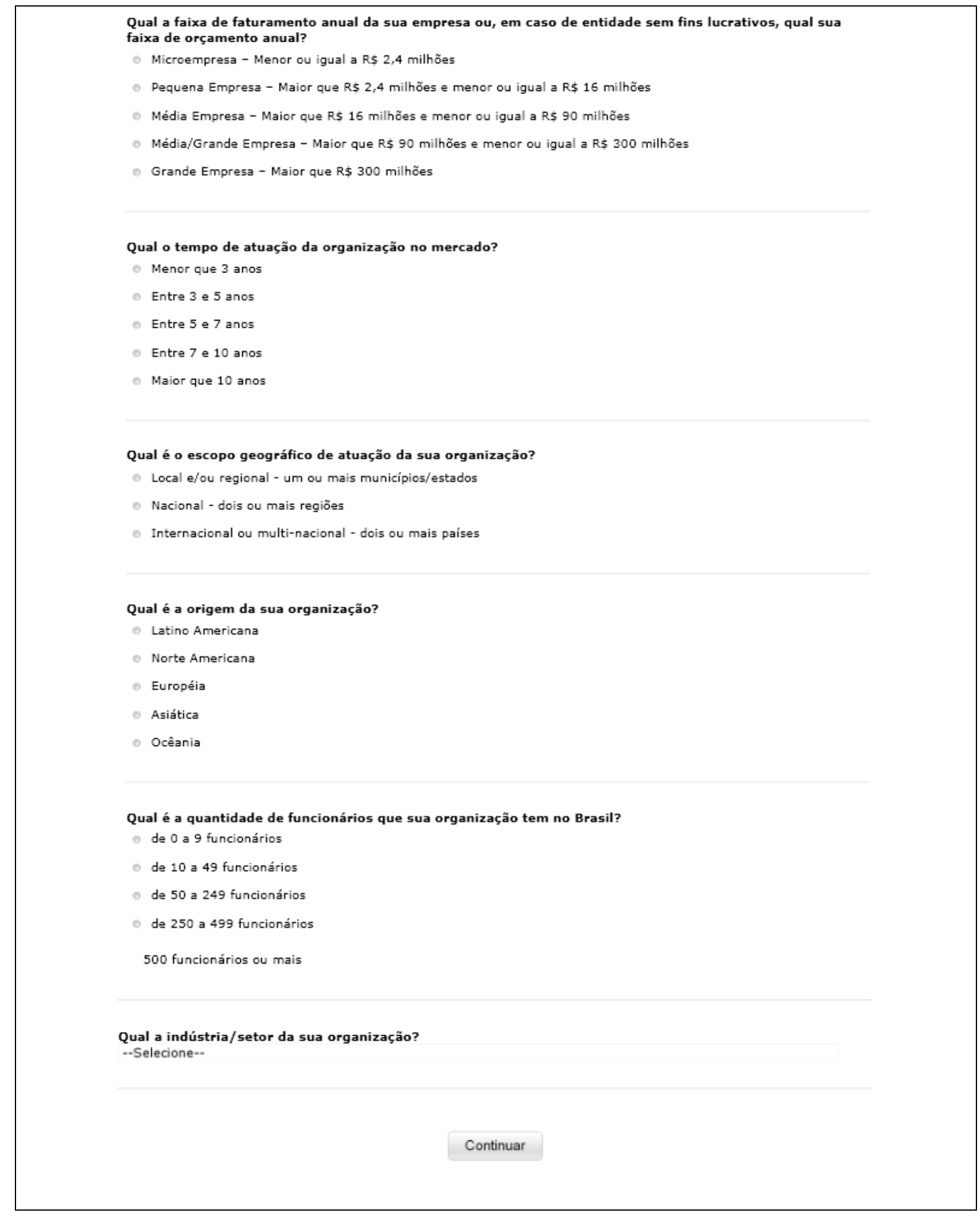


Questionário referente à importância dos facilitadores organizacionais para a gestão de projetos dentro da organização:

Minha organização...

...reconhece a importância dos projetos para a sobrevivência no longo prazo.

...reconhece a importância dos projetos para a criação e sustentação de vantagem

competitiva.

...tem uma metodologia e estratégia

claramente definida de desenvolvimento da

prática de gestão de projetos.

...treina as partes interessadas ou impactadas

(stakeholders) em gestão de projetos.

...promove o alinhamento dos projetos à estratégia organizacional.

...disponibiliza os recursos necessários ao

sucesso dos projetos.

...disponibiliza os sistemas de gestão de

projetos necessários ao sucesso dos projetos.

...aloca patrocinadores necessários ao

projeto.

...possui área de suporte à gestão de

projetos, como PMO (escritório de projetos).

...promove treinamento nas competências de gestão de projetos.

...faz avaliação de desempenho das equipes e gestores de projetos.

...usa critérios múltiplos para avaliar o

resultado dos projetos como benefício,

retorno do investimento ou sustentabilidade.

...compara suas práticas de gestão de

projetos com outras organizações.

(benchmarking)

...aplica gestão do conhecimento gerado nos projetos. (lições aprendidas)

...dá a autonomia necessária ao gerente e

equipe para alcançar os objetivos do projeto.

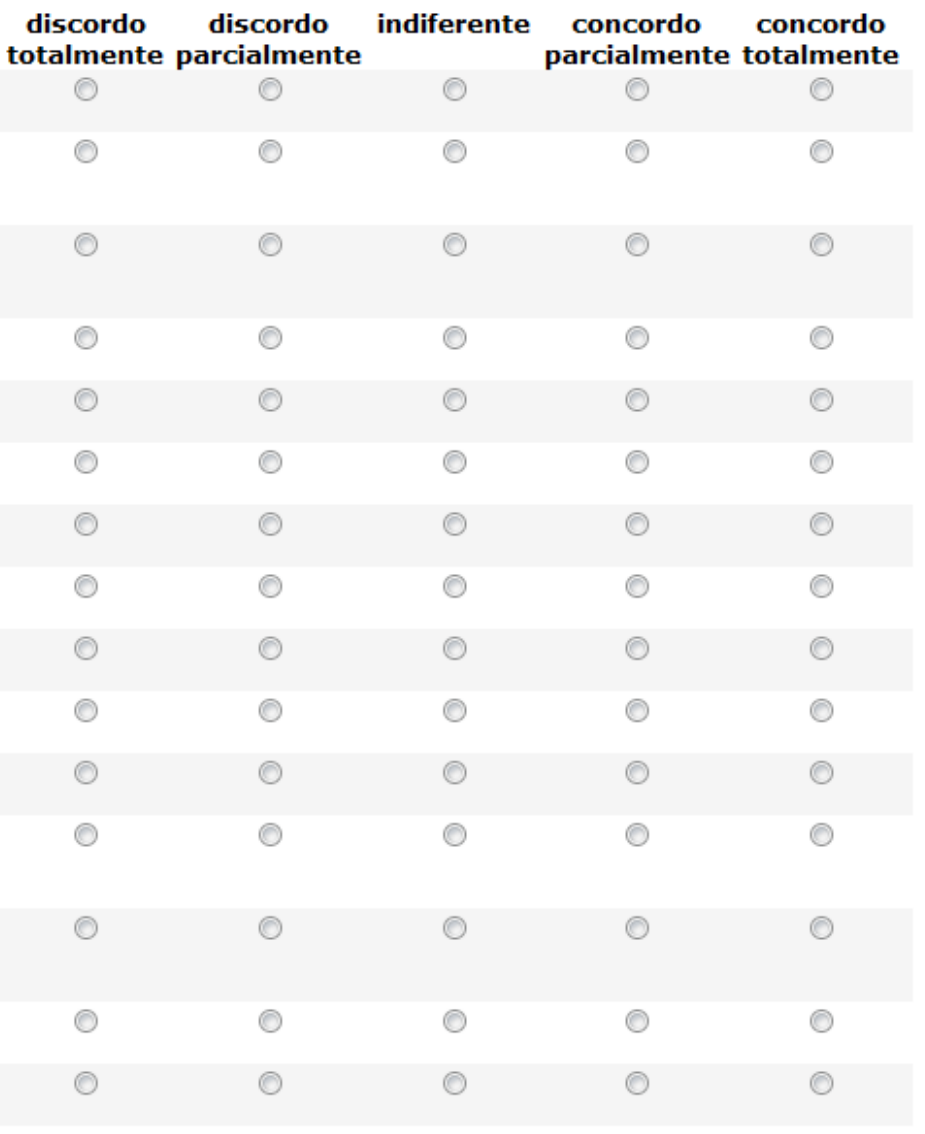


Questionário referente a maturidade de planejamento em gestão de projetos dentro da organização:

Nos projetos que participo, minha organização...

$\begin{array}{ccc}\begin{array}{c}\text { Nenhuma ou } \\ \text { poucas } \\ \text { vezes }\end{array} & \begin{array}{c}\text { Muitas } \\ \text { vezes mas } \\ \text { não de } \\ \text { forma }\end{array} & \begin{array}{c}\text { Muitas } \\ \text { vezes e de } \\ \text { forma } \\ \text { padronizada }\end{array} \\ & \begin{array}{c}\text { padronizada } \\ \end{array}\end{array}$

Gerencia a Gerencia e

realização

no padrão

promove

melhorias

contínuas

...desenvolve o business case, termo de abertura ou início. (project charter)

...identifica as principais partes interessadas

ou impactadas. (stakeholders)

...desenvolve o plano de gerenciamento do projeto.

...identificaclaramente o propósito do projeto

e os requisitos de negócio que o originaram.

...define o escopo do projeto e formula o

Dicionário Estrutura Analítica de Projeto.

...faz a decomposição do escopo de projeto

em uma Estrutura Analítica de Projeto.(EAP ou

WBS)

...define e sequencia as atividades do projeto.

...estima os recursos e as durações das

atividades do projeto.

...desenvolve o cronograma do projeto.

...estima os custos e determina o orçamento

do projeto.

...planeja a qualidade do projeto.

...cria o plano de gerenciamento dos recursos humanos.

...cria o plano de gerenciamento das

comunicações.

...cria o plano de gerenciamento dos riscos.

....identifica os riscos do projeto.

...realiza a análise qualitativa dos riscos.

...realiza a análise quantitativa dos riscos.

...planeja as respostas aos riscos.

...planeja os contratos/compras. 